Review

\title{
A Review of the Multi-Physical Characteristics of Plant Aggregates and Their Effects on the Properties of Plant-Based Concrete
}

Herinjaka Haga Ratsimbazafy ${ }^{1, *}$, Aurélie Laborel-Préneron ${ }^{1,}{ }^{\dagger}$, Camille Magniont ${ }^{1,+}$, Philippe Evon $2,+$

1. Université de Toulouse, INSA, UPS, LMDC (Laboratoire Matériaux et Durabilité des Constructions), 135 avenue de Rangueil, 31077 Toulouse Cedex 04, France; E-Mails: ratsimba@insa-toulouse.fr; alaborel@insa-toulouse.fr; camille.magniont@insa-toulouse.fr

2. Université de Toulouse, INP, INRAe, ENSIACET, LCA (Laboratoire de Chimie Agro-industrielle), 4 allée Emile Monso, BP 44362, 31030 Toulouse Cedex 4, France; E-Mail: philippe.evon@toulouse-inp.fr

$\dagger$ These authors contributed equally to this work.

* Correspondence: Herinjaka Haga Ratsimbazafy; E-Mail: ratsimba@insa-toulouse.fr

Academic Editor: Jorge de Brito

Special Issue: New Trends on Circular Economy Building and Construction Materials

Recent Progress in Materials

2021, volume 3, issue 2

doi:10.21926/rpm.2102026
Received: March 26, 2021

Accepted: May 17, 2021

Published: June 20, 2021

\begin{abstract}
The use of plant aggregates obtained from agricultural co-products mixed with mineral binders to form eco-friendly insulating building materials has been initiated for a few years to bring environmentally friendly solutions to the construction sector. Several studies on different agro-resources have already been carried out, providing various information about the properties of plant aggregates and plant-based concrete. However, the characteristics of the agricultural co-product, which allow it to qualify as a plant aggregate for plant-based concrete, are not yet very clear despite the multitude of data, especially on hemp concrete. Therefore, it is important to gather numerous but very disparate pieces of information available in the literature concerning the properties of plant aggregates and their correlations
\end{abstract}


with composites. This review is based on the results of 120 articles and aims to identify the characterization methods and the multi-physical properties of plant aggregates affecting those of plant-based concrete and to propose additional factors that could influence the properties of the composites. A total of 18 plant aggregates of different origins used for plantbased concrete have been listed in the literature. In France, hemp shiv is the most studied one, but its quantity is quite low unlike cereal or oilseed straws and wood transformation residues. With the existence of several characterization methods, properties like microstructure, particle size distribution, bulk density, water absorption capacity, and chemical composition of aggregates are easily and frequently determined. In contrast, data on the apparent density of particles, the skeleton density, and the hygro-thermal properties of aggregates are rare. The particle size, density, and porosity have been identified as important parameters influencing the properties of the composites. Other parameters related to the behavior of the aggregates under wet compaction and compression of their stacking can also predict the physical and mechanical properties of the obtained plant-based concrete. Dosages of the constituents should be preferred as formulation parameters for future studies assessing the impact of the aggregate properties on the composites.

\section{Keywords}

Multi-physical properties; building materials; agricultural by-products; plant aggregates; plant-based concrete

\section{Introduction}

Climate change is one of the biggest threats faced globally and also a tough social and economic issue $[1,2]$. Considering its harmful effects, the construction sector has to face four major environmental issues including, Greenhouse gas (GHG) emissions, energy consumption, consumption of non-renewable resources, and waste production. Plant-based materials are alternative solutions due to their unique ecological benefits, home comfortability (humidity, thermal and acoustic regulation), and material sustainability [3]. Since prehistoric times, people have already used plant fibers as reinforcing materials by incorporating straws into bricks during the reign of Pharaoh [4]. However, scientific studies on fiber-reinforced concrete (FRC) made from plant fibers started at the end of the $20^{\text {th }}$ century. The defibration process of certain plant stems such as hemp, and textile flax generates woody particles (called shives) used for a long time as animal litter or combustion (i.e., for energy production). For about 30 years, to improve the environmental concerns linked to the construction sector, these plant particles or "plant aggregates" have been used as thermal insulating building materials, either in their bulk state or incorporated into mineral binders to form "plant-based concrete". Several plant aggregates including hemp shiv, flax shiv, coconut coir, wood chip, cereal or oilseed straws, rice husk, corn cob, diss stem, bamboo stem, cane bagasse, sugar beet pulp, miscanthus stem, and lavender straw have been already tested with mineral binders, but most of the studies on plant-based concrete were majorly concentrated on hemp shiv due to the development of the hemp industry [5]. Although France is the first European producer of hemp [6], hemp shiv is much less available than some agricultural by-products such as 
cereal straws [7]; thus, more research is required for the locally available plant by-products. Due to the highly diverse plant aggregates used in plant-based concrete, their multi-physical properties also vary with a multitude of characterization methods proposed by different researchers. Presently, no universal standard is available to govern the characterization of plant aggregates used in building materials. In turn, the work of RILEM (International Union of Laboratories and Experts in Construction Materials, Systems, and Structures) TC (Technical Committee) 236-BBM (bioaggregates-based building materials) was dedicated to this area. This work is relatively centered on the basic characteristics of hemp shiv as it is one of the most studied and widely used bio-aggregate in construction materials [5]. The properties and methods of characterization of hemp shiv and hemp concrete are the best known in the literature. Because of these observations, this review intends to identify all the aggregates of plant-based concrete mentioned in the literature as well as the correlation between their properties and those of the composites to understand the key parameters related to the aggregates thereby, assessing their potentials. This information can help in developing plant-based concrete that can be largely developed from available and compatible local agricultural resources.

In recent years, with the rapid growth of green construction technology, several studies based on the properties of plant-based concrete, including literature reviews, have been published. Lately, Sáez-Pérez et al. studied the factors such as the quality of the aggregate, the choice of the binder, the dosage of the constituents, and the manufacturing methods affecting the properties and performance of hemp aggregate concrete [8]. Similarly, Jami et al. published another review based on the properties of hemp concrete [9]. Interestingly, apart from discussing the usual properties of hemp concrete, they related mixing and manufacturing processes to each other and also addressed the possible applications of hemp concrete in the construction sector.

The present review discusses the multi-physical properties of plant aggregates and their effects on the properties of plant-based concrete. It summarizes 120 published articles based on the properties of plant aggregates and their impact on the characteristics of the composite formed with mineral binders. It is structured in two main parts. The first part is dedicated to the generalities of plant aggregates used with mineral binders. Firstly, the term "plant aggregate" was discussed and defined, followed by a classification of the listed plant aggregates according to their origins. Besides, their transforming process was indicated. Next, the availability of plant aggregates in France was briefly discussed. Lastly, a comprehensive review of the literature was carried out on the multiphysical properties of plant aggregates used in construction and the variety of methods applied to characterize them. The second part of the review treats the impact of diverse factors related to plant aggregates, such as their mass content, nature, and properties. Literature showed that the physical, mechanical, hygrothermal, and even acoustical properties of the composites may be affected by all these parameters.

\section{Overview of Plant Aggregates Used with Mineral Binder}

\subsection{Definition of the Term "Plant Aggregate"}

According to the fields of use, different terms have been used in the literature to designate vegetal additions into a mineral matrix. Since, for the first half of the $20^{\text {th }}$ century, the term "fiber" has been used to classify the vegetal additions into a cement matrix for the manufacture of 
prefabricated fiber-cement profiled elements, historically based on asbestos fibers but then substituted by vegetal fibers of different origins for various health reasons. The plant fibers incorporated in these materials have micro or nano dimensions and are used for the mechanical reinforcement of the cement matrix. The term "fiber" is also used in the formulation of cementbonded particle boards. The particles used in these formulations are in millimeters, and the prefabricated elements obtained are mainly used as elements of exterior walls or partitions. For 15 years, the term "plant aggregate" has been preferred over fibers to define particles with high intraparticle porosity and incorporated into the mineral matrix to improve its thermal insulation performance.

According to the FRD (Fibres Recherche Développement) report published in 2011 [10], to create the same semantic for plant fibers common to all sectors, a plant aggregate was defined as the part of the plant corresponding to the marrow or the ligneous parts of stems, obtained from postdecortication or post-refining separation, with millimeter to centimeter length varying according to the defibrated plant and customer demand (Figure 1). However, this was an incomplete definition because other parts of plants like coir [11], husk [12], cob [7], or pulp [13] are also considered aggregates. In addition, the length of the particles alone is not enough to differentiate the fibers from the aggregates because a few lengths are common in both of them, as shown in Figure 1.



Figure 1 Semantics of plant fibers [10].

To complete this definition, Laborel-Préneron et al. (2016) defined two geometrical parameters, including the inverse of aspect ratio (1/AR, with AR defined as the ratio of length to diameter) and the diameter (Figure 2). It made it possible to differentiate the fibers with the smallest 1/AR ratio and diameter values from the aggregates with 1/AR higher than 0.10 . However, the straws located between the fibers and aggregates were much more difficult to classify according to this criterion. 


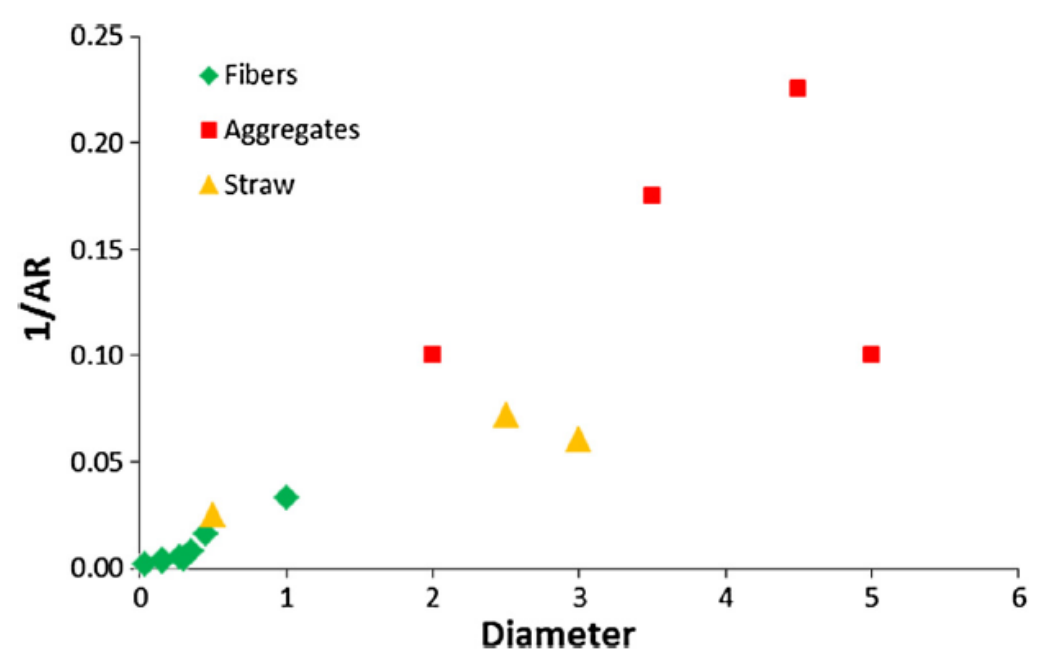

Figure 2 The graph depicting the variation in the inverse of the particle's aspect ratio (AR) as a function of its diameter [14].

The inverse of the $A R(1 / A R)$ as a function of the minor axis of all the plant aggregates incorporated in a mineral binder presented in this review is shown in Figure 3 and compared with those of the fibers reviewed in earlier studies [14]. Contradictory, the plant residues considered in this review and, which will be called here as "plant aggregates" were less elongated with an inverse AR higher than 0.05 and a minor axis (minor axis of the ellipse shape fitted to the particle) higher than $0.5 \mathrm{~mm}$ in comparison to fibers, after undergoing a decortication or a grinding process followed by sieving. The particles not included between these intervals were the small particles of hemp shiv (minor axis less than $0.5 \mathrm{~mm}$ ) and were not certified for construction uses [15].

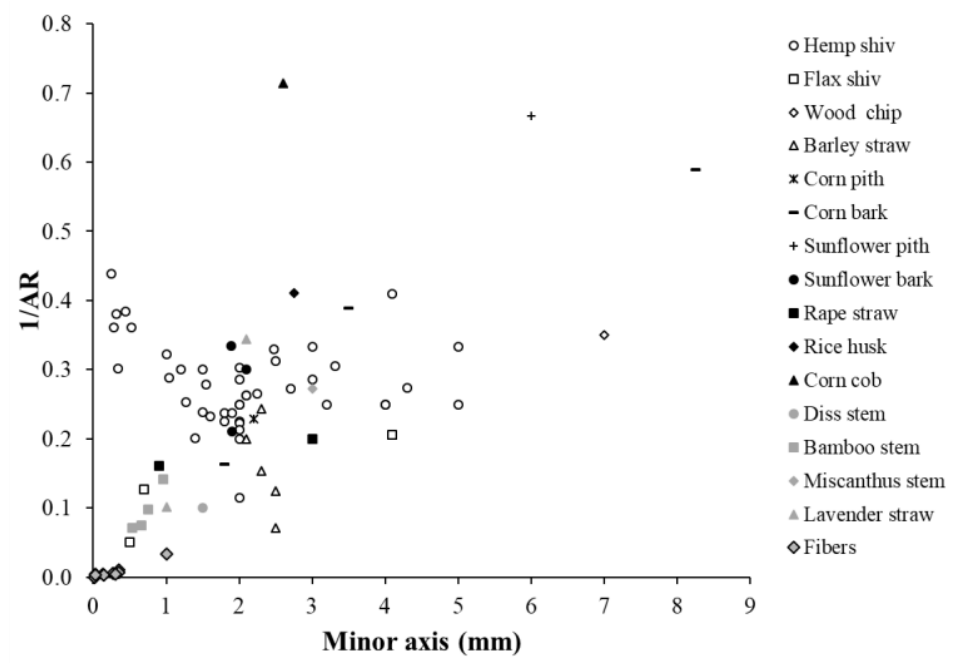

Figure 3 The inverse of the particle's aspect ratio (1/AR) as a function of its minor axis $[7,15-62]$.

Plant aggregates are derived from various parts of the plants and are often agricultural byproducts. To identify the nature and the processing of the by-products valued as plant aggregates in plant-based concrete, a classification based on their origin is presented in the following paragraph. 


\subsection{Classification, Nature, and Processing of By-products Considered as Plant Aggregates in Plant- based Concrete}

A total of 120 papers covering the properties of 18 plant aggregates and/or the properties of composites formed with mineral binders were reviewed. They were related to 18 different agricultural by-products, which were further classified into nine categories according to their origin as follows: fiber plant wastes, wood transformation residues, cereal straws, oilseed straws, wastes from cereal plants other than straws, wild plants, sugar plant wastes, energy crop residues, and aromatic plants. These plant aggregates are listed in Table 1.

Table 1 Classification of by-products used as plant aggregates in plant-based concrete and location of the related studies.

\begin{tabular}{|c|c|c|c|c|c|}
\hline Origins & Plants & Fractions & $\begin{array}{l}\text { Locations of } \\
\text { published } \\
\text { studies }\end{array}$ & References & $\begin{array}{l}\text { Number of } \\
\text { references }\end{array}$ \\
\hline \multirow[t]{3}{*}{ Fiber plant wastes } & Hemp & Shiv & $\begin{array}{l}\text { France, UK, } \\
\text { Slovakia, } \\
\text { Sweden, Spain, } \\
\text { Canada }\end{array}$ & $\begin{array}{l}{[7,15,16,20,28,} \\
29,32,35,36, \\
41,42,44-46, \\
49-54,59-89]\end{array}$ & 51 \\
\hline & Flax & Shiv & $\begin{array}{l}\text { France, Canada, } \\
\text { Poland }\end{array}$ & $\begin{array}{l}{[23,27,40,54,} \\
60,81,90-94]\end{array}$ & 11 \\
\hline & Coconut & Coir & Thailand, Brazil & {$[11,95,96]$} & 3 \\
\hline $\begin{array}{l}\text { Wood } \\
\text { transformation } \\
\text { residues }\end{array}$ & Wood & Chip & $\begin{array}{l}\text { France, Algeria, } \\
\text { Brazil, Australia, } \\
\text { Nigeria, Turkey, } \\
\text { Egypt, USA }\end{array}$ & {$[18,28,97-112]$} & 18 \\
\hline \multirow[t]{4}{*}{ Cereal straws } & Barley & Straw & $\begin{array}{l}\text { France, Algeria, } \\
\text { Egypt }\end{array}$ & $\begin{array}{l}{[7,22,24,38,41} \\
42,99,113,114]\end{array}$ & 9 \\
\hline & Wheat & Straw & France, Egypt & {$[24,60,88,99]$} & 4 \\
\hline & Corn & Stem & France, China & {$[16,17,43,65]$} & 4 \\
\hline & Rice & Straw & Egypt, China & [115-117] & 3 \\
\hline \multirow[t]{2}{*}{ Oilseed straws } & Sunflower & Stem & France & $\begin{array}{l}{[16,25,26,29,} \\
43,45,53,65, \\
118,119]\end{array}$ & 10 \\
\hline & Rape & Straw & France, UK & $\begin{array}{l}{[25,26,54,55,} \\
60,82]\end{array}$ & 6 \\
\hline \multirow{2}{*}{$\begin{array}{l}\text { Wastes from } \\
\text { cereal plants } \\
\text { other than straws }\end{array}$} & Corn & Cob & $\begin{array}{l}\text { France, } \\
\text { Portugal, Italy }\end{array}$ & {$[7,41,42,120]$} & 7 \\
\hline & Rice & Husk & $\begin{array}{l}\text { France, Spain, } \\
\text { UK, Vietnam }\end{array}$ & $\begin{array}{l}{[12,29,30,121-} \\
123]\end{array}$ & 6 \\
\hline
\end{tabular}




\begin{tabular}{llllll}
\hline Wild plants & Diss & Stem & $\begin{array}{l}\text { Algeria, France } \\
\text { Brazil, Nigeria, } \\
\text { Malaysia }\end{array}$ & {$[$ [38, 124-126] 127-129] } & 4 \\
\hline $\begin{array}{l}\text { Sugar plant } \\
\text { wastes }\end{array}$ & Sugar cane & Bagasse & $\begin{array}{l}\text { France, } \\
\text { Malaysia, UK }\end{array}$ & {$[121,130-133]$} & 5 \\
\hline $\begin{array}{l}\text { Energy crop } \\
\text { residues }\end{array}$ & Sugar beet & Pulp & France & {$[13,134]$} & 2 \\
\hline $\begin{array}{l}\text { Aromatic plant } \\
\text { straws }\end{array}$ & Lavender & Straw & France & {$[38,56,119]$} & 3 \\
\hline
\end{tabular}

Figure 4 exhibits the location of the reviewed articles as well as the nature of the studied plant aggregates. They were from different countries all over the world. However, most published studies were based in Europe, especially France.

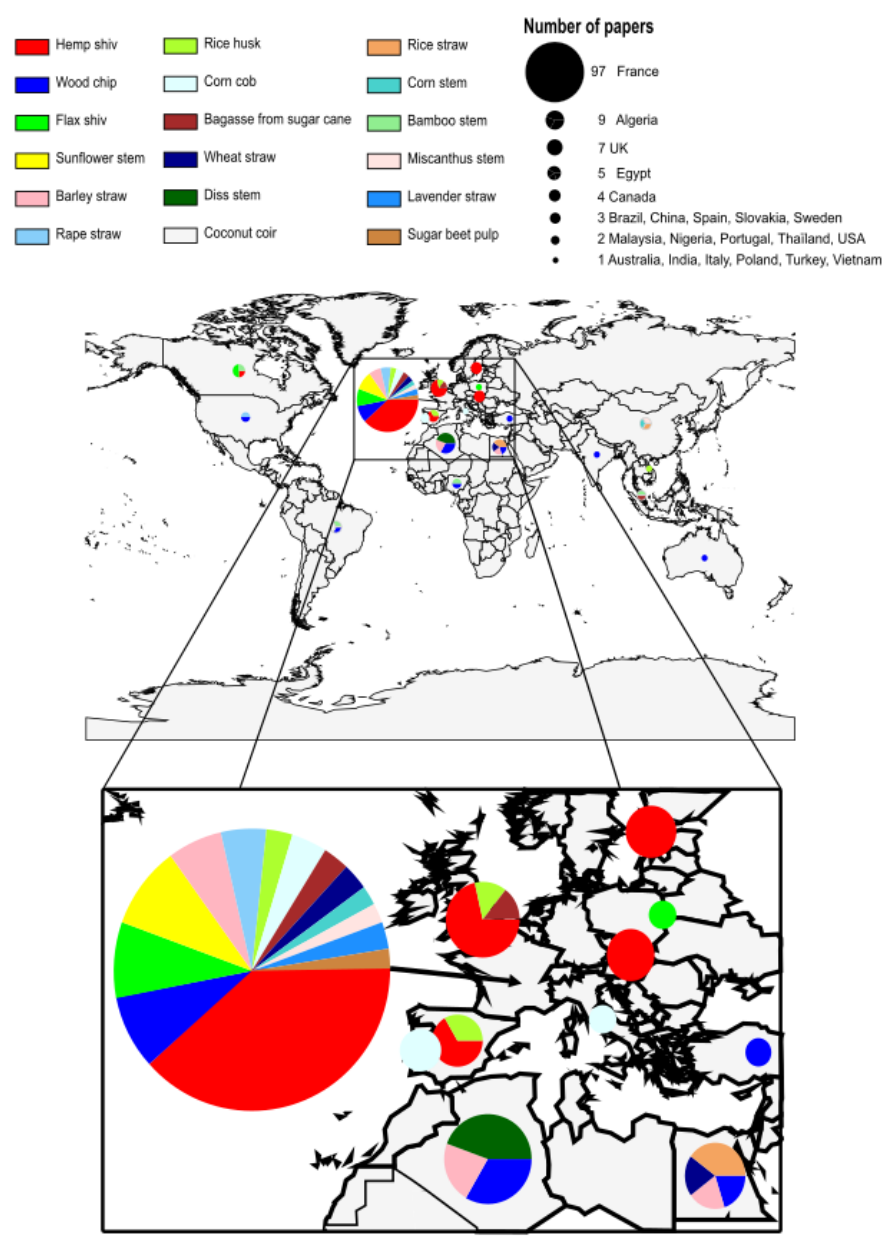

Figure 4 Location of published studies using agricultural by-products as plant aggregates in plant-based concrete and representation of the corresponding number of studies published per country (based on publications between 1986 and 2020). 
For each by-product, general information about the plant, its geographical location, and processing methods are detailed below.

\subsubsection{Fiber Plant Wastes}

Hemp shiv (51 papers out of 120). Hemp, scientifically called Cannabis Sativa L., is an annual plant from the Cannabaceae family with height varying from 1 to $3 \mathrm{~m}$. It is very popular for the quality of its fibers and is used in the automotive, paper, and textile industries or for producing ropes. In general, Cannabis Sativa L. species is found in Central Asia and especially in Europe. It is grown in temperate climates.

As shown in Table 1, the studies based on the use of hemp shiv with mineral binder were mainly done in France, UK, Slovakia, Sweden, Spain, and Canada. Hemp shiv is the by-product of the hemp defibration process and corresponds to the inner part of the fragmented stem, representing 40 to $60 \%(\mathrm{w} / \mathrm{w})$ of the Cannabis Sativa L. plant. Depending on whether the defibration process was done before grinding (i.e., complete or partial), pure shiv or fibered hemp shiv (i.e., shiv containing fiber impurities) can be obtained. In industry, whether the mechanical defibration is preceded or not by a retting process affects the chemical composition of hemp shives, especially the content of pectins. This can impact the hemp shiv/binder chemical interactions (setting delay), the hemp shiv/binder interface, and the mechanical properties of the manufactured hemp concrete [72]. In addition to untreated hemp shives (with or without pre-wetting with water) mixed with an enhanced mineral matrix, several treatments for hemp shives are presented in the literature to address these problems. The most common solution is the coating of the aggregates using mineral binder $[35,53]$, linseed oil [59], or water-repellent sol-gel [79]. Other treatments, such as the leaching of the hemp shives using a neutral or alkaline solution, were also studied $[53,83]$. All these treatments conducted on the hemp aggregates can have different impacts on the multi-physical properties of the composite.

Flax shiv (11 papers out of 120). Flax (Linum usitatissimum L.) is a member of the genus Linum in the Linaceae family. Flax is an annual plant and is cultivated for its fibers and/or seeds. It is cultivated in the cooler regions of the world. The world production of flax (linseed) was $2.95 \mathrm{Mt}$, led by Russia, Canada, Kazakhstan, and China [137]. The textile flax is $1.2 \mathrm{~m}$ tall with slender stems. Flax shives are obtained from the inner part of the flax stem and are produced as a by-product of flax fiber production from the textile industry [92]. In the case of oleaginous flax, the main final product is the seed. To avoid the lodging of the plants before the seed harvesting, a plant-growth regulator is thus most often applied, resulting in plants with much lower stem heights (less than $60 \mathrm{~cm}$ ). However, straws from oleaginous flax can also be valorized for their textile fibers [138], and the obtained shives can thus remain available as plant aggregates after the extraction of those fibers.

France, Canada, and Poland have majorly published research on flax concrete (Table 1). As for the hemp shives, the flax shives are the by-products obtained from the defibration of the flax stem, with or without retting before mechanical defibration and sieving. A few particle coating treatments to optimize the water absorption and the chemical interactions between flax shives and lime or cement have been reported in the literature. These included coating using a mixture of cement and sucrose [40], a PEC elastomer, [94], and linseed oil [93]. These treatments improve the mechanical properties and behavior of flax concrete in water and slightly reduce their thermal performance. 
Coconut coir ( 3 papers out of 120). The coconut is the fruit obtained from the tree named Cocos nucifera L. It belongs to the family of palms, or Arecaceae, and can attain a height of $25 \mathrm{~m}$. The coconut tree gives its first fruit at the age of five or six years and reaches its maximum production after about 15 years. An adult coconut tree can produce between 50 and 500 coconuts per year. Coconut coir is the fruit of the coconut palm, and it surrounds and protects the coconut. Its pith and short fibers are the by-products obtained from the extraction of long fibers. Coconuts grow abundantly in coastal areas of tropical countries [121]. Most of them are found in the Southeast of Asia, e.g., Indonesia, Philippines, and India, the leading producer with $70 \%$ of the world production. World production of coconuts is around 40 to $50 \mathrm{Mt} / \mathrm{y}$, producing around 15 to $20 \mathrm{Mt} / \mathrm{y}$ of coir husk. Coconut coir is thus a widely available by-product in tropical countries.

Thailand and Brazil are the main countries that have researched the mixture of coconut coir and cement (Table 1). Coconut coir is extracted by beating it using an automated mechanical extraction machine. After sieving, the by-product obtained is immediately mixed with cement or pretreated by washing it with tap water followed by drying in the sun [11]. The pretreatment can be done in two ways, washing-boiling-drying [95] or boiling-washing-drying [11]. Results have shown that pretreatment involving boiling majorly improves most of the mechanical properties of the composite.

\subsubsection{Wood Transformation Residues (Wood Chips) (18 Papers out of 120)}

Wood is the most abundant raw material in nature. There are two main types of wood: softwood and hardwood. Softwood refers to wood that comes from evergreen or coniferous trees like pine, spruce, cedar, and redwood, whereas hardwoods are obtained from deciduous trees like ash, oak, teak, birch, walnut, and mahogany. Wood is used for many purposes and in many forms, such as lumber, industrial, and energy wood. Russia, Canada, Brazil, and the USA are the leaders in terms of forest area, with $50 \%$ of the total forest area worldwide $\left(39,000,000 \mathrm{~km}^{2}\right)$. Several countries like France, Algeria, Brazil, Australia, Nigeria, Turkey, Egypt, and the USA have studied the mixing of wood chips with the mineral binder (Table 1).

Wood chips result from all kinds of woodworking activities. Several treatments of wood chips are proposed in the literature to solve the problems associated with their chemical interaction with the hydraulic binder and swelling. These include treatment with cold or hot water [97, 106, 109, 111], coating with hydraulic lime or linseed oil [106], and thermal treatment by mild pyrolysis under a nitrogen atmosphere [102, 104, 108].

\subsubsection{Cereal Straws}

Barley straw (9 papers out of 120). Barley, or Hordeum vulgare, is a cereal that belongs to the grass family. Globally, the use of barley grain is divided between animal feed (55 to 60\%), malt production (30 to $40 \%$ ), seed production (5\%), and human nutrition ( 2 to $3 \%$ ). Barley is harvested once or twice a year. It is currently popular in temperate areas where it is grown as a summer crop and in tropical areas where it is sown as a winter crop. In 2016, the world production of barley grain was $141 \mathrm{Mt} / \mathrm{y}$, led by the European Union, producing 41\% of the world's total production.

Research articles dealing with the mixing of barley straw with earth or Portland limestone cement are mainly from France, Algeria, and Egypt (Table 1). Barley straw is the stem rejected during seed harvesting. Apart from crushing and sieving, no special treatment is applied to the barley straw 
when combined with an earth binder. On the contrary, when mixed with Portland-limestone cement, several treatments, including immersing barley straw for some time in boiling water, gas oil, varnish, or waste oil of car engines, are applied to improve the straw/binder interface [113].

Wheat straw (4 papers out of 120). Wheat is a grass widely cultivated for its seed and cereal grain that is a worldwide staple food. Several species of wheat together form the genus Triticum, and among them, the most widely grown is common wheat (T. aestivum). The two current important varieties include durum wheat or Triticum turgidum L. (mostly grown in Europe, North America, and the Middle East) and soft wheat or Triticum aestivum (grown in mid-latitude countries like China, India, United States, Russia, France, Canada, and Germany). Wheat is grown on a larger land area than any other food crop (220.4 million ha in 2014). In 2016, the global wheat production was estimated as $749 \mathrm{Mt}$ led by EU (157.3 Mt/y) and followed by China (131.7 Mt/y), India (93.5 Mt/y), Russia $(73.3 \mathrm{Mt} / \mathrm{y})$, and the USA (62.9 Mt/y). Articles based on the mixing of wheat straw with a mineral binder are originated from France and Egypt (Table 1).

Like other straws, wheat straw is also the rejected part after seed harvesting. Aggregates are obtained by grinding and sieving. In the four reviewed references, wheat straws obtained did not undergo any specific treatment, but they were directly mixed with earth. No study was conducted on wheat straws mixed with any other mineral binder apart from earth, such as lime, cement, or pozzolanic binders.

Corn stem (4 papers out of 120). Corn (Zea mays L.) is an annual tropical herbaceous plant of the Poaceae family (grasses), widely grown as a cereal for its starch-rich grains but also, in some cases, as a forage plant. It is mainly used for animal feed, human food, and agro-food industries for the production of alcohol as biofuel, biogas, or bioplastics. Corn is the most widely produced grain in the world, with grain production slightly ahead of rice and wheat. The top two producers are the USA and China, accounting for nearly 60\% of the world's total production (1,038 Mt/y between 2014 and 2016). France and China are the countries mainly studying corn stem (pith, bark, or the whole stem) and mineral binder mixtures (Table 1 ).

The corn stems are ground in the first stage after harvesting to obtain aggregates of corn pith, bark, or stem (mix of pith and bark). Following it, in the case of corn pith or bark alone, mechanical separation is done using a tilted conveyor belt and a blowing system. Finally, sieving on a $1 \mathrm{~mm}$ sieve is done to remove the fines. No particular treatments are carried out on these aggregates as reported in the literature. Instead, they are directly mixed with either cement, lime, or pozzolanic binder $[17,43,65]$.

Rice straw (3 papers out of 120). Rice is the seed of the grass species Oryza sativa (Asian rice) and Oryza glaberrima (African rice). As a cereal grain, it is the most widely consumed staple food of a large part of the world's population, especially in Asia.

In 2016, the world production of rice grain was $741 \mathrm{Mt}$, led by China and India with a combined $50 \%$ of the total production. The cultivation of rice generates a lot of straw (60 to $85 \%$ of the plant aerial part). Egypt and China are doing extensive research on the use of rice straw particles as plant aggregates in combination with mineral binders. Like the first two cereal straws, the aggregates from rice straw are obtained after grinding and sieving. Treatment, such as immersion in water or 
sodium hydroxide, can be done on the rice straws according to ASTM-D1109-84 [139] to improve their compatibility with the cement [117].

\subsubsection{Oilseed Straws}

Sunflower stem (10 papers out of 120). Sunflower (Helianthus annuus L.), an annual plant of the Asteraceae family, is a native of North America. It is widely cultivated in all the continents, especially for its seeds rich in vegetable oil for cooking applications. The world's total harvest of sunflower seeds in 2016 was $42.1 \mathrm{Mt}$. Its main producers are Russia and Ukraine, with a production of $21.0 \%$ and $15.5 \%$, respectively, of the total produce.

Nine papers found in the literature about the properties of sunflower aggregates used in plantbased concrete were all from France. Sunflower straw is composed of a rigid external part named "bark" and a lightweight inner part with a honeycomb-like structure named "pith". Sunflower pith and bark are obtained by the same process of grinding, separation, and sieving as that used in the case of corn. No treatment applicable on the mixture of sunflower pith and mineral binder is proposed in the literature. However, several treatments are used with the sunflower bark, such as washing in clear water [53], soaking in a calcic lime solution, or coating with linseed oil or a paraffin wax [118]. The purpose of these treatments is to improve the aggregate/binder interface and, consequently, their compatibility.

Rape straw (6 papers out of 120). Rapeseed or Brassica napus L. is an annual plant with yellow flowers of the Brassicaceae family. It is widely grown for its seeds and is used as animal feed and for the production of edible oil or biofuel.

Rape is a global crop and is mainly cultivated in cool temperate zones. France and UK are the major countries that published articles about rape straw concrete. Rape straw is considered a waste resulting from the harvest of the seed part but can be milled to form aggregates. After sieving to remove fine particles, they are directly incorporated into the earth or lime binder to form the composite.

\subsubsection{Cereal plant wastes other than straw}

Corn cob (7 papers out of 120). The generalities of corn have already been discussed in the paragraph dedicated to corn stem. Countries involved in research on corn cob are France, Portugal, and Italy (Table 1). Corn cob is the central part of the maize ear, once cleared of its grains. It is then crushed to obtain aggregates. The corn cob is made up of three layers. The hardest inner layer is the only one used after a centrifuge-based separation process (the particles in each layer have different densities and are separated easily) [42]. In some other cases, all the crushed aggregates are used after removing fines [140,141], although the aggregates obtained absorb much more water.

Rice husk ( 6 papers out of 120). The general discussion on rice has already been conducted in the paragraph dedicated to rice straw. The main applications of rice husks include landfills in the soil and energy sources for the production of electricity or heat because of their high heating value [30]. In the construction sector, they have been the subject of research on ash from calcination.

In Table 1, the rice husks studied in the articles (6 out of 120) came from France, Spain, UK, and Vietnam. Rice husks are the agro-industrial by-products resulting from the rice hulling, and they 
represent $20 \%(\mathrm{w} / \mathrm{w})$ of the whole paddy rice grain harvested. They are mixed in their natural state with mineral binder [30], pre-soaked for $24 \mathrm{~h}$ to solve the water absorption problem [12], or even pre-treated with a lime solution before being used to improve the mechanical performance of the composite [122].

\subsubsection{Wild Plants}

Diss Stem (4 Papers out of 120). Diss also called Ampelodesmos mauritanicus, is from the Poaceae family. It is a very luxuriant monocotyledonous plant growing in a wild state around the Mediterranean basin. This plant has been used previously in the realization of vernacular constructions due to its natural mechanical and hydric qualities [124].

Algeria and France are the two countries researching aggregates produced from the stem of diss. Aggregates from diss stem are obtained after the grinding and sieving process. They are mixed with cement or clay binders; however, their mixture with cement undergoes a setting problem due to the presence of water-soluble substances contained in the plant. As a result, the diss aggregates are preferably boiled in water $[58,124]$ or covered with linseed oil before mixing with cement [58].

Bamboo stem (4 papers out of 120). The bamboos are evergreen perennial flowering plants in the Bambusoideae subfamily of the Poaceae grass family. Bamboo is one of the fastest-growing plants in the world due to a unique rhizome-dependent system. The internodal regions of the stem are usually hollow, and the vascular bundles in the cross-section are scattered throughout the stem instead of a cylindrical arrangement. Bamboo has been and is still widely used as an ornamental plant or for producing serving utensils and various materials. Apart from its structural use in the building industry (e.g., for the erection of scaffolds in Asia), it can also be used in the form of aggregates mixed with cement.

Most of the bamboo species are of Asian and American origin, found at varying altitudes up to $3,000 \mathrm{~m}$ in the Himalayas. Besides, a few species naturally occur in continental Africa and Oceania, while none in Europe. Only three articles were found in the literature on the use of bamboo's stem aggregates with cement and were from Brazil, Nigeria, and Malaysia (Table 1). Bamboo stem aggregates are obtained via the grinding and sieving process, and prior use may be washed in water at $45^{\circ} \mathrm{C}$ followed by air drying [127].

\subsubsection{Sugar Plant Wastes}

Bagasse from sugar cane (5 papers out of 120). Sugar cane corresponds to several species of tall perennial true grasses of the genus Saccharum, tribe Andropogoneae. It is used for sugar production. It has stout, jointed, and fibrous stalks rich in sugar (sucrose) and is accumulated in the stalk internodes. Global production of sugar cane in 2016 was 1.9 billion tons, with Brazil producing $41 \%$ of the world's total production, followed by India (18\%). The sugar cane industry produces large quantities of bagasse. It is estimated that world bagasse production is about $250 \mathrm{Mt} / \mathrm{y}$. Five articles from France, Malaysia, and the UK on the compatibility of sugar cane bagasse aggregates with cement were found in the literature (Table 1).

Bagasse is the fibrous residue of the sugar cane that is passed through the mill to extract the juice containing sugar. This by-product is then cut for use with a mineral binder. Two treatments, 
including a heat treatment by pyrolysis under a nitrogen gas flow $[130,131,133]$ and chemical treatment with an alkaline solution made of calcium hydroxide [133], were found in the literature to improve the setting of the composite and its thermal performance.

Sugar beet pulp ( 2 papers out of 120). Beet, also known as Beta vulgaris, is a subspecies of the plants belonging to the Amaranthaceae family. They are grown for their fleshy roots and used for the production of sugar, as a vegetable in the human diet, fodder plants, and more recently as a fuel source to produce bioethanol. Pulp is a by-product obtained from the processing of sugar beet and is mainly used as fodder for horses and other livestock.

Recently, in France, studies have been done for their use as plant aggregates for concrete after drying $[13,134]$. The aggregates are covered with cement or linseed oil to make them inert to the mineral matrix and reduce their strong affinity for water [13].

\subsubsection{Energy Crop Residues (Miscanthus Stem, 3 Papers out of 120)}

Miscanthus is a genus of perennial herbaceous plants of the Poaceae family (Gramineae) and native to Africa and South Asia. Some species of miscanthus (so-called "elephant grass" or Miscanthus giganteus) are gaining significant attention in the agricultural, industrial, and energy sectors for their productivity and energy value (biomass energy).

Research on the use of miscanthus aggregates for plant-based concrete is mainly done in France and China (Table 1). The miscanthus aggregates are obtained by drying, milling, and sieving the stems after harvest. Several treatments on miscanthus aggregates are carried out to improve the mechanical performance of the resulting plant-based concrete. These include enzymatic scarification with a cocktail made of cellulase, $\beta$-glucosidase, and xylanase after two distinct pretreatments with sulfuric acid or ammonia $[135,136]$ and saturation with water and impregnation with cement [31].

\subsubsection{Aromatic Plant Straws (Lavender Straw, 3 Papers out of 120)}

Lavender (Lavandula) is a genus of plants of the Lamiaceae family. They are dicotyledonous shrubs, mostly purple, and arranged in spikes. Most of them are highly fragrant, thus widely used in all branches of perfumery. Formerly, lavender was grown in France and some countries of the Mediterranean basin. Then the culture spread in Eastern Europe (Bulgaria, Russia, Ukraine, etc.) and even in Tasmania or Canada, where mutated plants could now resist freezing. The three articles about the mixing of lavender aggregates with a mineral binder found in the literature were from France (Table 1).

Lavender straw is a by-product of the production of lavender essential oil, extracted through hydrodistillation, and corresponds to the crushed stems. The obtained by-product is mixed with earth or with a pozzolanic binder. To limit the detrimental chemical interactions observed between the water-soluble components of the lavender straw and the pozzolanic binder, a mineral pretreatment based on a pozzolanic binder has been reported in the literature [56]. Nevertheless, the mechanical performance of composites formulated from these pretreated aggregates remained very limited. 


\subsection{Availability of By-Products Used as Plant Aggregates in Plant-based Concrete in France}

France is the most productive country in terms of publications on plant-based concrete (68 papers, Figure 4); hence, in this section, we mainly focused on the availability of the distinct byproducts in France.

Some existing studies assessed and compared the number of available by-products in a country $[7,142]$, which in turn took account of the non-harvestable parts (necessary to maintain soil fertility or inaccessible parts) and those allocated for other uses (e.g., litter, animal feed, energy, etc.). This assessment was essential before assessing a by-product.

Figure 5 compares the total quantities of the by-products available in France that can be used as plant aggregates in plant based-concrete and the number of articles published for each of them. Notably, due to the limited data available for each by-product instead, the total quantity was presented in the graph, and the numbers of articles published are mentioned wherever applicable. The data for this study was collected from earlier studies [6] and [143].

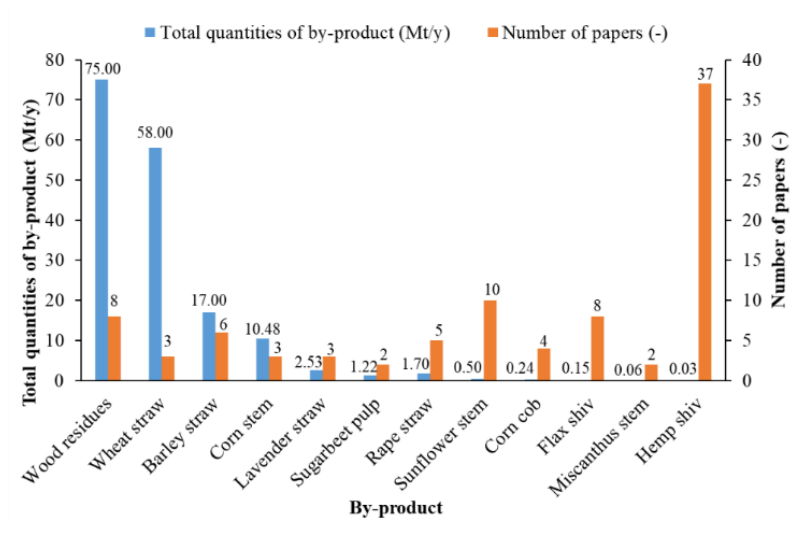

Figure 5 Comparison of the total quantities of by-products in France possibly usable as plant aggregates in plant-based concrete and the number of papers about each of them.

The results plotted in Figure 5 revealed that the number of published papers and the total quantities of agricultural by-products were uncorrelated. Widespread by-products such as wood residues and cereal straws have been studied very little. On the contrary, hemp shives $(0.03 \mathrm{Mt} / \mathrm{y})$, which represent only $0.02 \%$ of the total by-products in France, have been the most studied plant aggregates. This could be explained by the fact that the hemp sector was the first one to be established in France, in particular under the leadership of the "Construire en Chanvre" association. As a result, a lot of publications on the professional rules of hemp construction were published in 2007 and were last updated in 2012. The low availability of hemp shiv in several regions of France adds an economic and environmental additional cost in their transportation; thus, limiting the expansion of the hemp sector. This necessitates the diversification of the widely available byproducts and their complete characterization regarding their possible use as plant aggregates in plant-based concrete.

Thus, it would be of great interest to focus more research on the most available by-products such as wood chips, cereal straws, and even flax shives.

The diversification of these agricultural co-products raises the problem of their characterization. Indeed, in the case of material science, there is no standard protocol for the characterization of these plant additions. Between 2010 and 2016, some work was carried out by teams from 20 
laboratories within the framework of TC-Rilem 236 BBM, which partially resolved this problem by publishing recommendations in 2017 concerning the multi-physical characterization of plant aggregates [144]. However, these recommendations were based on the tests conducted only on hemp shives, and also several properties of plant particles were not addressed. The characterization of hemp shives and alternative plant aggregates are presented in the following section.

\subsection{Characterization Methods and Properties of Plant Aggregates}

This part summarizes the multi-physical characterization and properties of plant aggregates encountered in the literature. The most used bio-aggregate characterization protocols are those recommended by RILEM TC 236-BBM [5] and are based on hemp shives. However, there are also other ways for conducting such characterizations both on hemp shives and other plant aggregates. The various physical, hygro-thermal, and chemical characterizations of these plant aggregates are mentioned below.

\subsubsection{Physical Properties of Plant Aggregates}

Microstructure. Several methods have been proposed by RILEM TC 236-BBM [5] to analyze the microscopic structure of the plant aggregates. The most used are the imaging methods like scanning electron microscopy (SEM) and X-ray tomography. These methods can determine the pore size and its distribution, porosity, and microstructural morphology of the plant aggregates. SEM is a 2D technique carried out with a scanning electron microscope fitted with field emission and a secondary electron detector. Whereas X-ray tomography is a 3D image analysis including an X-ray source, a rotation state on which the object is fixed, an X-ray detector, and reconstruction software [5].

SEM requires at least two sections to analyze the microstructure of the plant aggregates, whereas X-ray tomography can do it directly. SEM analysis provides detailed structural information such as the shape and size of individual pores inside plant aggregates, but these are the representatives of only pores visible in the image. The X-ray tomography quantifies the pore size distribution, porosity, and tortuosity of the porous network. However, it does not apply to extremely large samples and pores much smaller than the resolution as they cannot be distinguished in such a situation. SEM and X-ray tomography methods together may determine the microstructural parameters of the plant aggregates more precisely. The combined SEM and X-ray tomographic Figure 6 and Figure 7 show the microstructural differences between various plant aggregates. Details about pore diameter and particle porosity of 12 plant aggregates are mentioned in Table $\mathbf{2}$ wherever data are available.

Apart from imaging methods, mercury intrusion porosimetry (MIP) can also be used to evaluate the pore size distribution of the internal open porosity of particles. In this method, mercury is inserted inside a particle by applying increasing pressures. The higher the pressure, the more the mercury will fill the small pores. The Wasburn equation relates the injection pressures to the pores accessible, as shown in Eq. (1)

$$
P=\frac{-2 \gamma \cos \theta}{r}
$$


where $P$ is the imposed pressure $(\mathrm{Pa}), \gamma$ is the interfacial energy (surface tension) of mercury $(\mathrm{N} / \mathrm{m})$, $\theta$ is the contact angle of mercury with the tested material $\left({ }^{\circ}\right)$, and $r$ is the radius of the pore $(\mathrm{m})$.

MIP method has two limitations, 1 ) the pores are rarely cylindrical, unlike what is taken as a hypothesis, and 2) the particle walls can be modified under the effect of pressures.

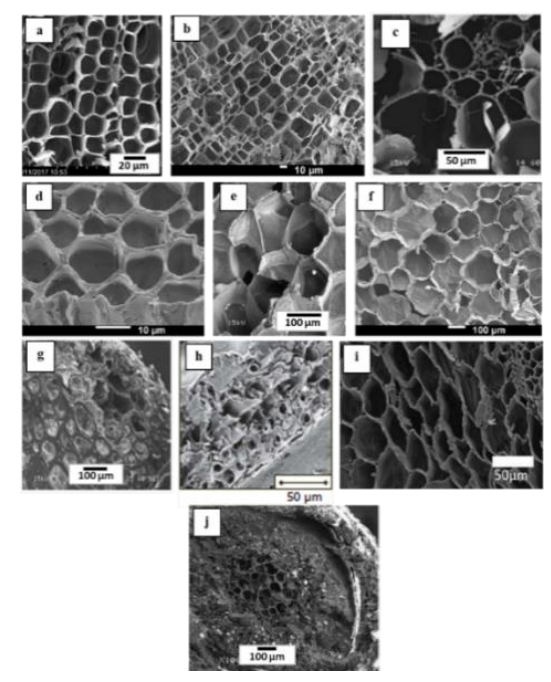

Figure 6 SEM cross-sectional images of (a) hemp shiv, (b) flax shiv, (c) barley straw, (d) wheat straw, (e) sunflower pith, (f) rape straw, (g) corn cob, (h) rice husk, (i) miscanthus stem, and (j) lavender straw [7, 30, 31, 38, 45, 60, 64].
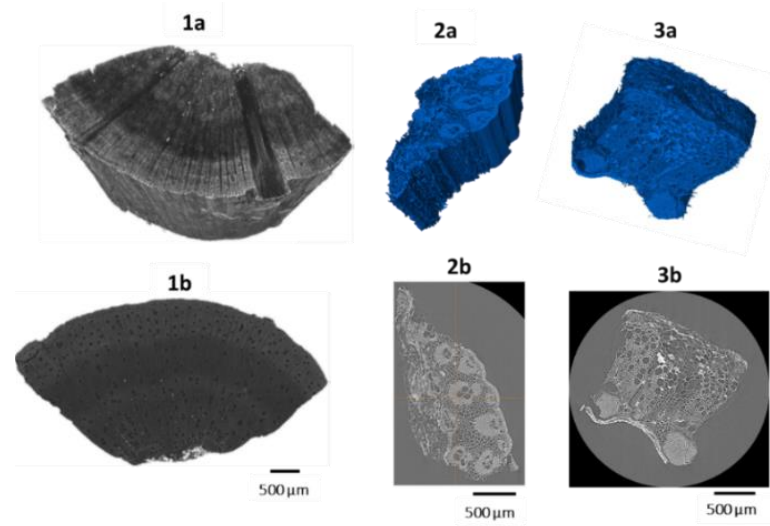

Figure 7 (a) 3D tomography reconstruction and (b) section images of (1) hemp shiv, (2) corn bark, and (3) sunflower bark [43, 64].

All the plant aggregates exhibited a highly porous structure, however, with some differences (Figure 6 and Table 2). Hemp shiv had a tubular microstructure with pore diameters ranging from 5 to $60 \mu \mathrm{m}$ and a cell wall thickness of about $4 \mu \mathrm{m}$. The 3D tomography reconstitution of Hemp shiv in Figure 7 showed longitudinal open pores with a particle porosity between $72 \%$ and $83 \%$. Flax shiv pores were also organized in the form of capillaries parallel to the growth direction of the plant, with pore diameters varying only from 15 to $33 \mu \mathrm{m}$. The particle porosity of flax shiv calculated in earlier studies [81] was around $71 \%$. Straws also exhibited a tubular microstructure with very thin cell walls $(<2 \mu \mathrm{m})$. Their pore diameters varied from 2 to $100 \mu \mathrm{m}$ in barley straw, from 6 to $30 \mu \mathrm{m}$ 
in wheat straw, and from 10 to $50 \mu \mathrm{m}$ in rape straw. 3D representations of both corn and sunflower bark showed a tubular and an alveolar structure (Figure 7) with the same pore diameters ranging from 10 to $80 \mu \mathrm{m}$. The particle porosity of corn bark was between 51 and 64\%, while that of sunflower bark could vary between $58 \%$ and $80 \%$. Sunflower pith had a particularly alveolar structure, with an average pore diameter greater than $100 \mu \mathrm{m}$ and thin cell walls. This large and high-porous structure of the sunflower pith could explain its lightness. With a tubular and an alveolar microstructure and pore diameters ranging from 20 to $80 \mu \mathrm{m}$, corn cob is different from other plant aggregates as its cell wall thickness is up to $45 \mu \mathrm{m}$. This structure makes the corn cob denser than all the other plant aggregates. Pore diameters varying from 1 to $30 \mu \mathrm{m}$ were detected in a single thin rice husk (about $80 \mu \mathrm{m}$ ), but its solid phase was predominant, and particle porosity varied from $34 \%$ to $50 \%$. Miscanthus stem showed tubular microstructure with pore diameters ranging from 30 to $50 \mu \mathrm{m}$ and a larger number of pores inside than outside thereby, making it denser (Figure 6). The porosity of miscanthus stem particles was around $82 \%$ to $84 \%$. SEM image of lavender straw in Figure 6 shows a concentrically organized tubular structure. All the biggest pores between 30 and $60 \mu \mathrm{m}$ were located in the center, surrounded by small square pores with a size ranging from 7 to $9 \mu \mathrm{m}$, which in turn were surrounded with a dense envelope containing pores of varying sizes. The cell wall thickness was between 1.5 and $2 \mu \mathrm{m}$.

Table 2 Pore diameter and particle porosity of 12 plant aggregates.

\begin{tabular}{llll}
\hline Plant aggregates & Pore diameter $(\mu \mathrm{m})$ & Particle porosity $(\%)$ & References \\
\hline Hemp shiv & & & {$[7,20,28,29,34,35,45,49$,} \\
& $5-60$ & $72-83$ & $50,53,55,60,63,64,69,74$, \\
Flax shiv & $15-33$ & 71 & $86,89]$ \\
Barley straw & $2-100$ & - & {$[23,40,60,81]$} \\
Wheat straw & $6-30$ & - & {$[7,24,38]$} \\
Corn bark & $10-80$ & $51-64$ & {$[24,60]$} \\
Sunflower pith & $>100$ & - & {$[43]$} \\
Sunflower bark & $10-80$ & $58-80$ & {$[25,45]$} \\
Rape straw & $10-50$ & 78 & {$[25,43,53]$} \\
Corn cob & $20-80$ & - & {$[25,54,55,60]$} \\
Rice husk & $1-30$ & $34-50$ & {$[7,140,141]$} \\
Miscanthus stem & $30-50$ & $82-84$ & {$[30,122]$} \\
Lavender straw & $7-60$ & - & {$[31]$} \\
\hline
\end{tabular}

The above results showed that the microstructure of the plant aggregates is a characteristic feature, which is often studied in the literature and varies significantly from one plant aggregate to another. Besides, the microstructure impacts other properties of aggregates, such as their density or their water absorption capacity, as discussed in the following paragraphs. 
Particle size distribution and shape of the plant aggregates. Two main methods are recommended by the RILEM TC 236-BBM [5] to determine particle size in plant aggregates, such as mechanical sieving and image analysis. Mechanical sieving uses sieves with standardized square meshes to study soil and mineral aggregates (NF ISO 3310-1 [145] and ASTM E-11-95 [146]). This method only finds the width of the particles as they can pass through the sieve in the direction of their length. Thus, only spherical plant aggregates like corn cob particles are suitable for this method but not the elongated ones such as straw. Image analysis is more adapted for the majority of the elongated plant aggregates. In this method, firstly, the particles are sieved at $500 \mu \mathrm{m}$ to remove dust. They are then homogenized before being scanned on a black background to obtain better contrast for the image analysis by using the software. However, this method is only performed with a small number of particles. So, the precision of the results can be limited by the representativeness of the sample. Moreover, the dimensions obtained are only related to the 2D projection of the particles. Geometrical parameters obtained via image analysis include major and minor axis, equivalent area diameter (EAD) are based on a particle with a perfect circular cross-section, circularity, and $A R$ ( $A R$, ratio of major length to the minor length). Figure 8 presents the extreme major and minor axis length curves (i.e., the maximum limits of the major axis and the minimum limits of the minor as observed in the literature) of seven different plant aggregates and shows the extent of each particle size. Nevertheless, in terms of shape and size, two hemp shives of different origins differed more significantly than a hemp shiv compared with a corn or sunflower bark [65]. Indeed, the particle size of plant aggregates is an easily adjustable parameter according to the calibration process. A list of median values of the length, width, and AR of plant aggregates found in the literature is also presented in Table 3.

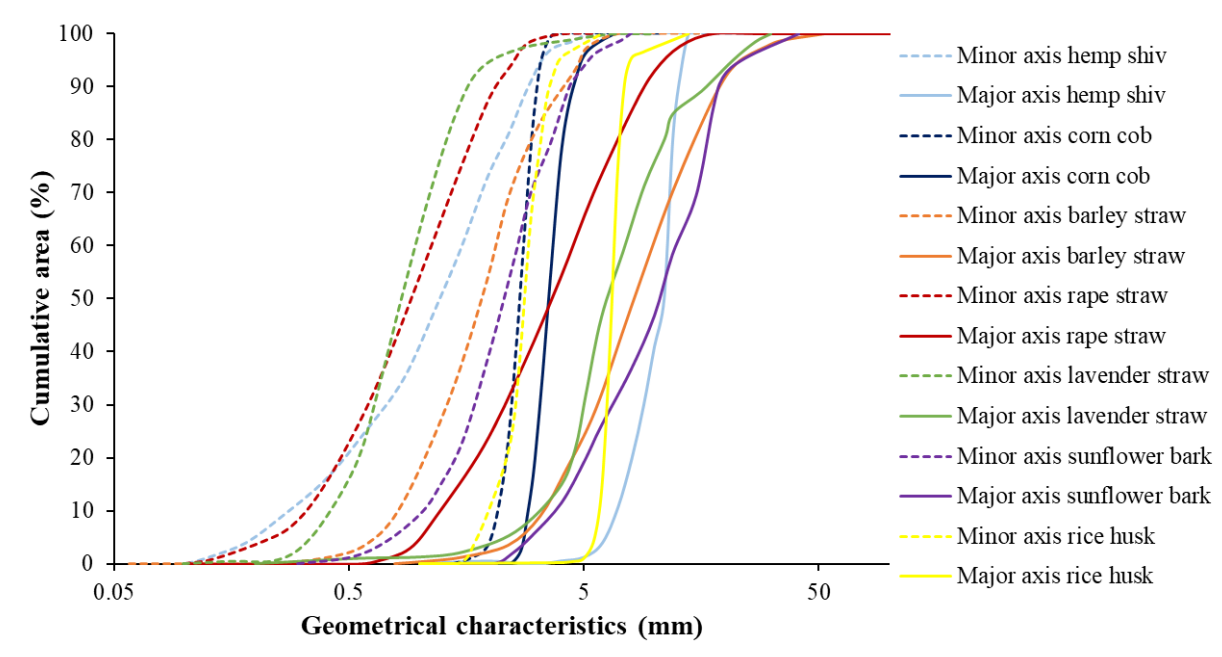

Figure 8 Extreme minor and major axis curves obtained by image analysis for seven different plant aggregates [7, 30, 38, 53, 56, 62, 82].

Table 3 Median length, width, and AR values of the plant aggregate particles.

\begin{tabular}{lllll}
\hline Plant aggregates & $\begin{array}{l}\text { Median particle } \\
\text { length }(\mathbf{m m})\end{array}$ & $\begin{array}{l}\text { Median particle } \\
\text { width }(\mathbf{m m})\end{array}$ & $\begin{array}{l}\text { Aspect ratio } \\
\text { AR }(-)\end{array}$ & References \\
\hline Hemp shiv & $0.7-30.0$ & $0.25-5.0$ & $2.28-8.75$ & $\begin{array}{l}{[7,15,20,28,29,32,} \\
35,41,42,45,50-54,\end{array}$
\end{tabular}


$60-62,65,69,70,82$,

\begin{tabular}{|c|c|c|c|c|}
\hline & & & & $\begin{array}{l}60-62,65,69,70,82, \\
88]\end{array}$ \\
\hline Flax shiv & $5.5-20.0$ & $0.5-4.1$ & $4.87-20.00$ & {$[23,55,60,93]$} \\
\hline Wood chip & 20.0 & 7.0 & 2.86 & {$[18,97]$} \\
\hline Barley straw & $7.6-35.0$ & $2.0-2.5$ & $4.10-14.00$ & {$[7,41,42]$} \\
\hline Wheat straw & $9.0-12.00$ & $1.1-1.2$ & $8.18-10.00$ & [60] \\
\hline Corn bark & $9.0-14.0$ & $1.8-8.3$ & $1.70-6.11$ & {$[17,43,65]$} \\
\hline Sunflower pith & 9.0 & 6.0 & 1.50 & {$[45]$} \\
\hline Sunflower bark & $5.7-9.0$ & $1.8-8.3$ & $2.99-4.74$ & {$[43,53,65,118]$} \\
\hline Rape straw & $3.9-15.0$ & $0.9-3.0$ & $5.00-6.20$ & {$[54,60,82]$} \\
\hline Corn cob & $3.6-5.0$ & $2.6-3.7$ & $1.40-1.50$ & {$[7,41,42,60]$} \\
\hline Rice husk & 6.7 & 2.7 & 2.44 & {$[29,30]$} \\
\hline Diss stem & $10.0-15.0$ & 1.5 & 10.00 & {$[58]$} \\
\hline Bamboo stem & $6.8-8.8$ & $0.5-1.0$ & $7.09-14.17$ & {$[33,127]$} \\
\hline Miscanthus stem & 11.0 & 3.0 & 3.67 & [31] \\
\hline Lavender straw & $5.0-30.0$ & $1.5-3.0$ & $3.33-10.00$ & {$[38,56]$} \\
\hline
\end{tabular}

The very small space between the major and minor axes of corn cob explained the similarity between these two dimensions. In addition, the steepness of their slope indicated a little variation in the dimensions. The AR value of the corn cob was very close to 1 (between 1.40 and 1.50 in Table 3 ), indicating a nearly circular cross-section. Rice husk also exhibited a similar steep spindle, but the distance between the two curves was larger than that of the corn cob, which indicated that major and minor axes were quite regular but not the same. This resulted in an AR value higher than 1 (i.e., between 2 and 3 in Table 3), thereby explaining the elongation in the particle. The grading curves of the remaining five aggregates were quite similar. Their ARs were superior to that of rice husk (i.e., from 2 to 14), indicating highly elongated particles of straws and stem barks.

Apart from the AR, circularity has also been used to validate the difference in shape between two or more aggregates. It varies between 0 (elongated shape) and 1 (circular shape). For example, the difference in circularity between two hemp shives and two bark particles from corn and sunflower is shown in Figure 9. Besides, the shape of the particles impacts their granular arrangement and consequently their bulk density.

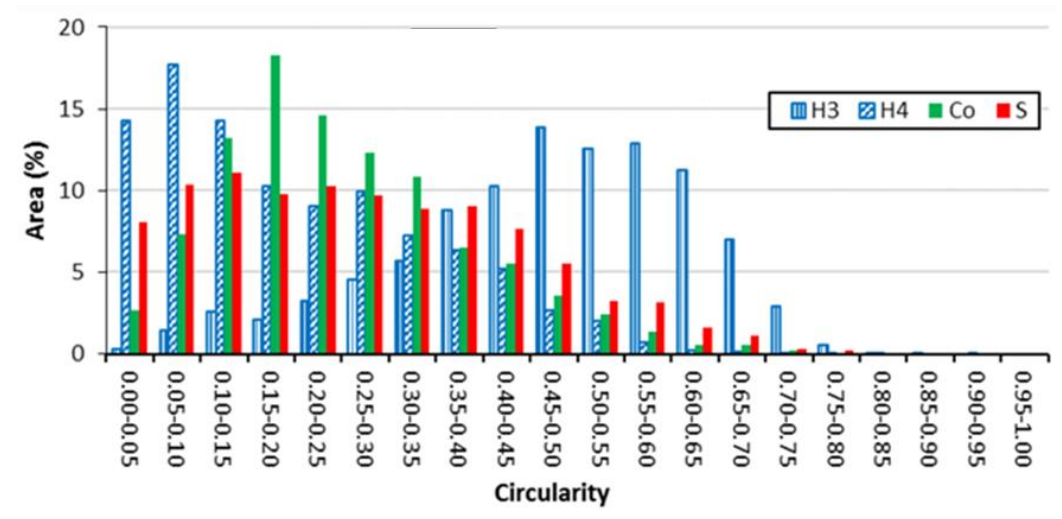

Figure 9 Circularity of hemp shives (H3: hemp shiv (batch number 3), H4: hemp shiv (batch number 4)), corn bark (Co), and sunflower (S) [65]. 
Densities. The plant aggregates have three distinguishable densities, namely, the bulk density of the particle arrangement, the apparent density of particles, and the skeleton density. As illustrated in Figure 10, in a bulk arrangement of plant aggregates, the bulk density is considered as the ratio of the mass to the volume of the solid particles along with the intra-and inter-particle voids. For the apparent density of the particles, the volume includes that of the solid plus the intra-particle voids. Lastly, the skeleton density takes into account the volume of the solid part only.

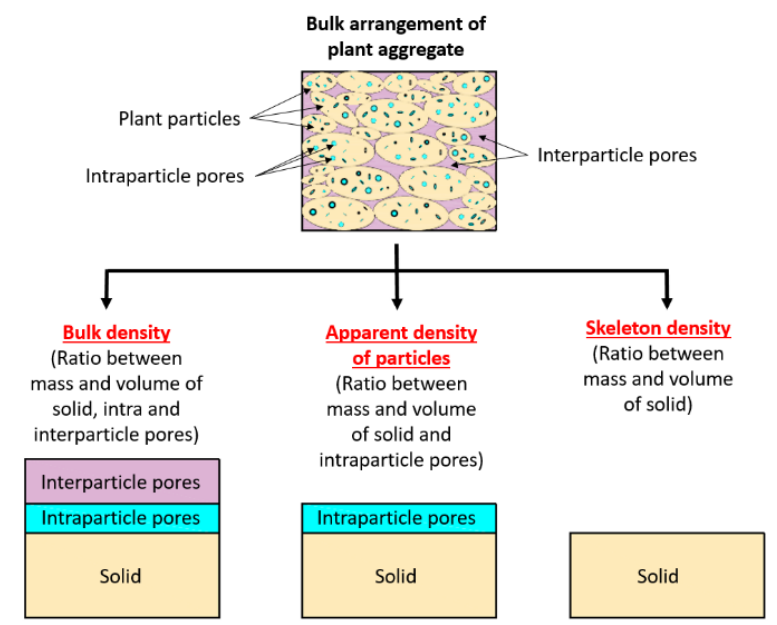

Figure 10 Illustration showing the calculation for bulk density, apparent density, and skeleton density of the plant aggregate.

It is possible to determine all kinds of porosities existing in a plant aggregate arrangement from all three densities. The total porosity of the bulk arrangement of plant aggregates is the sum of the inter-particle (the volume percentage of voids between particles in a bulk aggregate arrangement) and the intra-particle porosity (the volume percentage of voids inside the particles). The results of these previously defined parameters for each plant aggregate are presented in Table 4. 
Table 4 The bulk density, the apparent density of particles, skeleton density, total porosity, and inter and intra-particle porosity values of the plant aggregates available in the literature.

\begin{tabular}{|c|c|c|c|c|c|c|c|}
\hline $\begin{array}{l}\text { Plant } \\
\text { aggregates }\end{array}$ & $\begin{array}{l}\text { Bulk density } \\
\left(\mathrm{kg} / \mathrm{m}^{3}\right)\end{array}$ & $\begin{array}{l}\text { Apparent } \\
\text { density of } \\
\text { particles } \\
\left(\mathrm{kg} / \mathrm{m}^{3}\right)\end{array}$ & $\begin{array}{l}\text { Skeleton } \\
\text { density } \\
(\mathrm{kg} / \mathrm{m} 3)\end{array}$ & $\begin{array}{l}\text { Total porosity } \\
\text { (\%) }\end{array}$ & $\begin{array}{l}\text { Inter-particle } \\
\text { porosity (\%) }\end{array}$ & $\begin{array}{l}\text { Intra-particle } \\
\text { porosity (\%) }\end{array}$ & References \\
\hline Hemp shiv & $\begin{array}{l}70-163 \\
\text { (37 references) }\end{array}$ & $\begin{array}{l}250-320 \\
\text { (7 references) }\end{array}$ & $\begin{array}{l}1259-1500 \\
\text { (9 references) }\end{array}$ & $\begin{array}{l}90-92 \\
\text { (9 references) }\end{array}$ & $\begin{array}{l}55-61 \\
\text { (7 references) }\end{array}$ & $\begin{array}{l}32-37 \\
(5 \\
\text { references) }\end{array}$ & $\begin{array}{l}{[7,15,16,20,28,29,32,35,} \\
41,42,45,46,50-54,60-63, \\
65,66,69-71,74,76,80,82- \\
89]\end{array}$ \\
\hline Flax shiv & $\begin{array}{l}90-141 \\
\text { (9 references) }\end{array}$ & $\begin{array}{l}374 \\
\text { (1 reference) }\end{array}$ & $\begin{array}{l}1270-1342 \\
\text { (2 references) }\end{array}$ & $\begin{array}{l}90-93 \\
(2 \text { references })\end{array}$ & $\begin{array}{l}76 \\
\text { (1 reference) }\end{array}$ & $\begin{array}{l}17 \\
\text { (1 reference) }\end{array}$ & {$[23,40,55,60,90-94]$} \\
\hline $\begin{array}{l}\text { Coconut } \\
\text { coir }\end{array}$ & - & - & $\begin{array}{l}1125 \\
\text { (1 reference) }\end{array}$ & - & - & - & {$[96]$} \\
\hline Wood chip & $\begin{array}{l}50-280 \\
\text { (5 references) }\end{array}$ & $\begin{array}{l}233-690 \\
\text { (5 references) }\end{array}$ & $\begin{array}{l}1100-1200 \\
\text { (1 references) }\end{array}$ & $\begin{array}{l}82-87 \\
\text { (1 reference) }\end{array}$ & $\begin{array}{l}52-70 \\
\text { (3 references) }\end{array}$ & - & {$[18,99-101,105,106,111]$} \\
\hline $\begin{array}{l}\text { Barley } \\
\text { straw }\end{array}$ & $\begin{array}{l}47-107 \\
\text { (5 references) }\end{array}$ & - & $\begin{array}{l}870 \\
\text { (1 references) }\end{array}$ & $\begin{array}{l}94 \\
\text { (1 references) }\end{array}$ & - & - & {$[7,24,41,42,99]$} \\
\hline $\begin{array}{l}\text { Wheat } \\
\text { straw }\end{array}$ & $\begin{array}{l}25-54 \\
\text { (2 references) }\end{array}$ & - & $\begin{array}{l}865-1478 \\
\text { (2 references) }\end{array}$ & $\begin{array}{l}96-98 \\
(2 \text { references })\end{array}$ & - & - & {$[24,60]$} \\
\hline Corn pith & $\begin{array}{l}18 \\
\text { (1 reference) }\end{array}$ & - & - & - & - & - & {$[16]$} \\
\hline
\end{tabular}




\begin{tabular}{|c|c|c|c|c|c|c|c|}
\hline Rice straw & $\begin{array}{l}96-160 \\
\text { (1 reference) }\end{array}$ & - & - & - & - & - & {$[117]$} \\
\hline Corn bark & $\begin{array}{l}75-120 \\
\text { (3 references) }\end{array}$ & - & - & - & - & - & {$[17,43,65]$} \\
\hline $\begin{array}{l}\text { Sunflower } \\
\text { pith }\end{array}$ & $\begin{array}{l}14-20 \\
\text { ( } 2 \text { references) }\end{array}$ & $\begin{array}{l}35 \\
\text { (1 reference) }\end{array}$ & - & - & $\begin{array}{l}43 \% \\
\text { (1 reference) }\end{array}$ & - & {$[16,45]$} \\
\hline $\begin{array}{l}\text { Sunflower } \\
\text { bark }\end{array}$ & $\begin{array}{l}98-168 \\
\text { (4 references) }\end{array}$ & $\begin{array}{l}296 \\
\text { (1 reference) }\end{array}$ & $\begin{array}{l}1540 \\
\text { (1 reference) }\end{array}$ & $\begin{array}{l}94 \\
\text { (1 reference) }\end{array}$ & $\begin{array}{l}67 \\
\text { (1 reference) }\end{array}$ & $\begin{array}{l}27 \\
\text { (1 reference) }\end{array}$ & {$[43,53,65,118]$} \\
\hline Rape straw & $\begin{array}{l}73-125 \\
\text { (4 references) }\end{array}$ & $\begin{array}{l}256 \\
\text { (1 reference) }\end{array}$ & $\begin{array}{l}1162-1411 \\
\text { ( } 2 \text { reference) }\end{array}$ & $\begin{array}{l}89-94 \\
(2 \text { reference) }\end{array}$ & $\begin{array}{l}49 \\
\text { (1 reference) }\end{array}$ & $\begin{array}{l}40 \\
\text { (1 reference) }\end{array}$ & {$[54,55,60,82]$} \\
\hline Corn cob & $\begin{array}{l}212-497 \\
\text { (5 references) }\end{array}$ & - & $\begin{array}{l}1333 \\
\text { (1 reference) }\end{array}$ & $\begin{array}{l}72 \\
\text { (1 reference) }\end{array}$ & - & - & {$[7,41,42,60,141]$} \\
\hline Rice husk & $\begin{array}{l}98-122 \\
\text { ( } 3 \text { references) }\end{array}$ & $\begin{array}{l}453 \\
\text { ( } 3 \text { references) }\end{array}$ & $\begin{array}{l}690-780 \\
\text { (3 references) }\end{array}$ & $\begin{array}{l}82-87 \\
\text { ( } 3 \text { references) }\end{array}$ & $\begin{array}{l}73-78 \\
\text { ( } 3 \text { references) }\end{array}$ & $\begin{array}{l}9-10 \\
(3 \\
\text { references) }\end{array}$ & {$[29,30,122]$} \\
\hline Diss stem & $\begin{array}{l}37-50 \\
\text { ( } 2 \text { references) }\end{array}$ & - & - & - & - & - & {$[58,124]$} \\
\hline $\begin{array}{l}\text { Bamboo } \\
\text { stem }\end{array}$ & $\begin{array}{l}298 \\
\text { (1 reference) }\end{array}$ & $\begin{array}{l}500-780 \\
\text { (1 reference) }\end{array}$ & - & - & - & - & {$[33,127]$} \\
\hline $\begin{array}{l}\text { Miscanthus } \\
\text { stem }\end{array}$ & $\begin{array}{l}78-119 \\
\text { (1 reference) }\end{array}$ & $\begin{array}{l}222-250 \\
\text { (1 reference) }\end{array}$ & $\begin{array}{l}1400-1406 \\
\text { (1 reference) }\end{array}$ & $\begin{array}{l}92-94 \\
\text { (1 reference) }\end{array}$ & $\begin{array}{l}52-65 \\
\text { (1 reference) }\end{array}$ & $\begin{array}{l}30-39 \\
\text { (1 reference) }\end{array}$ & [31] \\
\hline
\end{tabular}


Recent Progress in Materials 2021; 3(2), doi:10.21926/rpm.2102026

Lavender 64

straw

(2 references)

$[38,56]$ 
Several results for bulk density in contrast to the low number of results for the apparent density of particles and skeleton density of all the plant aggregates were observed in Table 4. For example, in the case of hemp shiv, there were 37 references for bulk density and only 7 and 9 references for the apparent density of particles and skeleton density, respectively. This difference was explained by the existence of a protocol well defined by the RILEM to determine the bulk density of plant aggregates, while there was no recommendation for the two other densities. The methods of calculating and the results of each kind of density of the plant aggregates were developed in the following subsections.

Bulk density. The most widely used method present in the literature for determining the bulk density of plant aggregates was proposed by the RILEM TC 236-BBM [144]. In this method, bulk density is measured in a dry state (specimens are dried at $60^{\circ} \mathrm{C}$ until their weight becomes constant). The measurement is performed with a cylindrical mold (height at least twice the diameter and the diameter is at least equal to $10 \mathrm{~cm}$ ). Other methods are also cited in the literature [18, 31, 67, 92], but the principle remains the same, i.e., drying the material and measuring its mass by knowing its apparent volume. Nevertheless, differences between certain values could be related to the fact that whether the aggregates were compressed or not in the container before being weighed. For example, in the case flex shiv, the density of $90 \mathrm{~kg} / \mathrm{m}^{3}$ value was calculated without compaction [81], while the value of $141 \mathrm{~kg} / \mathrm{m}^{3}$ was obtained after compaction with a tamping rod ( 25 strokes on each of the two layers of aggregates) [91]. Thus, the $141 \mathrm{~kg} / \mathrm{m}^{3}$ density was much closer to a tapped density value. This indicated that the proposed protocol must have a comparable level of compaction as in the case of the RILEM protocol (with ten shakes of the cylinder from top to bottom to ensure a loose arrangement).

In general, the results showed that the pith particles and some straws had the lowest bulk densities (sunflower pith $14-20 \mathrm{~kg} / \mathrm{m}^{3}$, wheat straw $25-54 \mathrm{~kg} / \mathrm{m}^{3}$, diss stem $37-50 \mathrm{~kg} / \mathrm{m}^{3}$, barley straw $47-107 \mathrm{~kg} / \mathrm{m}^{3}$, lavender straw $64 \mathrm{~kg} / \mathrm{m}^{3}$, and rape straw 73-125 kg/m $\left.\mathrm{m}^{3}\right)[7,16,24,41,42,45$, 54-56, 58-60, 99, 124]. Hemp shiv, corn bark, miscanthus stem, flax shiv, wood chip, rice straw, sunflower bark, and rice husk had medium bulk density values (between 70 and $168 \mathrm{~kg} / \mathrm{m}^{3}$ ). On the opposite, corn cob and bamboo stem were the heaviest aggregates (more than $200 \mathrm{~kg} / \mathrm{m}^{3}$ ). These results were aligned with the microstructures observed previously and were associated with the inter-particle pores, which in turn were linked to the elongation of the particles. In addition to the intra-particle porosity, the inter-particle one could be enhanced by a more elongated shape of the plant particles. Figure 11 presents the mean of the bulk density as a function of the mean of the AR for all plant aggregates when both parameters are available. The results showed that the more the particles are elongated, the greater the inter-particle porosity and, therefore, the lower the bulk density. The low densities of corn and sunflower pith were ascribed to their high particle porosity due to their highly porous microstructure. 




Figure 11 Mean of bulk density as a function of the mean of aspect ratio (AR) of plant aggregates.

Bulk density allows characterizing plant aggregates as loose-fill insulating materials. However, aggregates rearrange themselves when they are mixed with a binder and compacted in the wet state in a composite, thereby limiting their inter-particle porosity that would also be partially filled by the binder. This necessitates the measurement of the apparent density of the particles to determine the particle porosity.

The apparent density of the particles. The apparent density of the particles has been previously measured based on a straight section of stem and the corresponding area determined by image analysis and the measured height [5]. Other methods encountered in the literature include mercury intrusion porosimetry (MIP), X-ray tomography estimation [43], the water displacement method or Archimedes method [31, 105], and utilization of fine sand less than $250 \mu \mathrm{m}$, which eliminates the voids surrounding the particles and allows to determine their exact volume $[13,147]$.

All these methods are limited by the reliability of the volume of the particles or stem obtained. In the case of the method proposed in earlier studies [118], the fact that the walls of the stem are not perfectly parallel and the uncertainty in the accuracy of the perpendicularity of the section probably lead to an error in the value of the stem volume. In MIP, the particle volume is determined from the volume of solid and open pores, while the closed pores are neglected. The volume estimation from X-ray tomography may be biased due to the imprecision in resolution. With Archimedes method, first immersion in the water swells up the particle, thereby changing its volume. In the fine sand method, the compressing of the particles may modify the volume; thus, it is necessary to ensure the same level of compaction in the sand from one measurement to another. Nevertheless, this method could be interesting if the protocol and the representative elementary volume (REV) are properly implemented.

The majority of apparent densities of particles identified in the literature were between 250 $\mathrm{kg} / \mathrm{m}^{3}$ for hemp and up to $780 \mathrm{~kg} / \mathrm{m}^{3}$ for bamboo stems (Table 4). On the contrary, sunflower pith 
had a very low value of $35 \mathrm{~kg} / \mathrm{m}^{3}$ due to the presence of several and very large pores and thin cell walls, resulting in a low apparent density of the particles. Hence, it could be said that the apparent density of the particles is closely related to their microstructure. It is to be noticed that results for the apparent density of particles varied widely, depending on the method used or the treatments experienced by the particles. For future research and development, a standardized method would be required to avoid diversification of the results so that they can have more precision.

Skeleton density. The skeleton density of plant aggregates is measured with a manual pycnometer method [24, 29-32, 49, 50, 55, 60, 86, 87]. Successive weightings of pycnometer (i.e., pycnometer with dry aggregates, pycnometer with aggregates filled with filling fluid, and pycnometer filled with water) give the mass of solid aggregates and their volume. Nozahic et al. (2012) estimated the value of the skeleton density of lignocellulosic aggregates, and the latter was equal to that of the cellulose $\left(1540 \mathrm{~kg} / \mathrm{m}^{3}\right)$ [53]. It depends on the constituents of the cell walls. The majority of identified values were between 1100 and $1540 \mathrm{~kg} / \mathrm{m}^{3}$, which was in agreement with the real densities of the pure chemical components of the cell walls. The low values recorded for rice husk $\left(690-780 \mathrm{~kg} / \mathrm{m}^{3}\right)[29,30,122] \mathrm{might}$ be due to the closed pores, which were not detected by the pycnometer method. The volume of the solid was thus overestimated, thereby reducing the resulted skeleton density.

Table 4 indicated that for the majority of aggregates arranged in bulk, the inter-particle porosity is always higher than the intra-particle due to the elongated shapes of the aggregates, which generate a lot of intergranular voids. Sunflower pith has the lowest inter-particle porosity (43\%) due to its circular shape, resulting in fewer intergranular voids, whereas rice husk has the greatest interparticle porosity (73-78\%) due to its convex and elongated shape, leading to widely spaced particles aggregates. In the composite, the inter-particle porosity is filled by the rearrangement of the aggregates and the binder matrix. The intra-particle porosity data of the sunflower pith is not available in the literature. However, it should be the highest one in particular due to its original porous microstructure. For the rest of the aggregates, this parameter is between $9 \%$ for rice husk and $40 \%$ for rape straw. In terms of total porosity, it could be said that bulk plant aggregates are porous materials. Corn cob, which is the densest aggregate, is also least porous with $72 \%$ of total porosity, followed by wood chip and rice husk (82-87\%). Shiv, straw, and stem are the most porous aggregates with more than $90 \%$ of total porosity. The porosity of plant aggregates generally plays an important role in their water absorption capacity, as discussed below.

Water absorption. The water absorption capacity $w(t)$ of a plant aggregate is defined as the quantity of water it can absorb per unit of time and is calculated according to Eq. (2) mentioned below:

$$
w(t)=\frac{m(t)-m_{0}}{m_{0}} * 100
$$

where $m(t)$ is the wet mass of the aggregates $(\mathrm{kg})$ for an immersion time $\mathrm{t}$ and $m_{0}$ is the initial dry mass (kg).

Water absorption is an essential parameter for plant aggregates when they are mixed with a mineral binder. In most cases, plant aggregates have very high water absorption rates, which creates a competition between the water absorbed by the aggregates and that required for the hydration 
of the binder. This competition can thus induce a disturbance in the setting of the binder $[20,28$, 49].

The most widely used method in the literature to determine the water absorption of plant aggregates was the one proposed by RILEM TC 236-BBM [144]. The water absorption measurements are carried out at several time intervals to determine the evolution of the absorption kinetics of the aggregates. This allows the prediction of their short-term behavior (i.e., in the initial minutes) during the first contact of the water/aggregate/binder mixture and also their behavior at saturation. Nozahic et al. (2012) proposed a model for the kinetics of water absorption in plant aggregates as a logarithmic function of time:

$$
w(t)=I R A+K_{1} \cdot \log (t)
$$

where $I R A$ is the initial rate of absorption, corresponding to the water absorption rate after $1 \mathrm{~min}$ and representing the absorption of water only on the surface of the particles (\%), and $K_{1}$ is the coefficient of water absorbed by the particle over time $\left(\% \cdot \log (\min )^{-1}\right)$.

Laborel-Préneron et al. (2018) represented the water absorption as a function of the logarithm of time for three different aggregates (hemp shiv, barley straw, and corn cob), as shown in Figure 12. This representation of water absorption in mass percentage suggested that barley straws have the highest absorption capacity (IRA of $247 \%$ ), followed by hemp shiv (IRA of $218 \%$ ) and corn cob (IRA of 48\%). However, the dosage of aggregates in the plant-based concrete formulation might be very different, which means that the mass representation of water absorption is not a good parameter for predicting its impact on the formulation of the composite. Instead, the volume representation would be much more consistent.

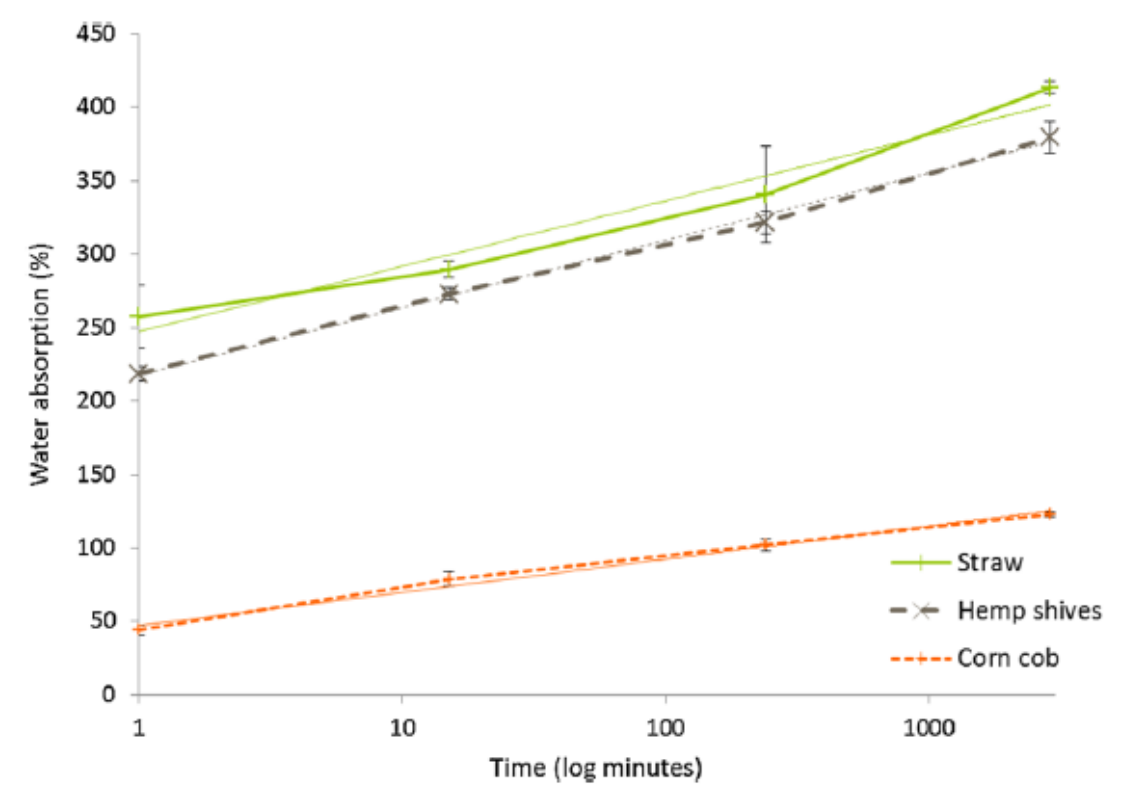

Figure 12 Water absorption as a function of the logarithm of time in hemp shiv, barley straw, and corn cob [7].

Table 5 presents, wherever applicable, the IRA and $\mathrm{K}_{1}$ data of different plant aggregates obtained through RILEM and other methods. Most of the hemp shiv aggregates had higher water absorption at IRA (122-218\%) in comparison to values obtained by the RILEM method (190-240\%). This 
difference could be explained based on the fact that other methods did not use salad spinner before weighing $[28,49,118]$ or just used an absorbent paper to remove water from the aggregate surface [31]. Consequently, an additional amount of water could be present between the aggregates and might increase the absorption value. Diverse results have also been observed with the RILEM method due to different origins of the hemp, which might differ the size, and the spin might also vary from one operator to another. As expected, the same RILEM method provided the lowest absorption capacity (IRA of $48 \%$, and $\mathrm{K}_{1}$ of $9.8 \% \cdot \log (\mathrm{min})^{-1}$ ) of the corn cob due to its low porosity as compared with other plant aggregates, followed by lavender straw (IRA of $100 \%$, and $K_{1}$ of 12.5\%.Log $\left.(\mathrm{min})^{-1}\right)$. All other straws, shives, and barks, with higher porosities revealed higher water absorption capacity (IRA $>100 \%$ and $K_{1}>17 \%$. Log $(\mathrm{min})^{-1}$ ). According to the definition of $\mathrm{K}_{1}$, a correlation could be expected between it and the apparent density of the particles. However, this hypothesis could not be verified due to the lack of data. Indeed, the density of the particles was rare in the literature and it was only very recently that the kinetics of water absorption was represented as a function of the logarithm of time. It is thus necessary to find a standardized method which can easily determine the apparent density of the particles.

Table 5 IRA and $K_{1}$ values of different plant aggregates found in the literature.

\begin{tabular}{|c|c|c|c|c|c|c|}
\hline $\begin{array}{l}\text { Plant } \\
\text { aggregates }\end{array}$ & $\begin{array}{l}\text { RILEM } \\
\text { method }\end{array}$ & & & $\begin{array}{l}\text { Other } \\
\text { methods }\end{array}$ & & \\
\hline & IRA (\%) & $\begin{array}{l}\text { K1 } \\
\left(\% . \log (\min )^{-1}\right)\end{array}$ & References & IRA (\%) & $\begin{array}{l}\text { K1 } \\
\left(\% . \log (\min )^{-1}\right)\end{array}$ & References \\
\hline Hemp shiv & $\begin{array}{l}122- \\
218\end{array}$ & $19.5-50.0$ & $\begin{array}{l}{[7,35,69,} \\
76]\end{array}$ & $190-240$ & 20.1 & $\begin{array}{l}{[28,50,53,} \\
73]\end{array}$ \\
\hline $\begin{array}{l}\text { Barley } \\
\text { straw }\end{array}$ & 247 & 19.4 & [41] & 300 & - & [24] \\
\hline $\begin{array}{l}\text { Wheat } \\
\text { straw }\end{array}$ & - & - & - & $180-225$ & - & [24] \\
\hline Corn bark & $\begin{array}{l}105- \\
106\end{array}$ & $18.5-19.8$ & {$[43,65]$} & - & - & - \\
\hline $\begin{array}{l}\text { Sunflower } \\
\text { bark }\end{array}$ & $\begin{array}{l}141- \\
148\end{array}$ & $17.8-18.5$ & {$[43,65]$} & 216 & 57.3 & [53] \\
\hline Rape straw & 218 & 23.9 & {$[82]$} & - & - & - \\
\hline Corn cob & 48 & 9.8 & [7] & - & - & - \\
\hline Beet pulp & - & - & & 160 & - & [13] \\
\hline $\begin{array}{l}\text { Lavender } \\
\text { straw }\end{array}$ & 100 & 12.5 & {$[56]$} & - & - & - \\
\hline
\end{tabular}

The studies reported in the literature showed that the physical properties of plant aggregates also influence their hygro-thermal properties, as discussed in the next section. 


\subsubsection{Hygro-thermal Properties of the Plant Aggregates}

Plant aggregates are used as insulating materials. Thus, to ensure indoor comfort apart from their physical properties, their hygro-thermal properties are also important. These properties are discussed in the following section.

Sorption-desorption isotherms. The sorption-desorption isotherm property links the moisture content of the material at equilibrium to the ambient relative humidity $(\mathrm{RH})$ at a given temperature. It is evaluated by using the saturated salt solution (SSS) technique or the dynamic vapor sorption (DVS) method.

The standard NF EN ISO 1270 [148] governs the SSS technique. Briefly, plant aggregates samples are dried at $40^{\circ} \mathrm{C}[24,32,69,114]$ in an oven until mass stabilization (change in mass less than $0.1 \%$ between two weighings in $24 \mathrm{~h}$ ). Following this, at least $10 \mathrm{~g}$ of the material to be tested is put in a container that is not sensitive to humidity variation (glass cups, for example) and then kept in a ventilated sealed desiccator or box at $23^{\circ} \mathrm{C}$ in which the $\mathrm{RH}$ is controlled by saturated salt solutions. Samples are tested gradually with the salt solutions after stabilization from the dry state to the saturated state for sorption and conversely for desorption isotherm.

In the DVS method, few particles between 10 and $100 \mathrm{mg}$ are put on a microbalance kept inside a sealed thermostatically controlled chamber at a constant temperature of $20^{\circ} \mathrm{C}[28], 23^{\circ} \mathrm{C}[7,32$, $43,114]$, or $\left.25^{\circ} \mathrm{C}[45,69]\right)$. Each study followed its way of programming the DVS, but the idea is to regulate the $\mathrm{RH}$ inside the controlled chamber in a step-wise manner from zero to more than $95 \%$ in the case of sorption and the reverse path for desorption. Literature showed three different ways to program the moisture equilibrium to move to the next level of relative humidity. The first one was a time criterion assuming stabilization of the sample (360 min, $720 \mathrm{~min}, 1,440 \mathrm{~min}$, or 2,160 $\mathrm{min})$. The second one considered a percentage change in the mass per unit time $(\mathrm{dm} / \mathrm{dt})$ over a period of more than $10 \mathrm{~min}$, below which it was assumed that the moisture attains a balance. Lastly, the third one was the combination of the two previous criteria.

Bui et al. (2017) carried out a comparative study of the two methods (SSS and DVS) on the barley straw. They concluded that sorption isotherms measured with the two methods were very close (a difference lower than $0.1 \%$ ). However, many factors inherent to the protocol of the SSS method led to greater disparities in the measurements, while the automatic weighing of the DVS method allowed more stability in the measurement of the kinetics of the water uptake. Unlike the SSS method, the DVS one allowed faster measurements, but for one sample only. However, it was limited by mass and volume, which could be problematic for porous building materials like concrete [114].

Sorption isotherms were obtained by plotting mass change against $\mathrm{RH}$ and illustrated the water vapor sorption capacity as a function of the relative humidity. Figure 13 shows different sorption curves of various plant aggregates measured with a DVS machine. 


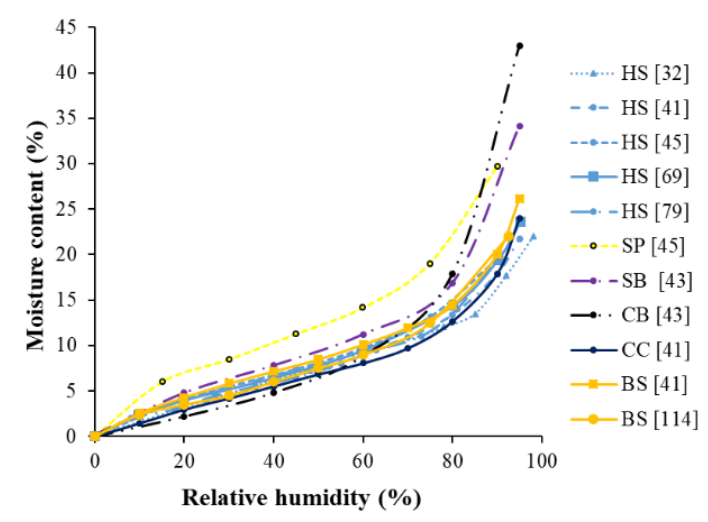

Figure 13 Sorption capacity of various plant aggregates (HS, hemp shiv; SP, sunflower pith; SB, sunflower bark; CB, corn bark; CC, corn cob; BS, and barley straw) [32, 41, 43, $45,69,79,114]$.

In general, sorption curves in Figure 13 are similar to type II or type III curves according to the IUPAC (International Union of Pure and Applied Chemistry) classification and are common for lignocellulosic materials. For relative humidities ranging from $0 \%$ to $50 \%$, sunflower pith had the highest sorption value, followed by sunflower bark, barley straw, hemp shiv, corn cob, and corn bark. This could be explained by the high amount of open porosities in the sunflower pith aggregates. In the capillary condensation domain (> 85\% RH), the water uptake for corn bark was the highest due to the presence of a greater number of smaller pores inside it. Notably, only the sorption curves are shown in Figure 13; however, several authors [7, 24, 28, 45, 78, 149] also took desorption measurements. All the authors observed a hysteresis phenomenon between the sorption and desorption curves. This phenomenon is usually explained by capillary condensation, the ink-bottle effect, and the contact angle difference between adsorption and desorption [149].

The sorption values for all these plant aggregates were higher than $20 \%$ at $95 \% \mathrm{RH}$. In general, plant aggregates have high sorption capacity inducing good moisture buffering and thus indoor comfort.

Thermal conductivity. The thermal conductivity $\lambda(\mathrm{W} / \mathrm{m} . \mathrm{K})$ is a common parameter used to characterize the insulating or conducting power of building materials. Indeed, the thermal conductivity of bulk plant aggregates is measured as a useful property when they are proposed as loose-fill insulation materials for buildings.

Several methods are used to measure thermal conductivity, but the two most encountered methods in the literature include the hot wire $[29,53,55,60,88]$ and hot plate $[7,35,41,45,56$, $99,106]$ method.

In the hot wire method, the five-centimeter-long hot wire sensor is embedded between two containers filled with bulk aggregates, and the heat is passed to attain a temperature rise $(\Delta T)$ of more than $10^{\circ} \mathrm{C}$ during a given heating time $(\mathrm{t})$. These parameters are used to give a high correlation coefficient $\left(R^{2}\right)$ between the experimental data and the fitting curve as described in Eq. (4).

$$
\Delta T=\frac{q}{4 \pi \lambda}(\ln (t)+K)
$$


where $\mathrm{q}$ is the heat flow per meter $\left(\mathrm{W} \cdot \mathrm{m}^{-1}\right)$, and $\mathrm{K}$ is a constant representing the thermal diffusivity of the material.

Whereas, in the hot plate method, the specimen is placed in a thin plastic box with a temperature difference $(\Delta T)$ aroused due to the hot and cold plate of the device. The steady-state is assumed to reach when the change in conductivity is less than $1 \%$ in $60 \mathrm{~min}$. At this point, the thermal conductivity of the specimen can be deduced from the apparent density of the system and the dimensions and thermal conductivity of the plastic box from Eq. (5),

$$
\lambda_{a p p}=\frac{Q \cdot e_{t}}{\Delta T \cdot S}
$$

where $\lambda_{\text {app }}$ is the apparent thermal conductivity of the specimen within the thin plastic box $(\mathrm{W} /(\mathrm{m} . \mathrm{K})), Q$ is the heat input (W), $e_{t}$ is the total thickness $(\mathrm{m})$, and $S$ is the cross-section of the specimen $\left(\mathrm{m}^{2}\right)$.

Figure 14 shows the variation of thermal conductivity as a function of bulk density. In general, the thermal conductivity increases with the bulk density because of the decrease in the porosity (intra-particle pores and inter-particle voids between plant aggregates) of the aggregates. The variations observed in some results might be due to the disparity in the environmental conditions (temperature and relative humidity) at the time of recording the measurements. The thermal conductivity of these plant aggregates is highly sensitive to the variation in temperature and relative humidity. The hot plate measurement method is less exposed to temperature and relative humidity variation compared to the hot wire measurement, and it must be done in a hygro-thermally stable environment. The differences observed between lavender and barley straws, even though they had roughly the same densities, might be due to the heat transfer by convection through the large interparticle pores between the arrangement of the lavender aggregates [56]. All the plant aggregates are very good insulating materials with thermal conductivities always less than $0.08 \mathrm{~W} \cdot \mathrm{m}^{-1} \cdot \mathrm{K}^{-1}$ except for corn cobs, which are very dense aggregates. In addition to this bulk property, the mixing of plant aggregates with reactive mineral binder also requires knowledge of their chemical properties.

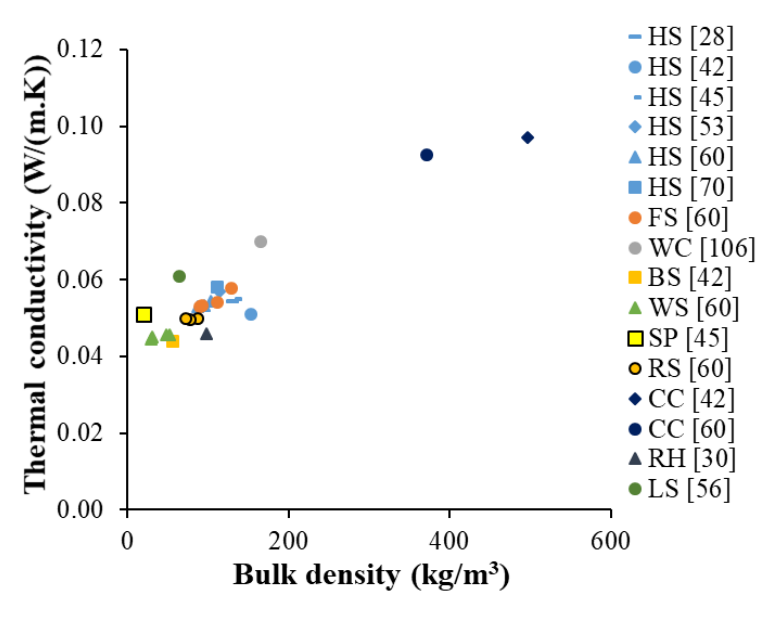

Figure 14 Thermal conductivities of plant aggregates versus their bulk densities (HS: hemp shiv, FS: flax shiv, WC: wood chip, RH: rice husk, BS: barley straw, WS: wheat straw, RS: rape straw, CC: corn cob, RH: rice husk, LS: lavender straw) [28, 30, 42, 45, 53, 56, $60,70,106]$. 


\subsubsection{Chemical Properties of the Plant Aggregates}

The properties of the plant aggregates are influenced by their chemical composition. Depending on the quantity and nature of the chemical components present in the aggregate, the hardness or compressibility, and durability of the latter may be affected. While mixing with a reactive mineral binder, the chemical components of the bio-aggregate can also react with the binder and impact its drying time like-wise the hydration mechanism; thus, affecting the overall mechanical properties and durability of the composite.

Magniont and Escadeillas (2017) reviewed the chemical composition of bio-aggregates and their interactions with mineral binders [150]. As bio-resources, the three main structural components of bio-aggregates are cellulose $(C)$, hemicelluloses $(H)$, and lignins $(L)$, coupled with other secondary components like ash, pectins, wax, proteins, and various extractives. They characterized the bioaggregates as per consecutively decreasing ranking of their three structural components as proposed by Vassilev et al. (2010) [151], who found that the bio-aggregates are of either CHL or CLH types (Figure 15) depending on their nature, i.e., wood residues (hemp and flax shives) and herbaceous or agricultural by-products (straws, stalks or fibers). Table 6 lists the chemical components of plant aggregates mentioned in this review. Indeed, all the plant aggregates are rich in cellulose, which is linked to their mechanical performance [152]. Hemicelluloses are easily dissolved under alkaline attack. Thus, corn cob with the highest quantity of hemicelluloses (37-41\%) is not suitable to mix with an alkaline mineral binder. Coconut coir, rice husk, and bamboo stem have the highest lignin contents as $30-46 \%, 26-31 \%$, and $18-32 \%$, respectively. Since Lignin is a polymer protecting the stem of the plant from chemical and physical aggressions, therefore, these aggregates rich in high lignin could have the longest durability.

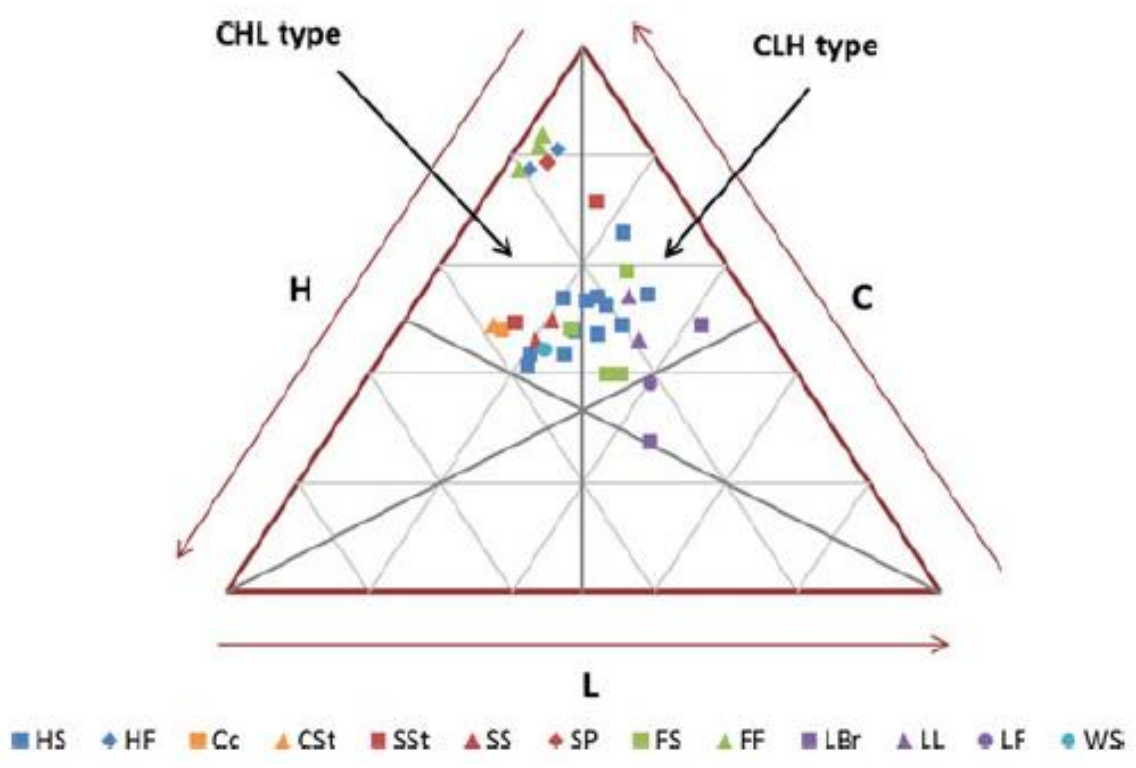

Figure 15 Structural composition of bio-aggregates (C: cellulose, $\mathrm{H}$ : hemicelluloses, $\mathrm{L}$ : lignins; HS: hemp shiv, HF: hemp fiber, Cc: corn cob, CSt: corn stalk, SSt: sunflower stalk, SS: marrow-less sunflower, SP: sunflower pith, FS: flax shiv, FF: flax fiber, LBr: lavender branches, LL: lavender leaves, LF: lavender flowers, and WS: wheat straw) [5]. 
Table 6 The list of the chemical components of the plant aggregates (contents are expressed in mass proportion of the dry matter).

\begin{tabular}{|c|c|c|c|c|c|c|c|}
\hline Origins & Plants & Fractions & References & Cellulose (\%) & Hemi-cellulose (\%) & Lignin (\%) & $\begin{array}{l}\text { Other chemicals (ash, } \\
\text { pectins, wax, proteins, } \\
\text { etc.) (\%) }\end{array}$ \\
\hline \multirow[t]{3}{*}{ Fiber plant wastes } & Hemp & Shiv & $\begin{array}{l}{[7,29,32,35,42,50} \\
53,60,69,72,74,83]\end{array}$ & $34.0-62.5$ & $9.0-37.0$ & $4.0-28.0$ & $5.5-28.0$ \\
\hline & Flax & Shiv & {$[60,90]$} & 44.6 & 24.41 & $21.0-22.0$ & $7.6-22.8$ \\
\hline & Coconut & Coir & {$[11,95]$} & $34.9-52.1$ & $0.3-33.7$ & $29.8-45.8$ & $10.2-26.8$ \\
\hline \multirow[t]{3}{*}{ Cereal straws } & Barley & Straw & {$[7,24,42]$} & 37.7 & $26.7-34.9$ & $5.5-15.8$ & - \\
\hline & Wheat & Straw & {$[22,60]$} & $37.6-43.0$ & 29.7-34.9 & $5.2-15.8$ & $11.7-21.2$ \\
\hline & Rice & Straw & {$[116,117]$} & $28.0-48.0$ & $19.8-31.6$ & $7.2-16.0$ & $11.6-28.8$ \\
\hline \multirow[t]{2}{*}{ Oilseed straws } & Sunflower & Bark & {$[29,53,118,119]$} & $38.6-47.4$ & $9.4-30.0$ & $3.5-18.6$ & $8.9-26.4$ \\
\hline & Rape & Straw & {$[60]$} & 53.1 & 18.1 & 9.6 & 18.5 \\
\hline \multirow{2}{*}{$\begin{array}{l}\text { Wastes from cereal } \\
\text { plants other than } \\
\text { straws }\end{array}$} & Corn & Cob & {$[7,42,60,141]$} & $32.5-48.1$ & $37.2-40.7$ & $3.3-14.7$ & $7.0-19.8$ \\
\hline & Rice & Husk & {$[29,30]$} & $25.0-35.0$ & $18.0-21.0$ & $26.0-31.0$ & $17.0-30.0$ \\
\hline \multirow[t]{2}{*}{ Wild plants } & Diss & Stem & [58] & $30.3-40.0$ & $2.72-11.1$ & - & 30.78 \\
\hline & Bamboo & Stem & {$[127]$} & 52.8 & 29.0 & 24.1 & 5.4 \\
\hline Sugar plant wastes & Sugar cane & Bagasse & {$[133]$} & $48.7-49.4$ & $18.5-25.6$ & 19.8-23.1 & $1.88-3.92$ \\
\hline Aromatic plant straws & Lavender & Straw & [119] & 33.7 & 13.9 & 14.7 & 30.4 \\
\hline
\end{tabular}


Apart from agronomic, environmental, and processing parameters, the same bio-aggregate showed variable results (Figure 15) due to the differences in the commonly used indirect time consuming gravimetric methods proposed by Klason (1922) [153], Saeman et al. (1954) [154], or Van Soest and Wine (1968) [155] to analyze the biomass composition. Sluiter et al. (2010) [156] identified numerous parameters that may give varying results in the case of the method based on sulfuric acid hydrolysis. These parameters include,

- the drying method (air-dried, dried at $100^{\circ} \mathrm{C}$, or $105^{\circ} \mathrm{C}$ ),

- the nature of the extracting solvents (alcohol/benzene, hot and cold water, acetone/water, etc.),

- the extraction time,

- the sample amount, and

- the temperature, time, biomass to acid ratio, and $\mathrm{H}_{2} \mathrm{SO}_{4}$ concentration of primary and secondary hydrolysis.

Other methods based on infrared microscopy $[63,72,96,116,118]$, thermogravimetric analysis [24], and X-ray diffraction [96] are also available in the literature to obtain results in less time with high accuracy and low cost.

All the studies agreed with the detrimental effects of extractives on mineral binders, such as disruption of the early setting and hardening mechanism, modifying the mechanical performance in the hardened state, and influencing the long-term durability [56, 65, 72, 119]. Bourdot et al. (2019) prepared binder pastes by mixing the pozzolanic binder with the extractives of five different hemp shives, sunflower and corn bark, and also the plant aggregates from them. As shown in Figure 16, in the case of the five tested hemp shives, the hydration delay in the model paste and the mechanical performance of the hemp concrete were directly related to the extractives content of the shiv. However, for different species, this conclusion was no longer valid because the nature of the watersoluble extractives or that of the products of the bio-aggregates obtained from the alkaline hydrolysis by the mineral binder would also intervene.
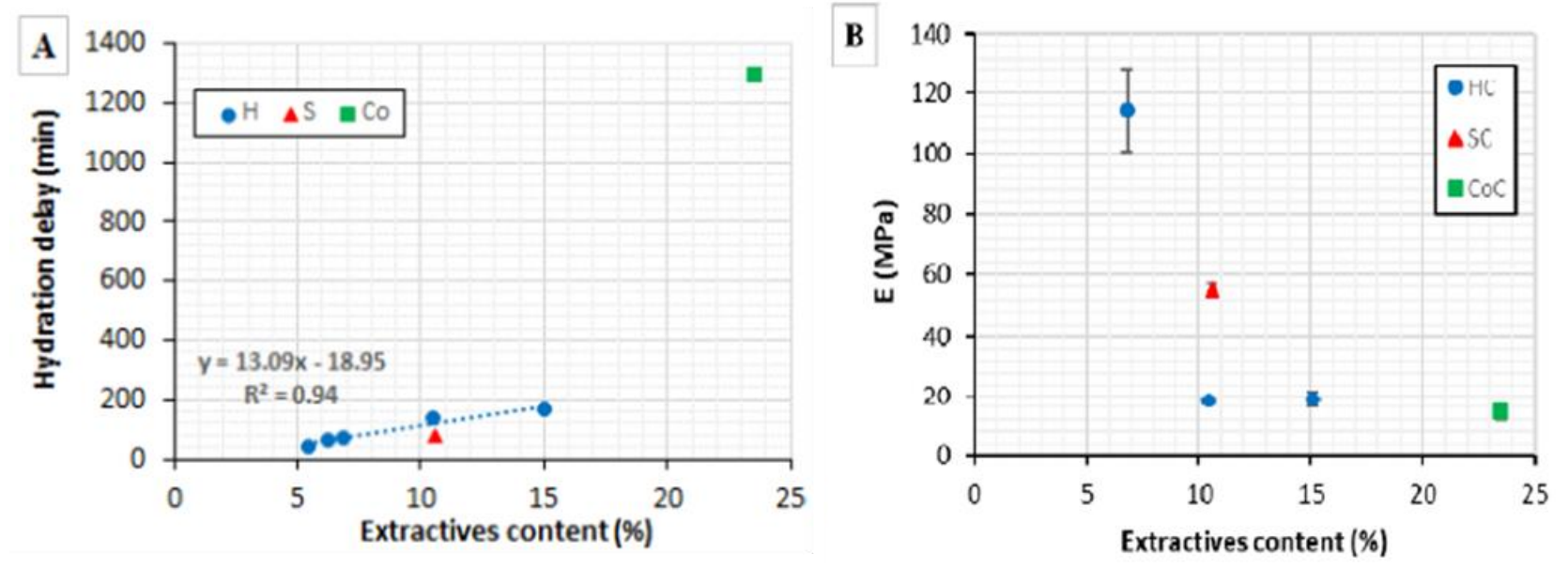

Figure 16 Evolution of the hydration delay of the model pastes and elastic modulus of plant-based concrete as a function of the extractives content of the bio-aggregates $(\mathrm{H}$ : hemp shiv, S: sunflower bark, Co: corn bark, HC: hemp concrete, SC: sunflower bark concrete, and CoC: corn bark concrete) [65]. 
In addition to these proposed conclusions, the difference between the number of the extractives and the intensity of the setting delay could be due to the differences in the extractable compounds obtained through neutral extraction $(\mathrm{pH} 7)$ and extractions done at a more basic $\mathrm{pH}$ (up to 12 inside the mineral binder at an early age). Extractions at $\mathrm{pH} 9$ and 12 must be performed for comparison. On the other hand, the representation of the extractives content as a mass percentage (kg of extractives/kg of aggregates) appeared as not the best indicator, given the fact that the aggregates do not have the same dosages in the composite mixture. It would be more judicious to seek another representation relative to the quantity of binder. Details related to the mechanisms of the chemical interactions impacting the properties of composites will be discussed in section 3.2.2.

\subsubsection{Conclusions}

Table 7 summarizes the properties of each plant aggregate that have been previously studied and the corresponding number of papers reported based on these studies.

Hemp shiv (51 references) is the most studied plant aggregate in the literature, and its properties are the best known, followed by wood chip (18 references), flax shiv (11 references), sunflower stem (10 references), and barley straw (9 references). Data concerning the other straws are reported less, while these straws are widely available in France. Thus, they could be developed as potential plant aggregates for plant-based concrete. Apart from these straws, comparatively very little data are available for wild plants, sugar plant waste, miscanthus, lavender, and coconut. The chemical properties, microstructure, particle size distribution, bulk density, and water absorption capacities of the plant aggregates are all systematically measured. The chemical compositions of all the plant aggregates reviewed in this paper were well investigated. The data for other physical properties of the plant aggregates, such as the apparent density of particles and the skeleton density, are scarce in the literature with unusual characterization methods, while they could have a predominant impact on the performance of the composite. Plant-based concretes are intended to be used for thermal insulation and moisture regulation. Mostly their hygro-thermal properties such as the sorption-desorption isotherm and thermal conductivity have been measured; however, there are a few measurements on plant aggregates alone, whereas these properties could also influence the properties of the final composite. In the following part, the impacts of the properties of plant aggregates on the composites are discussed in detail. 
Table 7 Summary of the number of articles on the properties of the plant aggregates used with a mineral binder.

\begin{tabular}{|c|c|c|c|c|c|c|c|c|c|c|c|}
\hline \multirow[b]{2}{*}{ Origins } & \multirow[b]{2}{*}{$\begin{array}{c}\text { Plants } \\
\text { aggregates }\end{array}$} & \multirow[b]{2}{*}{$\begin{array}{l}\text { Number } \\
\text { of } \\
\text { referenc } \\
\text { es }\end{array}$} & \multirow[b]{2}{*}{$\begin{array}{c}\text { Micro- } \\
\text { structur } \\
\text { e }\end{array}$} & \multicolumn{4}{|c|}{ Physical properties } & \multirow[b]{2}{*}{$\begin{array}{c}\text { Water } \\
\text { absorptio } \\
n\end{array}$} & \multicolumn{2}{|c|}{$\begin{array}{c}\text { Hygro-thermal } \\
\text { properties }\end{array}$} & \multirow{2}{*}{$\begin{array}{c}\text { Chemical } \\
\text { properties } \\
\text { Chemical } \\
\text { compositio } \\
\text { n }\end{array}$} \\
\hline & & & & $\begin{array}{c}\text { Particle } \\
\text { Size } \\
\text { Distributio } \\
\mathbf{n} \\
\end{array}$ & $\begin{array}{c}\text { Bulk } \\
\text { densit } \\
y\end{array}$ & $\begin{array}{c}\text { Apparen } \\
\text { t density } \\
\text { of } \\
\text { particles }\end{array}$ & $\begin{array}{c}\text { Skeleto } \\
n \\
\text { density }\end{array}$ & & $\begin{array}{c}\text { Sorption- } \\
\text { desorptio } \\
n \\
\text { isotherm }\end{array}$ & $\begin{array}{c}\text { Thermal } \\
\text { conductivit } \\
y\end{array}$ & \\
\hline \multirow{3}{*}{$\begin{array}{l}\text { Fiber plant } \\
\text { waste }\end{array}$} & Hemp shiv & 51 & 18 & 29 & 37 & 7 & 9 & 19 & 8 & 7 & 13 \\
\hline & Flax shiv & 11 & 6 & 4 & 9 & 1 & 2 & 3 & 0 & 0 & 2 \\
\hline & $\begin{array}{l}\text { Coconut } \\
\text { coir }\end{array}$ & 3 & 1 & 1 & 0 & 0 & 1 & 0 & 0 & 0 & 2 \\
\hline \multirow[t]{2}{*}{$\begin{array}{l}\text { Wood } \\
\text { transformati } \\
\text { on residues }\end{array}$} & Wood chip & 18 & 2 & 7 & 5 & 5 & 1 & 3 & 0 & 1 & 4 \\
\hline & $\begin{array}{l}\text { Barley } \\
\text { straw }\end{array}$ & 9 & 5 & 6 & 5 & 0 & 1 & 3 & 3 & 3 & 3 \\
\hline \multirow[t]{3}{*}{ Cereal straws } & $\begin{array}{l}\text { Wheat } \\
\text { straw }\end{array}$ & 4 & 2 & 4 & 2 & 0 & 2 & 1 & 1 & 1 & 1 \\
\hline & Rice straw & 3 & 0 & 1 & 1 & 0 & 0 & 0 & 0 & 1 & 2 \\
\hline & Corn stem & 4 & 2 & 3 & 4 & 0 & 0 & 2 & 1 & 0 & 1 \\
\hline \multirow{2}{*}{$\begin{array}{l}\text { Oilseed } \\
\text { straws }\end{array}$} & $\begin{array}{l}\text { Sunflower } \\
\text { stem }\end{array}$ & 10 & 7 & 7 & 4 & 1 & 1 & 5 & 2 & 2 & 4 \\
\hline & Rape straw & 6 & 2 & 3 & 4 & 0 & 1 & 2 & 0 & 0 & 1 \\
\hline \multirow{2}{*}{$\begin{array}{l}\text { Cereal plant } \\
\text { waste other } \\
\text { than straw }\end{array}$} & Corn cob & 7 & 5 & 5 & 5 & 0 & 1 & 4 & 1 & 2 & 5 \\
\hline & Rice husk & 6 & 2 & 2 & 3 & 3 & 3 & 3 & 0 & 2 & 2 \\
\hline
\end{tabular}


Recent Progress in Materials 2021; 3(2), doi:10.21926/rpm.2102026

\begin{tabular}{|c|c|c|c|c|c|c|c|c|c|c|c|}
\hline \multirow[b]{2}{*}{ Wild plants } & Diss stem & 4 & 4 & 2 & 2 & 0 & 0 & 2 & 0 & 0 & 1 \\
\hline & $\begin{array}{l}\text { Bamboo } \\
\text { stem }\end{array}$ & 4 & 1 & 3 & 1 & 1 & 0 & 0 & 0 & 0 & 1 \\
\hline \multirow{2}{*}{$\begin{array}{l}\text { Sugar plant } \\
\text { waste }\end{array}$} & $\begin{array}{l}\text { Bagasse } \\
\text { from sugar } \\
\text { cane }\end{array}$ & 5 & 0 & 1 & 0 & 0 & 0 & 1 & 0 & 1 & 1 \\
\hline & $\begin{array}{l}\text { Sugar beet } \\
\text { pulp }\end{array}$ & 2 & 1 & 1 & 0 & 0 & 0 & 1 & 0 & 0 & 0 \\
\hline $\begin{array}{l}\text { Energy crop } \\
\text { residues }\end{array}$ & $\begin{array}{l}\text { Miscanthus } \\
\text { stem }\end{array}$ & 3 & 1 & 2 & 1 & 1 & 1 & 1 & 0 & 0 & 1 \\
\hline $\begin{array}{l}\text { Aromatic } \\
\text { plant straws }\end{array}$ & $\begin{array}{l}\text { Lavender } \\
\text { straw }\end{array}$ & 3 & 2 & 2 & 1 & 0 & 0 & 1 & 0 & 1 & 1 \\
\hline \multicolumn{2}{|c|}{ TOTAL } & 153 & 61 & 83 & 84 & 19 & 23 & 51 & 16 & 21 & 45 \\
\hline
\end{tabular}




\section{Effects of Various Parameters of the Plant Aggregates on the Properties of Plant-based Concrete}

Literature shows that various parameters related to plant aggregates could influence the properties of plant-based concrete. In this section, (i) the evolution of the factors such as the amount and nature of the plant aggregates, and (ii) their characteristic effects on the properties of the obtained composites are discussed. This analysis will allow distinguishing the preponderant parameters linked to plant aggregates having impacts on the properties of plant-based concrete.

\subsection{Effects of the Content and the Nature of thePlant Aggregates on the Properties of Plant-based Concrete}

\subsubsection{Effects on the Physical Properties of the Plant-based Concrete}

As a lightweight building material, density is an important property of plant-based concrete. Several authors have studied the evolution of the density of the composite by varying the amount of plant aggregate in the composite [18, 22, 23, 25, 28, 30-32, 38, 41, 45, 49, 61, 67, 77, 97, 99, 102]. However, it was difficult to compare the results from the different studies. Since the formulation and the manufacturing parameters varied, the densities of the plant aggregates were different; besides, the dosages of the plant aggregate and binder ( $\mathrm{kg}$ of constituents per $\mathrm{m}^{3}$ of composites in the fresh state) were rarely known. These difficulties only allowed investigating the evolution of the densities of the composites as a function of the variation in the amount of the plant aggregates (Figure 17). Notably, the references taken into account in this figure were only those containing mixtures with a varying amount of plant aggregate. The "plant aggregate content" is defined as the mass percentage of the plant aggregate compared to the sum of all the constituents (aggregate, binder, and water) in the initial fresh state. It is directly given as a formulation parameter in the articles or deduced from the masses of all the constituents, or the A/B and W/B ratios ( $A$ for aggregate, $B$ for binder, and $W$ for water). In Figure 17, the points corresponding to the results obtained from the same study using the same plant aggregate were linked together to highlight the trend in the evolution of the densities of the composites as a function of the mass percentage of the plant aggregates. 

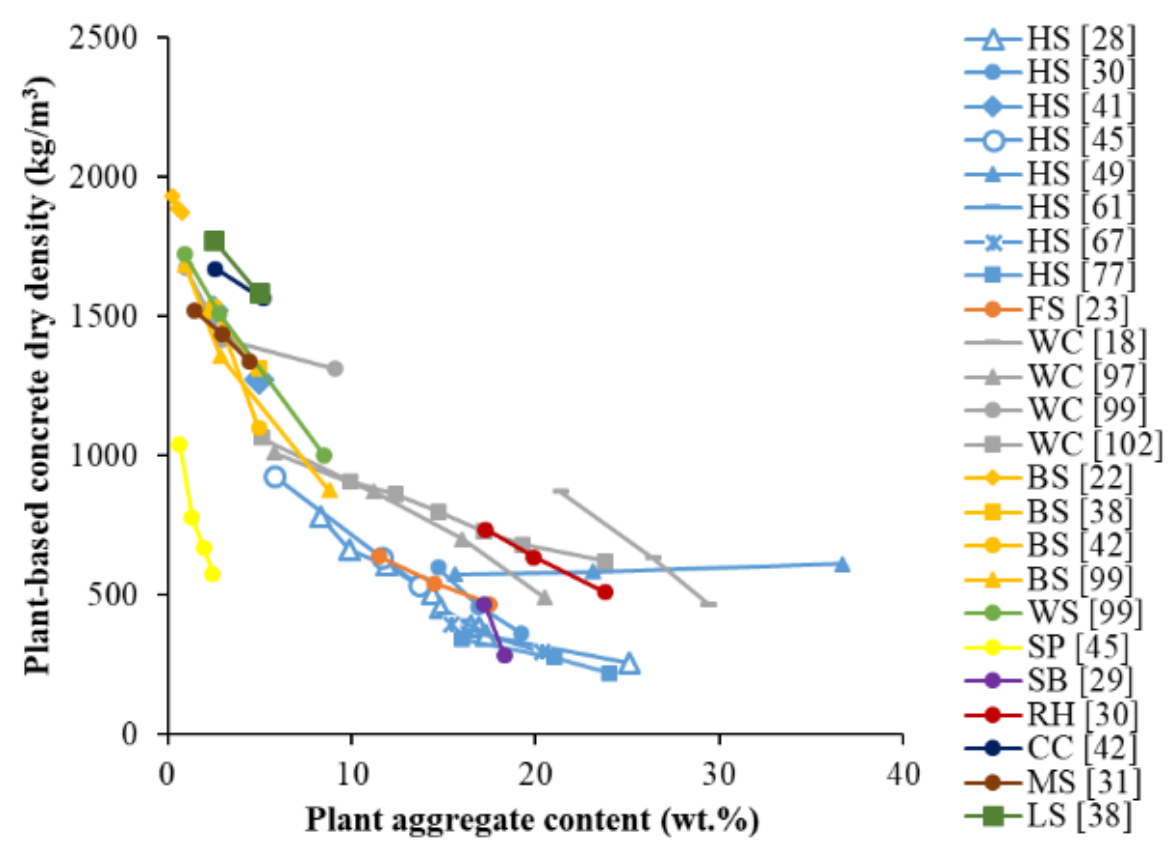

Figure 17 Evolution of dry density of the plant-based concrete as a function of the plant aggregate content for various studies (HS: hemp shiv; FS: flax shiv; WC: wood chip; BS: barley straw; WS: wheat straw; SP: sunflower pith; SB: sunflower bark; RH: rice husk; CB: corn cob; MS: miscanthus stem; and LS: lavender straw) [18, 22, 23, 28-31, 38, 41, 45, $49,61,67,77,97,99,102]$.

All authors except Nguyen et al. (2010) [49] showed that for any type of plant aggregate, the density of the composite decreased with the increasing content of the plant aggregate. This was attributed to the low bulk density of plant aggregates (from $20 \mathrm{~kg} / \mathrm{m}^{3}$ for sunflower pith to 497 $\mathrm{kg} / \mathrm{m}^{3}$ for corn cob) compared to that of mineral binder (above $1000 \mathrm{~kg} / \mathrm{m}^{3}$ ). However, this trend was different from the results found in the work of Nguyen et al. (2010) on hemp concrete. The latter showed an increase in the density of the composite with the increase in the amount of the hemp shiv. This result could be explained by the increase in the compaction stresses with the increase in the aggregate content during the sample manufacturing, resulting in the decrease in the intra-and inter-granular porosity of the plant aggregates and thus the increase in the density of the composite. Indeed, in the case of hemp shiv content varying from $15.6 \%$ to $36.7 \%$, the compaction stress used in this study varied from $0.30 \mathrm{MPa}$ to $1.60 \mathrm{MPa}$; thus, the density of the hemp concrete ranged from 575 to $612 \mathrm{~kg} / \mathrm{m}^{3}$. These results showed that the plant aggregate content (mass percentage in the fresh state) is not a good parameter to indicate the evolution of the density of the composite if the level of compaction is not taken into the account. Indeed, a plant aggregate dosage (mass of aggregate in $\mathrm{kg}$ per volume of composite in $\mathrm{m}^{3}$ ) would be much more relevant.

Even if the density of plant-based concrete generally follows the same decreasing trend as a function of the content of plant aggregate (mass percentage), some authors have pointed out a difference depending on the type of aggregate used. The raw earth composites with low contents of hemp shiv, barley straw, and corn cob (2.5wt.\% and 5wt.\%), Laborel-Préneron et al. (2018) [41] showed that densities of the composites with corn cob $\left(1878 \mathrm{~kg} / \mathrm{m}^{3}\right.$ and $\left.1754 \mathrm{~kg} / \mathrm{m}^{3}\right)$ were higher compared to those with hemp shiv $\left(1603 \mathrm{~kg} / \mathrm{m}^{3}\right.$ and $\left.1221 \mathrm{~kg} / \mathrm{m}^{3}\right)$ and barley straw $\left(1519 \mathrm{~kg} / \mathrm{m}^{3}\right.$ and $1315 \mathrm{~kg} / \mathrm{m}^{3}$ ). Giroudon et al. (2019) [38] also found high-density values for raw earth composites 
incorporated with lavender straw $\left(1772 \mathrm{~kg} / \mathrm{m}^{3}\right.$ and $\left.1585 \mathrm{~kg} / \mathrm{m}^{3}\right)$ compared to those made from barley straw $\left(1519 \mathrm{~kg} / \mathrm{m}^{3}\right.$ and $\left.1315 \mathrm{~kg} / \mathrm{m}^{3}\right)$. Ashour et al. (2011) observed no significant difference in the density of the composites with a low aggregate content of less than $1 \mathrm{wt} . \%$ in the earthen plasters comprised of barley straw, wheat straw, or wood shaving. On the contrary, with an aggregate content of about $9 \mathrm{wt} . \%$, the composite made from wood shaving showed high density in comparison to those made from barley and wheat straws. These variations in the results were attributed to the differences in the bulk densities of the plant aggregates. However, Chabannes et al. (2014) [30] showed that with the same plant aggregate content (19wt.\%) and bulk density (about $103 \mathrm{~kg} / \mathrm{m}^{3}$ ), the dry density of rice husk concrete was much higher than that of the hemp concrete $\left(634 \mathrm{~kg} / \mathrm{m}^{3}\right.$ and $364 \mathrm{~kg} / \mathrm{m}^{3}$, respectively). Besides, even with the same content and bulk density of the plant aggregate, the rice husks and hemp shives behaved completely differently in their wet states and under compaction during the concrete production. Rice husks compacted easily compared to hemp shives, which required the addition of more material. Thus, it could be concluded that apart from bulk density, it is highly important to analyze other parameters as well, representing the real behavior of the aggregates in the composite. For the sake of comparison, it is also more relevant to use dosage (mass of constituents (in $\mathrm{kg}$ ) per volume of concrete (in $\mathrm{m}^{3}$ )) and/or volume percentage (\%) as formulation parameter instead of mass percentage, which does not control the real dosage of the binders in composites and also compare the eventual impacts of the nature and properties of the plant aggregates.

The density of plant-based concrete is closely linked to its porosity. The density of the composite decreases as the plant aggregate content increases implies an increase in the composite's porosity. Plant aggregates have a porous structure; hence, by increasing their quantity, the porosity of the composite also increases, keeping all the other parameters constant. Moreover, an increase in the amount of the aggregate contributes more to inter-granular porosity, which also enhances the porosity of the composite. For example, Benmahiddine et al. (2020) [23] showed an increase in the porosity of flax concrete from $72 \%$ to $76 \%$ when the content of flax shiv was increased in the range of $12 \mathrm{wt} . \%$ to $18 \mathrm{wt} . \%$.

\subsubsection{Effects on the Mechanical Properties of the Plant-based Concrete}

For their application as insulating materials, plant-based concrete requires a minimum of mechanical strength to be self-supporting and to handle the stresses during transport and implementation. Previously reported studies showed that the compressive strength and Young's modulus of the plant-based concrete decreased as a function of the plant aggregate mass content (Figure 18) [18, 23, 31, 38, 42, 45, 61, 77, 97, 102]. 


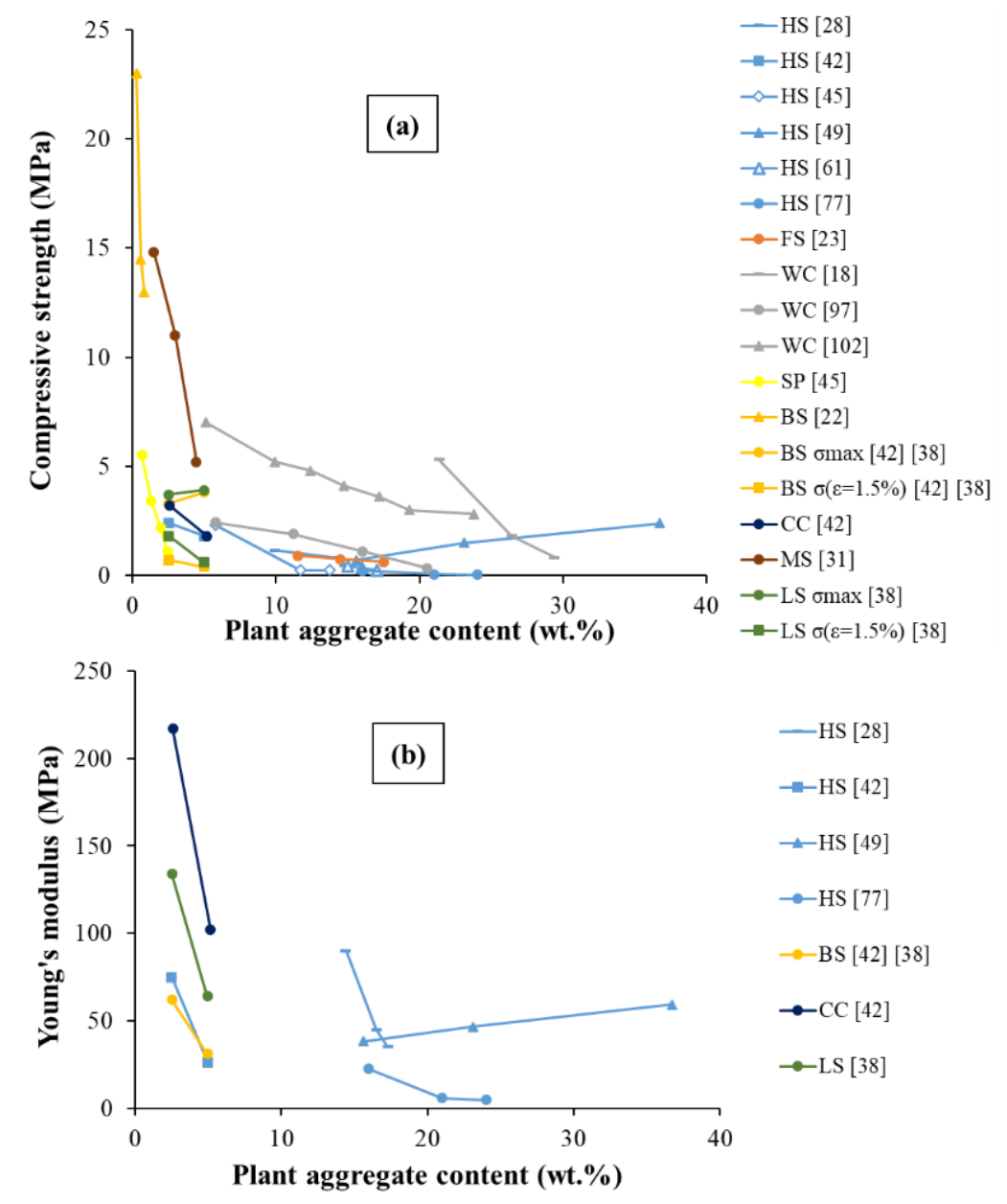

Figure 18 Evolution of (a) compressive strength and (b) Young's modulus of the plantbased concrete as a function of plant aggregate content (HS: hemp shiv; FS: flax shiv; WC: wood chip; BS: barley straw; SP: sunflower pith; SB: sunflower bark; RH: rice husk; MS: miscanthus stem; and LS; lavender straw) $[18,23,28,30,31,38,41,45,49,61,77$, 97, 102].

The results were attributed to the impact of the porosity of the added aggregates, reducing the mechanical strength and stiffness of the composite. Moreover, Niyigena et al. (2018) [15] assumed that the increase in the aggregates content enhanced the specific surface area of the aggregates, resulting in a weak bonding at the interface between the binder and plant particles, thus, reducing the compressive strength. However, some results deviated from this trend and emphasized that it is not possible to compare results from different studies. For example, Nguyen et al. (2010) [49] observed an increase in the compressive strength due to the increased compaction level at the initial state, which also decreased the porosity. The raw earth composites made from elongated plant particles of barley and lavender straw [38, 42] showed that the maximum compressive strengths slightly increased from 3.3 $\mathrm{MPa}$ to $3.8 \mathrm{MPa}$, and from 3.7 MPa to 3.9 MPa, respectively. Laborel-Préneron (2017) et al. and Giroudon et al. (2019) [38, 42] ascribed this increase to a consolidated phenomenon due to the high compressibility of the straws. The elongated shape of the aggregates could also increase the compressive strength by limiting the crack openings. Also, this increase in the maximum stress was accompanied by an increase in the corresponding strain, which went up from $8 \%$ to $20 \%$ for barley straw and from $4 \%$ to $9 \%$ for lavender straw, respectively 
for a $2.5 \%$ and $5 \%$ plant aggregate content. These results showed that the maximum compressive stress was not a good indicator of the use of composites. Consequently, other indicators corresponding to the stresses in the elastic behavior phase (the strain equal to $1.5 \%$ or $5 \%$ ) were proposed in the literature to have comparable results representing the performance of the composites in use $[15,38,42,43,65]$. The decreasing trend of the compressive strength corresponding to a stress level of $1.5 \%$ with the content of aggregates is shown in Figure 18.

Concerning the nature of the aggregate, the raw earth composites with corn cob, hemp shiv, and barley straw showed varying mechanical behaviors during compression depending on the types of aggregates used (Figure 19) [42]. Also, with the same plant aggregate mass content, the rigidity of the composite formed with corn cobs was much higher in comparison to the composite formed with hemp shiv and barley straw. Besides, the strain level at maximum stress of the barley straw composite was quite high compared to those of the other two composites because of its high compressibility. Chabannes et al. (2014) [30] (between hemp and rice husk concrete) and Brouard et al. (2018) [25] (between sunflower pith, sunflower bark, and rape straw concrete) also concluded that the nature of aggregate had a strong influence on the mechanical behaviors during the compression of the composites. The impact of the characteristics of the plant aggregates on the mechanical performance of the composites is discussed in section 3.2.2.

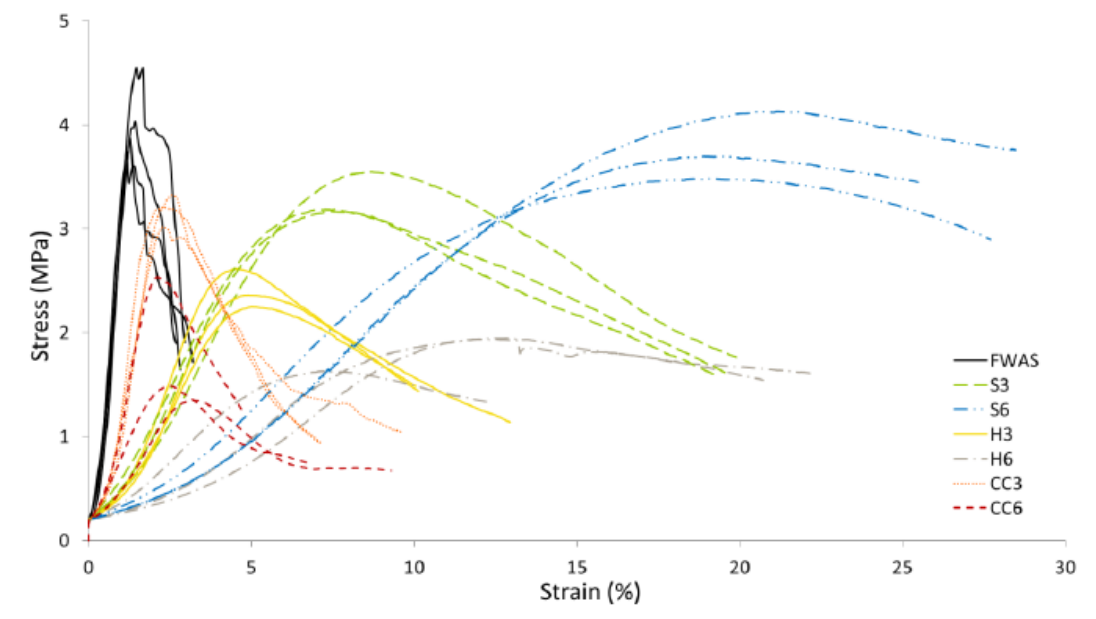

Figure 19 Strain-stress diagram (FWAS: fines from washing aggregate sludge; SX, HX, and CCX, respectively composites with barley straw, shiv hemp, and corn cob at Xwt.\% (2.5wt.\% or $5 w t . \%)[42]$.

Cérézo (2005) [28] is one of the few researchers who compared the compression behavior of hemp concrete with different hemp shiv contents to the compression behavior of a slightly compacted $16 \mathrm{~cm}$ diameter $\times 32 \mathrm{~cm}$ high specimen made of only dry hemp shiv. She concluded that for a roof formulation ( $25.1 \%$ hemp shiv mass content), the behavior of the concrete was identical to the ductile performance of the aggregates alone, with no peak and low mechanical resistance (Figure 20). The mechanical behavior improved as the aggregate content decreased from $17.3 \%$ for A4-1 to 9.9 for A3-2 and became much similar to the behavior of the binder alone. The mechanical behavior of aggregates stacks could therefore be a good indicator of the behavior of the composite at low binder dosage. 


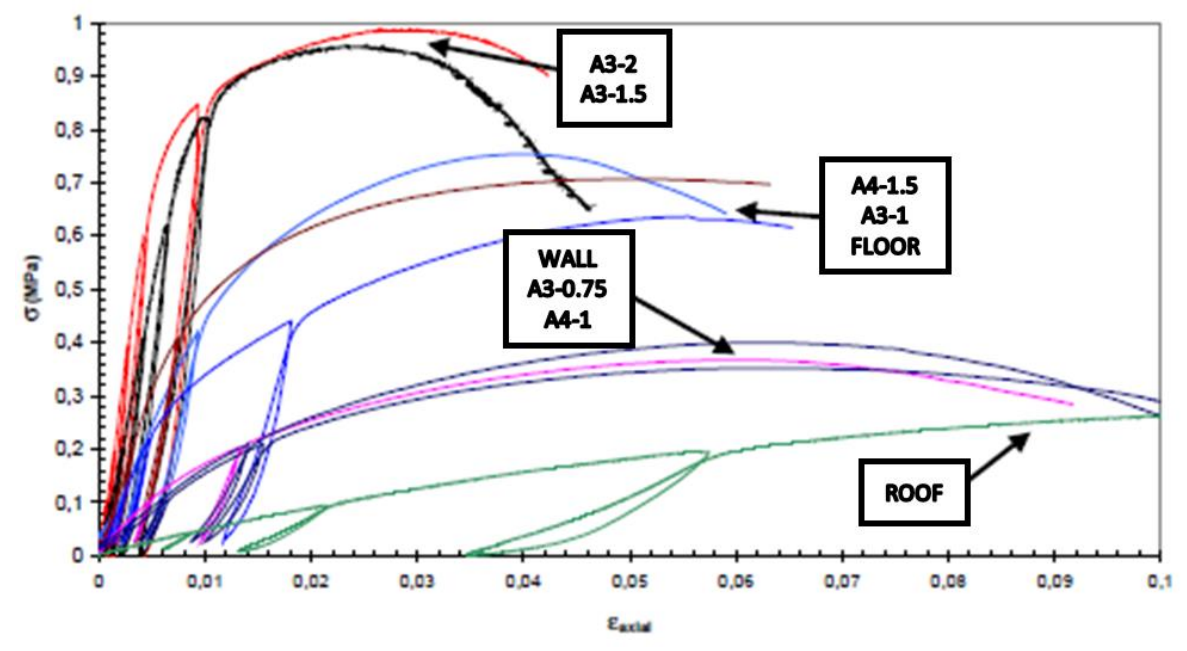

Figure 20 Strain-stress diagram of different hemp concrete formulations with different wt.\% of hemp shiv at 1 year (ROOF: 25,1\%; A4-1: 17.3\%; A3-0.75: 16.9\%; WALL: 16.5; FLOOR: 14.2; A3-1: 14.8; A4-1.5: 14.4; A3-1.5: 11.9; A3-2: 9.9) [28].

\subsubsection{Effects on the Thermal Properties of the Plant-based Concrete}

Several studies have shown a quasi-linear relationship between the density and the thermal conductivity of the plant-based concrete [11, 25, 28, 30, 35, 38, 45, 56, 61, 97, 99, 102]. In Section 3.1.1, it was found that the density of the plant-based concrete decreased with the increasing plant aggregate content. Figure 21, therefore, logically highlights a reduction in the thermal conductivity of the plant-based concrete with the increasing plant aggregate content.

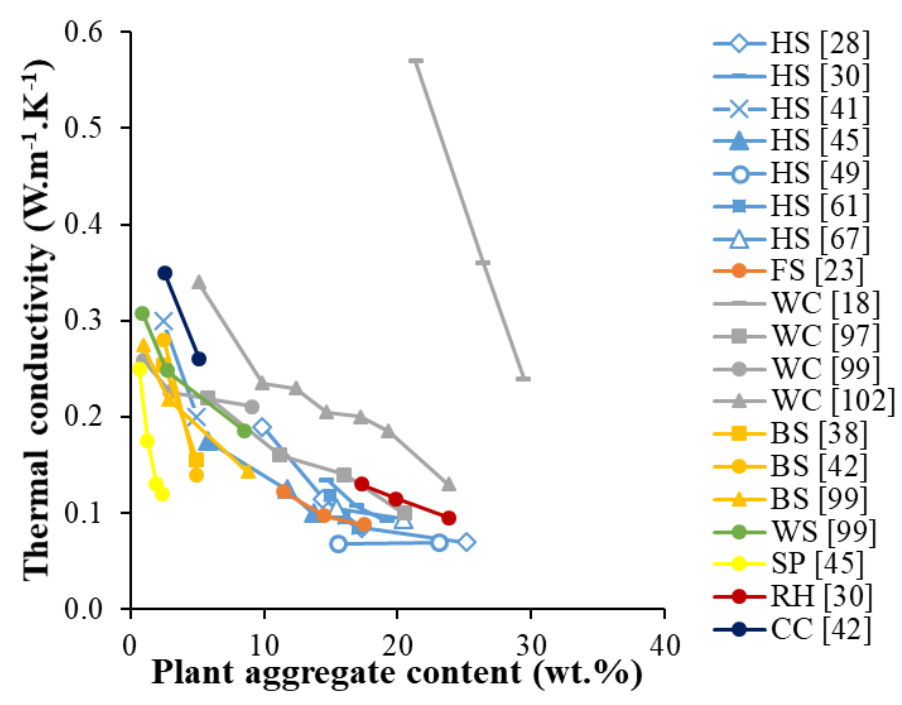

Figure 21 Evolution of thermal conductivity of the plant-based concrete as a function of the plant aggregate content in various studies (HS: hemp shiv; FS: flax shiv; WC: wood chip; BS: barley straw; WS: wheat straw; SP: sunflower pith; RH: rice husk; and CC: corn cob) $[18,23,28,30,31,38,41,45,49,61,67,77,97,99,102]$. 
A lot of explanations are available for this phenomenon. First, the addition of the porous plant aggregates increases the porosity of the composite, which in turn improves its thermal performance. Simultaneously, an increase in the amount of aggregate decreases the amount of binder, which is a good thermal conductor; thus, decreasing the thermal conductivity of the composite. Exceptionally, the increase in thermal conductivity was ascribed to an increased density of the composite due to stronger compaction stress at an initial state with the increase in the amount of aggregates [49]. A difference in the thermal conductivity between the composites depending on the type of aggregate, the binder used, and the density of the composite due to the level of compaction was observed at the same aggregate content [49, 50]. Moreover, Brouard et al. (2018) [25] showed that even with the same plant aggregates mass content of $54 \mathrm{wt} . \%$ the thermal conductivity of the plant-based concrete formed with different kinds of plant aggregates was very different $\left(0.071 \mathrm{~W} \cdot \mathrm{m}^{-1} \cdot \mathrm{K}^{-1}\right.$ for rape straw concrete and $0.158 \mathrm{~W} \cdot \mathrm{m}^{-1} \cdot \mathrm{K}^{-1}$ for sunflower bark concrete), although these differences were not only due to the nature of the aggregates. Even with the same mass content of constituents or the same A/B ratio, the dosages $\left(\mathrm{kg} \cdot \mathrm{m}^{-3}\right)$ of all the constituents were different, especially that of the binders, which significantly impacted the thermal conductivity. The dry densities of each composite were, therefore, very different $\left(438 \mathrm{~kg} \cdot \mathrm{m}^{-3}\right.$ for rape straw concrete and $714 \mathrm{~kg} \cdot \mathrm{m}^{-3}$ for sunflower bark concrete) like-wise their thermal conductivities. Thus, it could be concluded that to study the impact of the nature of the aggregates; it is necessary to work with a constant dosage and/or volume percentage of constituents ( $\mathrm{kg}$ of constituents per $\mathrm{m}^{3}$ of composites or volume percentage of constituents).

\subsubsection{Effects on the Hygric Properties of the Plant-based Concrete}

The literature shows that plant-based concrete has moisture regulation capacities. Since the sorption capacity of the aggregate is greater than that of the binder, the sorption capacity of the composite increases simultaneously with the content of the plant aggregate $[25,41,55,157]$.

Ashour et al. (2011) showed that at a low aggregate content of $1 \mathrm{wt} . \%$, the sorption curves of the composites made by incorporating barley straw, wheat straw, and wood shavings in a mixture of clay and sand were not significantly different. The difference began to be more significant at $3 w t . \%$ and was very pronounced at 9wt.\% [157]. The composite made of barley straw had the greatest sorption capacity, followed by wheat straw and wood shavings (Figure 22). 



Figure 22 Water adsorption isotherms of earth plaster made with wheat straw, barley straw, and wood shavings, and without straw at $20{ }^{\circ} \mathrm{C}$ with (a) $9 w t . \%$, (b) $3 w t . \%$ and (c) 1wt.\% of aggregate content [157].

For the same aggregate mass contents (2.5wt.\% and 5wt.\%), Laborel-Préneron et al. (2018) showed that there was little difference between the sorption curves of composites made from barley straw, hemp shiv, and corn cob [41]. Brouard et al. (2018) also made the same observation in rape straw and sunflower bark concrete at 54wt.\% aggregates mass content [25]. Rahim et al. (2015) found that the difference between the sorption curves of hemp concrete and flax concrete was not remarkable at low $\mathrm{RH}$, but it was much more pronounced at above $70 \%$. Especially at $95 \%$ $\mathrm{RH}$, the moisture density was $95 \mathrm{~kg} / \mathrm{m}^{3}$ and $160 \mathrm{~kg} / \mathrm{m}^{3}$ for hemp and flax concrete, respectively [81].

Few studies investigated the impact of the formulation on the water absorption capacity of plantbased concrete. Water absorption test was carried out by capillarity based on the AFPC-AFREM protocol [158], ASTM C 67-03 standard [159], or ISO 15148 standard [160]. It was observed that if the capillary absorption of the plant aggregate was higher than that of the binder, absorption kinetics increased with the plant aggregate content [45, 161]. For example, Magniont et al. (2012) [45] reported the absorption coefficients of hemp concrete with 5.8wt.\%, $11.8 \mathrm{wt} . \%$, and $32 \mathrm{wt} . \%$ of hemp shiv as $5.7 \mathrm{~kg} / \mathrm{m}^{2}, 9.5 \mathrm{~kg} / \mathrm{m}^{2}$, and $16.0 \mathrm{~kg} / \mathrm{m}^{2}$, respectively at $15 \mathrm{~min}$. Similarly, plant-based concrete made from sunflower pith had less but not negligible absorption capacities of $1.75 \mathrm{~kg} / \mathrm{m}^{2}$, $2.75 \mathrm{~kg} / \mathrm{m}^{2}$, and $2.75 \mathrm{~kg} / \mathrm{m}^{2}$ compared to that of hemp concrete, even at very low proportions of pith particles equal to $0.7 \mathrm{wt} . \%, 1.3 \mathrm{wt} . \%$ and $2.0 \mathrm{wt} . \%$, respectively. When the binder absorption capacity was greater than that of the aggregate $[32,85]$, the absorption coefficient decreased with the increase in the amount of the aggregate. For example, the capillary absorption coefficient of plant-based concrete made from hemp shiv and earth binder decreased from $0.058 \mathrm{~kg} . \mathrm{m}^{-2} \cdot \mathrm{s}^{-1 / 2}$ to $0.031 \mathrm{~kg} \cdot \mathrm{m}^{-2} \cdot \mathrm{s}^{-1 / 2}$ when the dry mass content of the plant aggregate increased from $42 \%$ to $53 \%$ [32].

The water vapor permeability measured with the wet cup method (NF EN ISO 12572) evaluated the hygric performance of the plant-based concrete. Laborel-Préneron et al. (2018) [41] and Abbas et al. (2020) [16] have shown that the nature of aggregate and binder impacted the water vapor diffusion resistance factor. For example, Abbas et al. (2020) showed that the water vapor diffusion 
resistance factor of the plant-based concrete (using HB binder: mix of cement and lime) made with sunflower pith (HB-S, $\mu=4.7 \pm 0.3$ ) and maize pith (HB-M, $\mu=5.1 \pm 0.6)$ with the same mass proportions of aggregates (5wt.\%) were of the same order of magnitude while that made with hemp shiv ( $\mathrm{HB}-\mathrm{H}, \mu=4.0 \pm 0.3)$ was slightly lower even with higher mass proportion (15wt.\%). Lagouin et al. (2019) concluded that the water vapor permeability of sunflower bark concrete (MS, $\mu=1.35$ $\pm 0.16)$ and maize bark concrete $(\mu=1.40 \pm 0.20)$ was not significantly influenced by the nature of the aggregate [43]. However, this similarity could come from the fact that both the aggregates used were from the bark with similar properties.

The moister buffer value (MBV) is another parameter to assess the capacity of a material to moderate the variation in $\mathrm{RH}$. As shown in Figure 23, Benmahiddine et al. (2020) [23] concluded that MBV of flax concrete increased with the increase in the flax shiv content. The MBV values for the formulations F1-1, F1-2, and F1-3 with 11.5wt.\%, 14.5wt.\%, and 17.5wt.\% flax shiv, were 2.18 $\pm 0.15 \mathrm{~g} /\left(\mathrm{m}^{2} . \% \mathrm{RH}\right), 2.45 \pm 0.10 \mathrm{~g} /\left(\mathrm{m}^{2} . \% \mathrm{RH}\right)$, and $2.82 \pm 0.21 \mathrm{~g} /\left(\mathrm{m}^{2} . \% \mathrm{RH}\right)$, respectively. This was due to the high moisture regulation capacity of flax shives. However, the results varied in the literature depending on the combination of binder and plant aggregate used. Laborel-Préneron et al. (2018) and Rahim et al. (2016), [41,55] worked with three different aggregates, and Ratiarisoa et al. (2016) worked with two different aggregates [56]). The results showed that the MBV depended both on the water vapor permeability and the sorption capacity of the composites, which were, as shown above, influenced by the nature and the dosage of plant aggregates. Thus, it could be concluded that the nature of the aggregate influences the moisture buffering capacity of the composite.
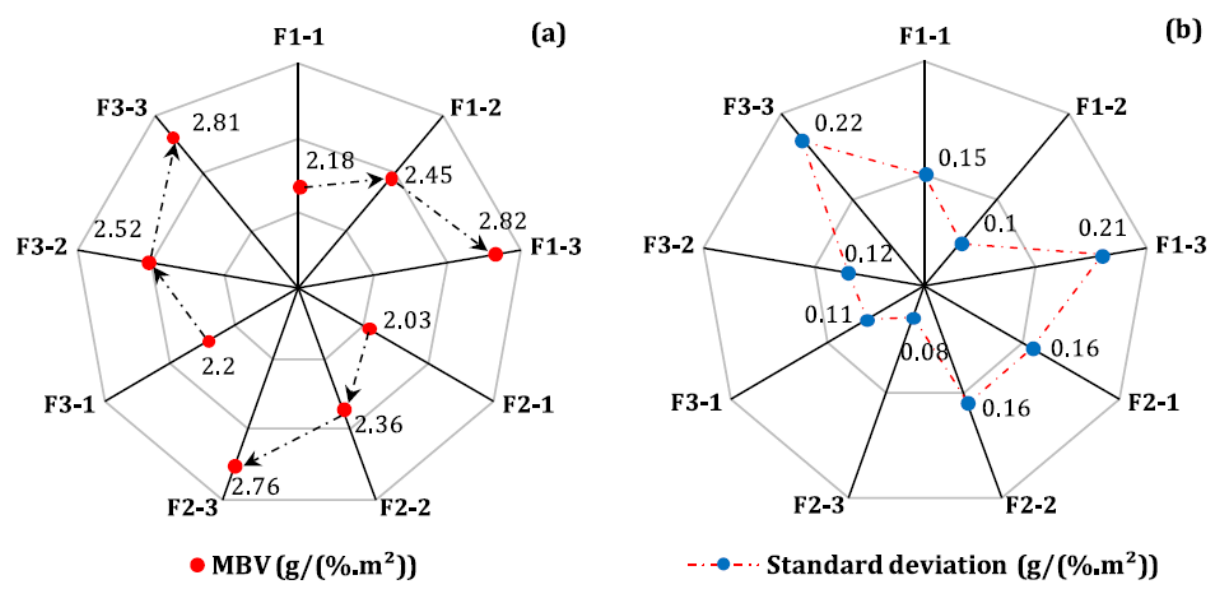

Figure 23 (a) Moisture buffer value (MBV) of the flax concrete, (b) its standard deviations (Fi-j: formulation with i (1: mix of medium and large, 2: medium, 3: large) flax shives size and $\mathrm{j}(1: 11.5 \%, 2: 14.5 \%, 3: 17.5 \%)$ flax shives mass content) [23].

\subsubsection{Effects on the Acoustical Properties of the Plant-based Concrete}

Three papers studied the impact of the content of plant aggregates on the acoustical properties of plant-based concrete. This was done by measuring the acoustical absorption coefficient with Kundt or impedance tubes $[28,31,162]$. All of them showed that the sound absorption peak shifted to a higher frequency, depending on the amount of the plant aggregate.

Cérézo (2005) observed two peaks in the case of hemp concrete, as shown in Figure 24 . This observation was consistent with the others results of hemp concrete reported in the literature [163, 
164]. The first peak corresponding to the coating and roof formulations shifted from $300 \mathrm{~Hz}$ to 500 $\mathrm{Hz}$ with aggregate contents of $8.3 \%$ and $25.1 \%$, respectively. The amplitude of the second peak located at $1500 \mathrm{~Hz}$ decreased until it almost disappeared at very low aggregate content.

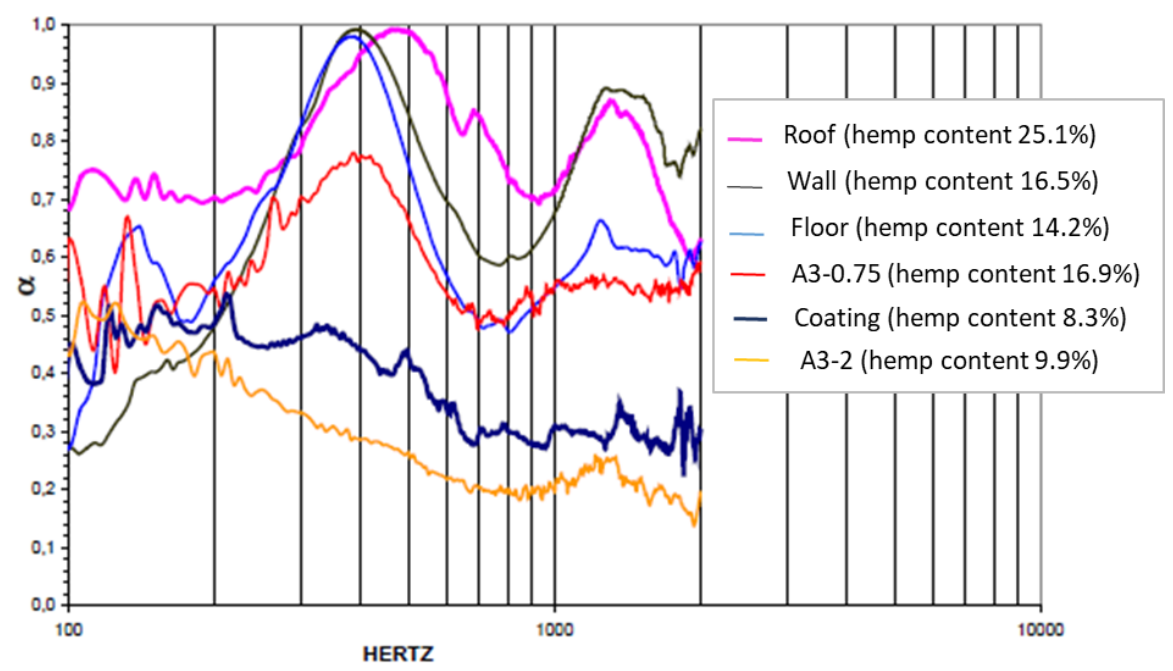

Figure 24 Acoustical absorption of different hemp concrete formulations in $10 \mathrm{~cm}$ thick samples [28].

Similarly, Chen et al. (2017) [31] observed a single peak for miscanthus concrete that shifted from $700 \mathrm{~Hz}$ to $1300 \mathrm{~Hz}$. The addition of plant aggregates increased the open porosity inside the composite, which improved its acoustical performance. In addition, it was observed that in the case of the composites made from the composed binder (mixture of hydraulic lime, calcareous charges, hydrophobic, and rheological admixtures) and hemp shiv $\left(\mathrm{C} 2-\mathrm{H}^{*}\right)$, and sunflower pith (C2-S), the air resistivity of the composites varied from one aggregate to another [165] and was equal to 11625 N.s. ${ }^{-4}$.and 36250 N.s. $\mathrm{m}^{-4}$ for $\mathrm{C}^{-}-\mathrm{H}^{*}$ and C2-S, respectively. However, as mentioned previously, the unknown dosages $\left(\mathrm{kg} \cdot \mathrm{m}^{-3}\right)$ of binder in the two mixtures made the comparison difficult. Thus, it is more rationale to consider a dosage of the constituents as a formulation parameter to compare different composites; thus, capable of isolating and studying the effect of the nature of the aggregate.

The properties of aggregates, their size, and porosity may bring these acoustical differences between the composites and are discussed in the following part. Nevertheless, various studies showed that the type and amount of the binder and the degree of compaction are the principal parameters influencing sound absorption [76, 163, 164, 166, 167].

\subsection{Effects of the Characteristics of the Plant Aggregates on the Properties of the Plant-based Concrete}

\subsubsection{Effects on the Physical Properties of the Plant-based Concrete}

The bulk density, size of the particles, and compressibility of the plant aggregates impacted the density of the composites $[15,17,20,23,25,30-32,42,46,55,61,84]$. However, all the results reported in the literature were not consistent since the composites have different types of binder, dosages of binder, and levels of compaction. Figure 25 shows the evolution of densities of the plant- 
based concrete as a function of the bulk density and the medium length of the used particles, and the points of the same study are linked together for those which showed a similar trend.

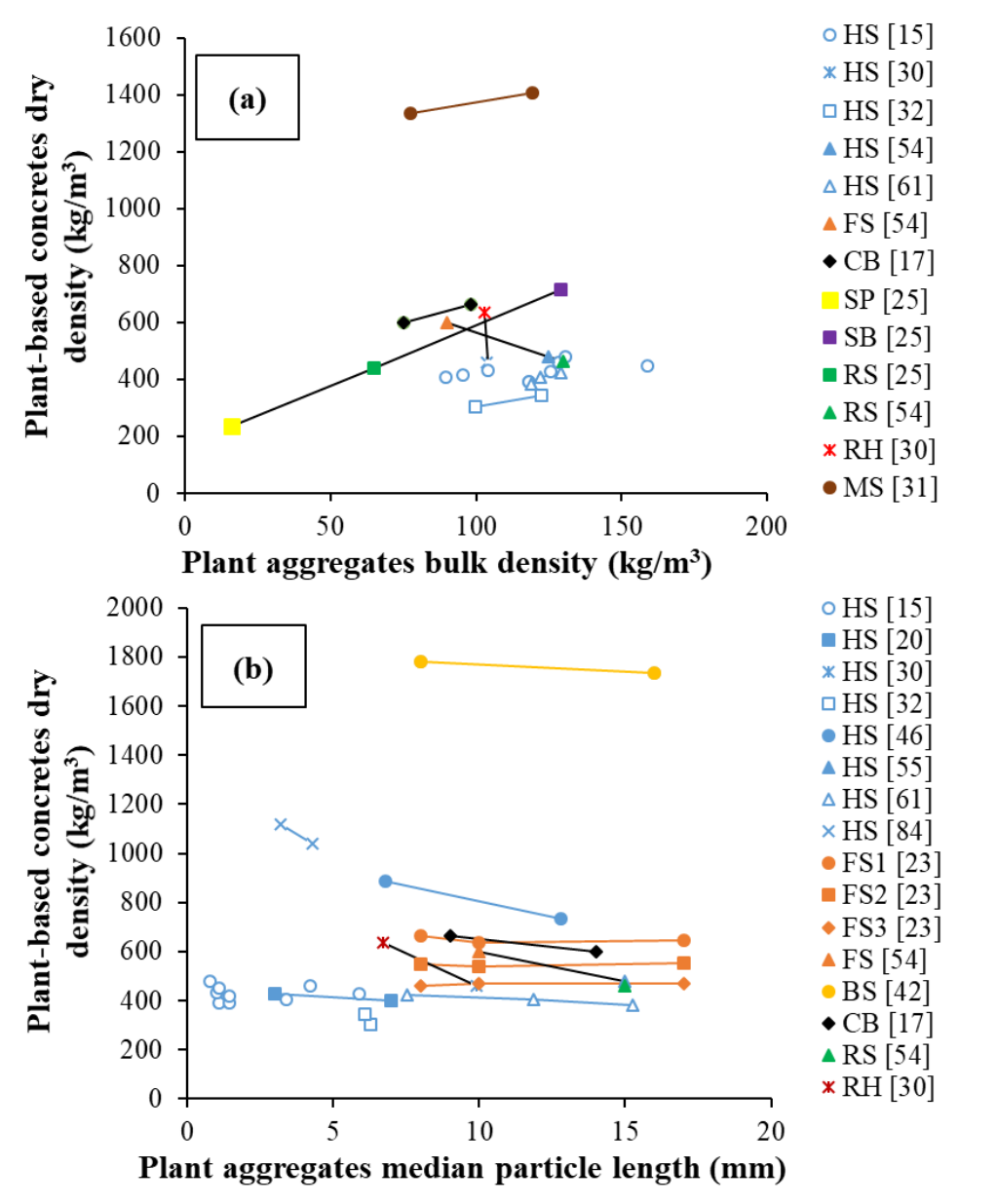

Figure 25 Evolution of the density of plant-based concrete as a function of (a) the bulk density, and (b) the median particle length of plant aggregates (HS: hemp shiv; FS: flax shiv, $16 \%$ of content; FS1: flax shiv, $11.5 \%$ of content; FS2: flax shiv, $14.5 \%$ of content; FS3: flax shiv, $17.5 \%$ of content; WC: wood chip; BS: barley straw; WS: wheat straw; SP: sunflower pith; $\mathrm{SB}$ : sunflower bark; $\mathrm{RH}$, rice husk; $\mathrm{CB}$, corn bark; MS: miscanthus stem; and LS: lavender straw) $[15,17,20,23,25,30-32,42,46,55,61,84]$.

The results shown in Figure 25a were contradictory to each other. Some authors found that increasing the bulk density of aggregates increased the density of the composite $[25,31,32,61]$. At first glance, these results appeared logical as a denser aggregate will contribute to a denser composite. However, other authors observed opposite results $[30,55]$. For example, in the case of concrete made with hemp shiv, flax shiv, and rape straw, Rahim et al. (2016) observed a decrease in the density of the composite when the bulk density of the aggregates increased. The respective bulk densities of flax shiv, hemp shiv, and rape straw were $90 \mathrm{~kg} / \mathrm{m}^{3}, 125 \mathrm{~kg} / \mathrm{m}^{3}$, and $130 \mathrm{~kg} / \mathrm{m}^{3}$, whereas the dry densities of the obtained composites were $598 \mathrm{~kg} / \mathrm{m}^{3}, 478 \mathrm{~kg} / \mathrm{m}^{3}$, and $462 \mathrm{~kg} / \mathrm{m}^{3}$, respectively. This might be due to the difference in the compaction behavior of the aggregates in the composites. Although, the same mass proportion of aggregate (16wt.\%) and binder (36wt.\%) was considered for each mixture, the highly compressed flax shiv increased the dosages $\left(\mathrm{kg} / \mathrm{m}^{3}\right)$ of binders and aggregates in the composite. Hence, the density of flax shiv concrete was higher 
compared to those of hemp and rape straw. The variability in the dosages of binder therefore did demonstrate the real influences of the properties of the aggregates. Considering this difference in the compaction behavior of the aggregates, it could also be said that the dosages $\left(\mathrm{kg} / \mathrm{m}^{3}\right)$ of the constituents are much more relevant formulation parameters compared to the mass proportions (\%). Besides, it is well known that during the manufacture of composites, the interparticle porosities are mainly filled and reduced by the binder and rearrangement of the aggregates under compaction, therefore it is necessary to characterize the intrinsic properties of the aggregates including particle porosity and density. Recently, Niyigena et al. (2018) compared hemp concrete made from hemp shives of different origins, sizes, and densities [15]. The influence of the aggregate bulk density on that of concrete did not follow any particular trend. Hence, it could be said that the bulk density of aggregate could not be correlated with the density of the composite since it did not reflect the true behavior of the aggregates in the composites. It was also observed that each aggregate reacted differently under compaction in the wet state in the composite, but no test currently allows to quantify the capacity of the aggregates to rearrange and compress. So, this necessitates developing a testing method to quantify and understand the behavior of different plant aggregates and optimize their amounts for the formulation of plant-based concrete.

Most of the studies found that the density of the composites generally decreased $[17,20,30,42$, $46,55,61,84]$ or remained constant [23] with the increase in the median length of the aggregates (Figure 25b ]. This decrease was attributed to the fact that longer aggregates provide more interparticle porosity. However, given that the inter-particle porosity was partially reduced in the composite after compaction and addition of binder, the decrease in the density of the composite was often very less $[20,61]$ or even absent [23]. Hence, the median length of the particles could be considered as a parameter influencing the density of the composites, but its impact was less significant than the dosage and the nature of the aggregates.

\subsubsection{Effects on the Mechanical Properties of the Plant-based Concrete}

Although the mechanical properties of the composite followed a decreasing trend with the increase in the plant aggregate mass content, the results found in the literature were much more divided concerning the correlation between the plant aggregate properties and mechanical performances of the composite. Several studies have already been carried out to determine, directly or indirectly, the effects of bulk density, the size of the particles, and the chemical composition of the plant aggregates on the mechanical properties of plant-based concrete. Unfortunately, due to the variation in the several parameters (formulation, specimen shapes, and mechanical test procedures), it was very difficult to conduct a global comparison of the results found in the literature. Thus, in Figure 26 and Figure 27, the results of only those articles which studied the impact of bulk density and median particle length of plant aggregates on the compressive strength and Young's modulus of plant-based concrete, respectively, are presented. 

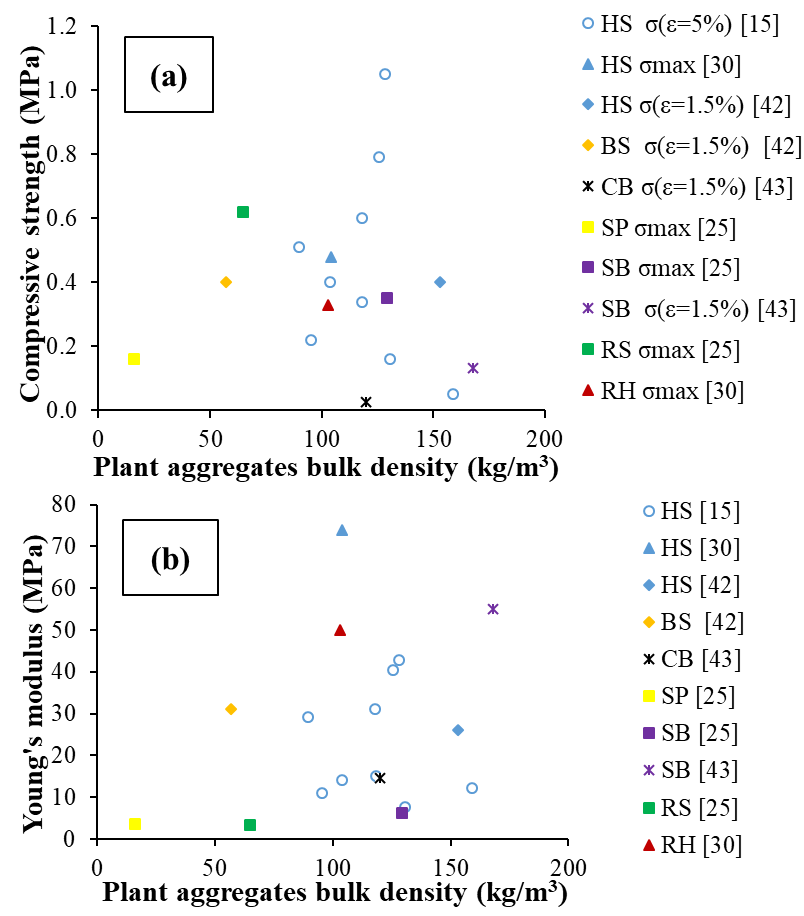

$\circ$ HS [15]

$\triangle \mathrm{HS}[30]$

- HS [42]

- BS [42]

* CB [43]

SP [25]

- SB [25]

* SB [43]

- RS [25]

$\triangle \mathrm{RH}[30]$

Figure 26 Evolution of (a) compressive strength and (b) Young's modulus of plant-based concrete as a function of the plant aggregate bulk density (HS: hemp shiv; CB: corn bark; SP: sunflower pith; SB: sunflower bark; RS: rape straw; and $\mathrm{RH}$, rice husk) [15, 25, 30, 42, 43].


Figure 27 Evolution of (a) compressive strength and (b) Young's modulus of plant-based concrete as a function of the plant aggregate median particle length (HS: hemp shiv; FS: flax shiv; BS: barley straw; CB: corn bark; and $\mathrm{RH}$, rice husk) $[15,17,20,23,30,42,52$, $61,84]$. 
Irrespective of the nature of the plant aggregates [15, 25, 30, 42,43], many studies showed that the bulk density of plant aggregates was not correlated with the compressive strength and Young's modulus of the composite. For instance, Niyigena et al. (2018) observed highly scattered results for both compressive strength $(\sigma(\varepsilon=1.5 \%))$ and Young's modulus in the case of several varieties of hemp with different bulk densities (Figure 26). Similarly, for aggregates of different nature but the same mass proportions in the composite, Brouard et al. (2018) [25] showed that the differences in the bulk density of sunflower pith $\left(16 \mathrm{~kg} / \mathrm{m}^{3}\right)$, rape straw $\left(65 \mathrm{~kg} / \mathrm{m}^{3}\right)$, and sunflower bark $\left(129 \mathrm{~kg} / \mathrm{m}^{3}\right)$ did not show any particular trend in the mechanical properties of the resulting plant-based concrete (0.16 MPa, 0.62 MPa, and 0.35 MPa, respectively for maximum compressive strength ( $\sigma \mathrm{max}$ ), and 3.7 MPa, 3.3 MPa and 6.2 MPa for Young's modulus). Although the comparison based on the maximum stress was not adequate as it did not represent the useful property of the composite (Cf. 3.1.2), the comparison of Young's modulus clearly showed that the rape straw concrete was least rigid even with a bulk density between the other two plant aggregates. Hence, the bulk density of the aggregate could not be correlated with the mechanical performance of the plant-based concrete. Also, the characterization of the bulk particle arrangement did not predict the behavior of the vibrocompacted particles in the composite. However, in the future, the characterization of a stack of moistened and compacted particles can be considered for better improvement.

In Figure 27a, the influence of the median particle length on the compressive strength did not show any trend due to the varying compressive strengths and several phenomena with opposite effects described in the literature [17, 20, 42, 84]. Increasing the median particle length of aggregates might increase the inter-granular porosity and weaken the mechanical performance of the composite [17, 42, 84], but in the short term (i.e., at 28 days) for plant-based concrete made of aerial lime with large size of particles, it might facilitate the diffusion of $\mathrm{CO}_{2}$ which is responsible for the setting and hardening of the binder and increases the mechanical performance of the composite[20].

The increase in the median particle length of the aggregates stiffened the composites [15, 30, 52] (Figure 27b). It could be due to the decrease in the specific surface area of the larger aggregates, making them more coated with the binders, unlike the smaller aggregates, or entanglement of the long particles within the composite acting as fiber reinforcers. In the case of hemp shiv and rice husk concrete [30], apart from the size of the aggregates, the compression behavior of the granular pile could also be an important parameter. The rice husk with a lot of inter-particle porosities due to its convex shape was easy to compress and could influence the stiffness of the composite. The contradictory behavior encountered in the case of barley straws in ref [42] could be due to the low mass proportion of the aggregates used (2.5wt.\%) in the composite.

The literature also mentions interactions between the water-soluble components inside plant aggregates and the mineral components of the binder, impacting the mechanical properties of the plant-based concrete. Magniont and Escadeillas (2017) [150] reviewed the interactions between bio-aggregates and mineral binders and highlighted the disturbing effects on the setting and hardening mechanisms of the mineral binder at an early age and medium and long term based modification of the properties and the durability of the composites. Diquélou et al. (2015) [72], via FTIR analysis, observed at an early age ( 3 days) a halo corresponded to some non-hydrated cement surrounding the hemp particles. Magniont and Escadeillas (2017) [150] listed several families of extractable chemicals identified as retarding agents for mineral binder hydration, e.g.:

- Monosaccharides such as glucose, galactose, mannose, rhamnose, arabinose, and xylose; 
- Non-cellulosic polysaccharides such as sucrose, arabinogalactan, xylan, starch, hemicelluloses, and pectins;

- Phenolic compounds such as tannins;

- Terpenes;

- Organic acids such as acetic acid or fatty acids.

Mostly, calorimetric measurements are conducted to assess the negative effect of the chemicals present in plant aggregates on the setting and hardening of the cement paste by comparing the heat released from a binder paste made with pure water and leaching solutions of plant particles or water mixed with powder of the plant particles. Figure 28 shows the compressive strengths of model pastes as a function of the water-soluble content of the aggregates after seven days. The results of the same study with the same binder were interrelated.

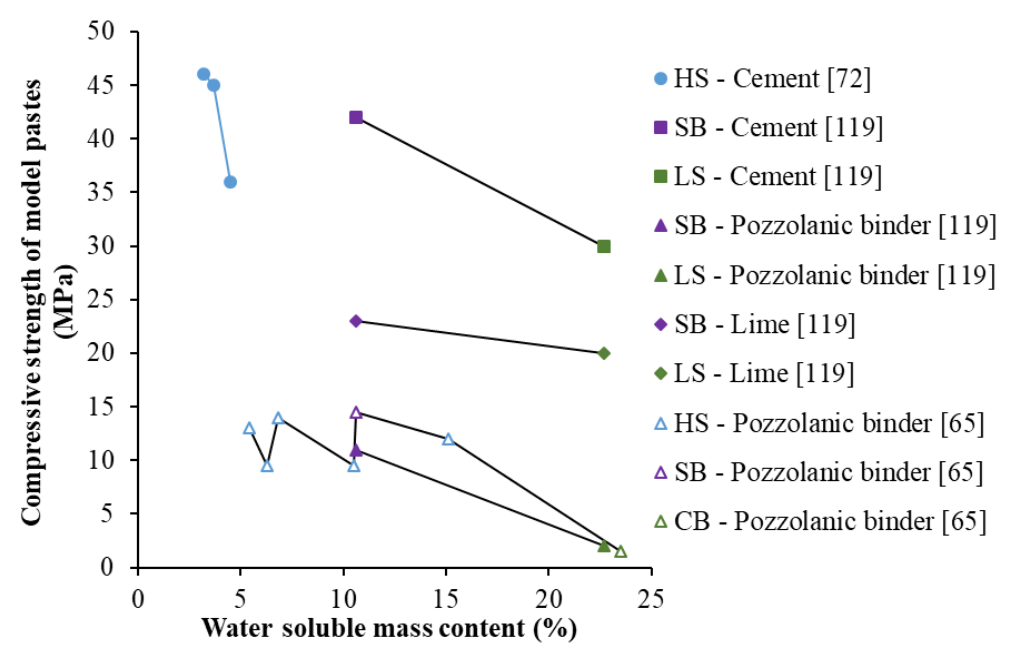

Figure $\mathbf{2 8}$ Compressive strength of model pastes after seven days as a function of watersoluble mass content (HS: hemp shiv; SB: sunflower bark; LS: lavender straw; and CB: corn bark) $[65,72,119]$.

Diquélou et al. (2015) correlated the delaying of the setting for three cement pastes made from the leaching solutions of the three different hemp shives with the compressive strength of the model pastes [72]. The compressive strength was found to decrease with the increase in the watersoluble mass content. However, in the worst case, they reported a decrease in compressive strength by $25 \%$ after seven days due to the reduced amount of hydrates (C-S-H and portlandite). Sabathier et al. (2017) also observed the same trend with model pastes made from the solutions containing sunflower bark or lavender straw extractives and three different binders [119]. In all the cases, the water-soluble content of sunflower bark (10.6\%) had little effect on the compressive strength of the binder pastes made with cement or a pozzolanic binder. On the contrary, the effects of the watersoluble content of lavender straw (22.7\%) were very significant. The compressive strengths of cement paste and pozzolanic paste were decreased by $25 \%$ and $50 \%$, respectively, after seven days. In contrast, the extractives from sunflower bark and lavender had no significant effect on the compressive strength of the lime-based binder pastes. The authors assumed that the water-soluble compounds did not influence the aerial setting due to the carbonation of $\mathrm{Ca}(\mathrm{OH})_{2}$. Bourdot et al. (2019) observed the same correlation between the water-soluble mass content of plant aggregates and the compressive strengths of the binder pastes, and the influence of the nature of water-soluble 
compounds in the case of the extractives taken from five different hemp shives, sunflower bark, and corn bark [65]. Finally, it could be inferred from these results on the model pastes that the mechanical performance of the composites could be correlated with the dosage and the nature of the water-soluble compounds in the aggregates. The various binders used to make plant-based concrete also indicated the necessity to study the effects of components resulting from basic extraction ( $\mathrm{pH} 9$ and 12 ).

To conclude, the bulk density of the plant aggregate could not represent the behavior of plant aggregate in the composite. Thus, it is important to find a suitable indicator capable of quantifying the behavior of aggregates under compaction in the wet state during the manufacture of plantbased concrete. The analysis of the results suggested that it is difficult and purposeless to compare the mechanical properties as the characteristic parameters varied from one study to another. Nevertheless, Young's modulus increased as a function of median particle length. Lastly, watersoluble compounds of the plant aggregates, depending on their nature and quantity, reacted with the binders and significantly reduced the compressive strength.

\subsubsection{Effects on the Thermal Properties of the Plant-based Concrete}

Bulk density, particle size, and thermal conductivity of plant aggregates were correlated with the thermal conductivity of the plant-based concrete in the literature. Figure 29 illustrates the variation of the thermal conductivity of plant-based concrete as a function of the bulk density and median particle length of the plant aggregate.

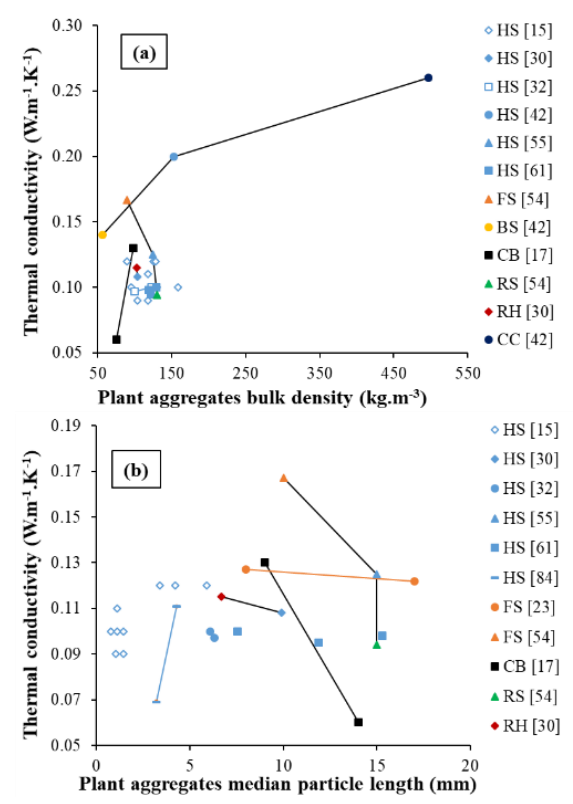

Figure 29 Evolution of the thermal conductivity of plant-based concrete as a function of (a) the bulk density and (b) the median particle length of plant aggregates (HS: hemp shiv; FS: flax shiv; $\mathrm{CB}$ : corn bark; RS: rape straw; and $\mathrm{RH}$ : rice husk) $[15,17,23,30,32$, $42,55,61,61,84]$.

No trend was observed in the case of the variation of the thermal conductivity of the composite with the bulk density of the aggregate (Figure 29a). Besides, the results of one study contradicted the results of another study. A few studies reported an increasing trend [17, 32, 41], while some a 
decreasing trend $[30,55]$ or no trend at all $[15,61]$ in the results obtained. These contradictions were explained by the fact that the bulk density of the aggregates does not represent the behavior of the aggregates in the composite. It is, therefore, necessary to characterize the aggregates by the particle density and porosity, which could be much more relevant in predicting the thermal conductivity of the composite.

In general, the thermal conductivity of hemp concrete decreased with the size of the aggregates as (Figure 29b) [17, 23, 32, 55]. The increased size of the aggregates offered more inter-granular porosity, which reduced the conductivity of the composite. The contradictory results of Stevulova et al. (2013) [84] and Niyigena et al. (2018) [15] were attributed to the different varieties of the hemp shiv aggregates used and the level of compaction experienced by the samples.

As mentioned in paragraph 2.4.2, the thermal properties of plant aggregates were not systematically measured, contrary to the thermal properties of the composites formed. Nevertheless, some studies measured the thermal conductivity of different plant aggregates and composites formed with the same mass proportion of aggregates, as shown in Figure 30 [25, 30, 42, 53].

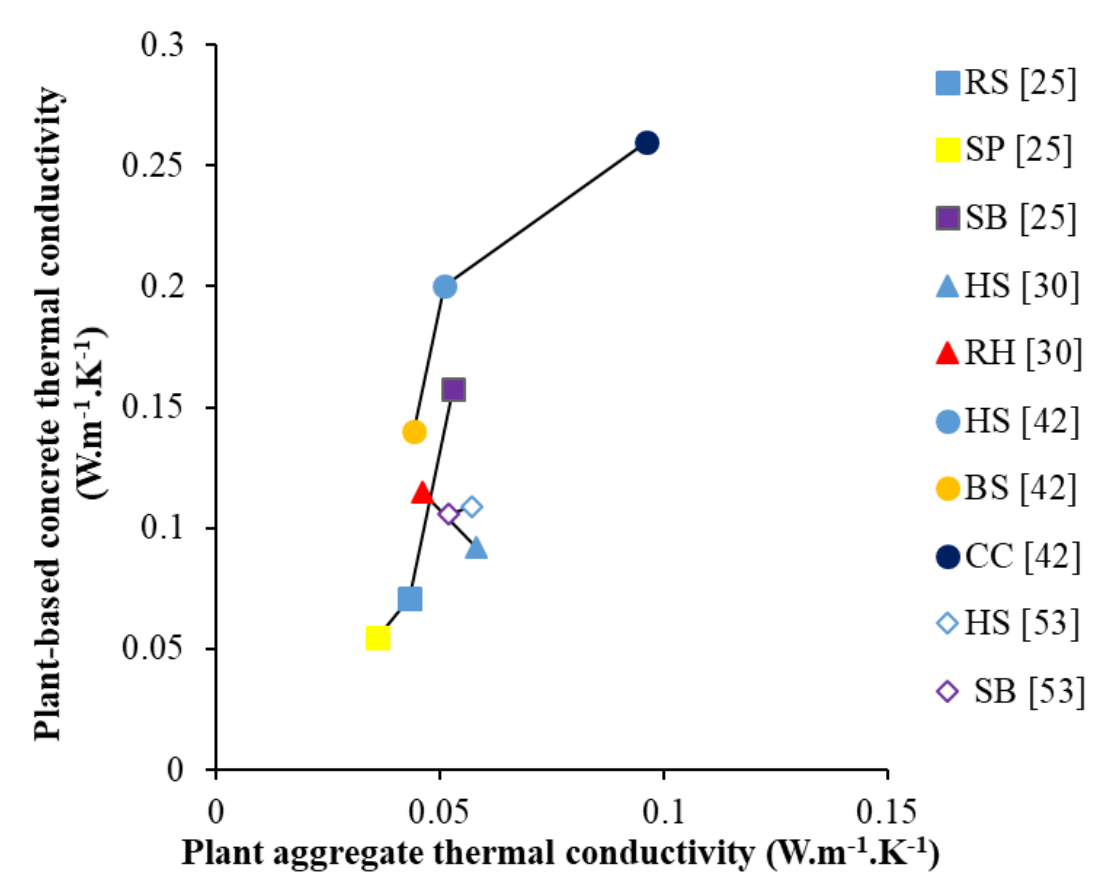

Figure 30 The thermal conductivity of plant-based concrete as a function of the thermal conductivity of bulk aggregates (HS: hemp shiv; BS: Barley straw; RS: rape straw; SP: sunflower pith; SB: sunflower bark; RH: rice husk; CC: corn cob) [15, 25, 30, 42, 53].

Generally, the thermal conductivity of the composite increased with that of the aggregate. For example, Brouard et al. (2018) [25] investigated the correlation between these two properties and found that with thermal conductivities of $0.036 \mathrm{~W} \cdot \mathrm{m}^{-1} \cdot \mathrm{K}^{-1}$ for sunflower pith, $0.043 \mathrm{~W} \cdot \mathrm{m}^{-1} \cdot \mathrm{K}^{-1}$ for rape straw, and $0.053 \mathrm{~W} \cdot \mathrm{m}^{-1} \cdot \mathrm{K}^{-1}$ for sunflower bark, the thermal conductivities of the concrete formed were $0.055 \mathrm{~W} . \mathrm{m}^{-1} . \mathrm{K}^{-1}, 0.071 \mathrm{~W} \cdot \mathrm{m}^{-1} \cdot \mathrm{K}^{-1}$ and $0.157 \mathrm{~W} \cdot \mathrm{m}^{-1} \cdot \mathrm{K}^{-1}$, respectively. In contrast, Chabannes et al. (2014) observed a decrease in the thermal conductivities of the composites as a function of thermal conductivities of the aggregates (rice husk and hemp shiv) [30]. The rice husks compressed more during manufacture, had a higher density $\left(637 \mathrm{~kg} / \mathrm{m}^{3}\right)$ than that of the hemp 
concrete $\left(459 \mathrm{~kg} / \mathrm{m}^{3}\right)$, even for the same $A / B$ ratio of 1.5 . The higher the level of compaction, the more difficult it would be to relate the performance of the bulk particle arrangement to that of the composite.

To summarize, the thermal conductivity of plant-based concrete increased with the particle length, but it was not influenced by the density and thermal conductivity of the bulk aggregates. On the contrary, the bulk density of an aggregate is not its real density inside the plant-based concrete, as it also depends on the compressibility and behavior of the aggregate with respect to water (settling or swelling). However, for future studies, density expressing the true behavior of each aggregate in the concrete could be a good parameter.

\subsubsection{Effects on the Hygric Properties of the Plant-Based Concrete}

Generally, for the same type of plant aggregate, its size does not affect the sorption and desorption isotherms of the resulting concrete. Benmahiddine et al. (2020) [23] made similar observations in the case of flax concrete comprised of flax shives with their average length varying from $8 \mathrm{~mm}$ to $17 \mathrm{~mm}$ (Figure 31).



Figure 31 Sorption isotherms of flax concrete made from shives of three different sizes [23].

Similar results were obtained by Ahmad and Chen in the case of corn stalk concrete with a slight $1 \%$ water content difference in favor of the concrete made from coarse aggregates at 95\% RH [17]. As mentioned in paragraph 3.1.3, the difference in sorption and desorption isotherms of plantbased concrete manufactured with different aggregates is not remarkable for low plant aggregate content $[26,41,81,157]$. However, it increases with the increase in the aggregate dosage and is significantly higher at high RH. Rahim et al. (2015) explained the difference between the sorption curves of hemp and flax concrete at high $\mathrm{RH}$ based on the size of the pores inside the flax shiv particles, which are smaller compared to those inside the hemp shiv, leading to more capillary condensation [81]. Ashour et al. (2011) also explained that the equilibrium moisture contents of plasters reinforced with barley and wheat straws are higher than that obtained with wood shavings due to the high moisture absorbing capacity of the pores of straws [157]. 
The capillary absorption of plant-based concrete also increased with the decrease in the particle size of the aggregates due to the increase in the specific surface area of the aggregates [84]. The capillary absorption coefficient varied with the plant-based concrete, depending on the type of plant aggregate used. Rahim et al. (2015), reported the capillary absorption coefficients of rape straw and hemp-lime concrete as $0.062 \mathrm{~kg} \cdot \mathrm{m}^{2} \mathrm{~s}^{-0.5}$ and $0.267 \mathrm{~kg} \cdot \mathrm{m}^{2} \mathrm{~s}^{-0.5}$, respectively [81]. The authors assumed that the porosity of rape straw lime concrete was more adapted to a capillary diffusion.

The hydric properties of plant-based concrete were strongly linked to the particle size and the porosity of the aggregates, especially with high contents [157]. Apparently, the porous structure of plant aggregates such as straws, sunflower pith, and flax shiv increased the sorption capacity of the concrete.

\subsubsection{Effects on the Acoustic Properties of Plant-Based Concrete}

Cérézo (2005) [28] and Chen et al. (2017) [31] emphasized that the plant aggregates with open porosities like hemp shiv and miscanthus stem improved the sound absorption when incorporated into a binding matrix. Thus, it could be assumed that an aggregate with more open porosity should increase the acoustic absorption of concrete. Besides, hemp and miscanthus stem concrete exhibited different acoustical absorption responses (double peaks and single peaks) [28, 31]. This observation estimated that the pore-scale of plant aggregates might be a parameter influencing the acoustical properties of plant-based concrete. However, so far, no conclusion could be made regarding the effect of the aggregate's physical properties on the acoustical properties of the composite.

\section{General Conclusion}

One hundred twenty articles on 18 different plant aggregates mixed with mineral binders were reviewed in this paper. This comprehensive review summarized the characteristics of the plant aggregates studied so far and the various associated experimental methods. It further explored the correlation of these properties with the useful properties of the obtained composites. However, this correlation was obscure; thus, it is necessary to find characterization methods for relevant indicators to easily correlate the properties of the aggregates with those of the composites.

The following points summarize the results of this analysis:

* The 18 plant aggregates mentioned in the literature were classified based on their origins. The comparison between the total number of the co-products and articles published in France showed an inconsistency. A third bibliography dealt with hemp shiv and represented only $0.02 \%$ of the total co-products. Therefore, future research should focus more on the available agro-resources such as wood chips, cereal straws, sunflower stem, or flax shiv.

* The microstructure and porosity of plant aggregates could be well assessed by combining SEM and X-ray tomography. These two imaging methods evidenced that the plant aggregates had highly porous structures, but their porosity, pore-scale, and cell pore characteristics were all different for each type of aggregates and could influence other properties like density and water absorption. In the case of the elongated aggregates, image analysis was often preferred instead of mechanical sieving to determine the particle size distribution and shape of plant aggregates, even though it only allowed $2 \mathrm{D}$ representation of the particles. 
* The bulk density of plant aggregates was the most well-known property in the literature; however, it could not represent the aggregates in the composite. Hence, for future studies, it is necessary to explore other density-related parameters like the density of particles and the skeleton one. Knowledge of the three densities of plant aggregates assisted in estimating various porosities such as total porosity, inter-particle, intra-particle, and particle porosity, which would be very useful to understand the properties of the composites.

* Several methods were mentioned in the literature to determine the water absorption of plant aggregates. However, they had highly variable results and did not estimate the real water requirements of the aggregates during the manufacture of the composites. Thus, it is necessary to develop methods to determine the true water absorption of each type of aggregate in a composite and optimize the formulation of plant-based concrete.

* Two methods were listed in the literature to perform the sorption-desorption test on plant aggregates: the SSS technique and the DVS method. The second method gave the most precise results but used only a small quantity of material which could raise the problem of representativeness.

* The hot wire and hot plate guarded methods recommended by TC RILEM 236-BBM were the most used methods in the literature to determine the thermal conductivity. The hot wire method was faster and easier to implement, while the second took a long time but gave results with more precision. All the studies claimed that the thermal conductivity of plant aggregates increased as a function of the bulk density. Except for corn cob, the thermal conductivities of all the plant aggregates were less than $0.08 \mathrm{~W} \cdot \mathrm{m}^{-1} \cdot \mathrm{K}^{-1}$, implying that these aggregates could be used as bulk insulating materials because of their very good insulating capacity.

* It is more appropriate to represent the amount of water-soluble compounds in terms of dosage $\left(\mathrm{kg}^{-3} \mathrm{~m}^{-3}\right)$ than mass proportion. These water-solubles were found to be responsible for the set delay of the binders in the composite. Also, it is preferable to use alkaline solutions ( $\mathrm{pH} 9$ and 12 ) instead of the usual neutral water solution $(\mathrm{pH} 7)$ used in the literature to determine the watersoluble content in the aggregates since the medium of reactive binders in which the aggregates are incorporated are often alkaline.

* In the literature, the common parameters used to describe a plant-based concrete formulation were either the mass content or the aggregate-to-binder ratio. The dosage of the constituents $\left(\mathrm{kg} . \mathrm{m}^{-3}\right.$ ) was supposedly more relevant to evaluate the effect of aggregates or binders on the composites with more precision. In general, a simultaneous increase in the dosage of aggregates and a decrease in the dosage of binder could lighten plant-based concrete by increasing its porosity and improve its hygro-thermal and acoustic properties. However, it could adversely affect their mechanical performance. Nevertheless, depending on the nature of the aggregates, the impact levels of the dosages of aggregates on the composites might vary with their properties. Apart from the aggregate dosage and nature, many other parameters such as the implementation methods, the curing conditions, and the age of the tested samples could also influence the properties of the composite, thereby making the study of an isolated parameter more difficult. Therefore, standardized curing and characterization methods are needed to study the impact of the nature and dosage of the aggregates.

* A variable binder dosage $\left(\mathrm{kg} / \mathrm{m}^{3}\right)$ was found to be an arduous method to assess the impact of the aggregate properties on the composite performances. Hence, it is necessary to find a suitable 
formulation method to keep a constant binder dosage for any type of aggregates to determine their impact on the composites.

* Despite the limitations associated with the simultaneous variation of many formulation parameters, an analysis was carried out to identify the aggregate parameters directly affecting the composite. The bulk densities, as well as the thermal conductivities of the bulk arrangement of plant aggregates, were not good indicators of the properties of composites. In contrast, the density and the porosity of the particles were intrinsic to the aggregates and could strongly affect all the properties of the composite.

* It was also observed aggregates under compaction in a wet state (as is the case during the manufacture of composites) behaved differently. Therefore, it is necessary to determine an indicator to quantify the influence of this phenomenon on the properties of plant-based concrete. In addition to this indicator, it would also be interesting to study the compression behavior of the compacted granular stacking without a binder, which seemed to influence the compression behavior of the composite.

* It was observed that when the median particle length of the aggregates increased, the density and the thermal conductivity of the composite decreased along with the increase in its Young's modulus. On the other hand, it did not affect the sorption-desorption isotherm of the composite.

* The mechanical parameters of plant-based concrete varied significantly from one study to another, thereby preventing any rigorous comparison between them. So, it would be important to define a unique compressive strength value by setting, for example, the same level of deformation to allow the comparisons.

* Extractives from plant aggregates and their chemical nature significantly influenced the mechanical performances of model pastes, which could also impact the properties of the composites.

This review demonstrated multiple properties of plant aggregates but not all relevant to the properties of the plant-based concrete. Thus, in the future, it would be important to find accurate indicators related to aggregates to assess the potential of local resources for producing green building materials.

\section{Acknowledgments}

The authors would like to acknowledge the Occitanie Region, Ovalie Innovation, the TarbesLourdes-Pyrénées conurbation community and the IUT Tarbes for the funding of this project.

\section{Author Contributions}

HH. Ratsimbazafy wrote the manuscript with support from A. Laborel-Préneron, C. Magniont and P. Evon.

\section{Competing Interests}

The authors have declared that no competing interests exist. 


\section{References}

1. IPCC - The Intergovernmental Panel on Climate Change [Internet]. Available from: https://www.ipcc.ch/.

2. The new urban agenda [Internet]. Habitat III; 2016 [cited 2016 October 17-20]. Available from: https://habitat3.org/the-new-urban-agenda/.

3. Amziane S, Arnaud L, Challamel N. Bio-aggregate-based building materials. 1st ed. New York: John Wiley \& Sons; 2013

4. Mwaikambo L. Review of the history, properties and application of plant fibres. Afr J Sci Technol. 2006; 7: 120-133.

5. Amziane S, Collet F. Bio-aggregates based building materials: State-of-the-art report of the RILEM technical committee 236-BBM. Berlin: Springer; 2017.

6. L'observatoire national des ressources en biomasse: Évaluation des ressources disponibles en France [Internet]. FranceAgriMer; 2016 [cited 2016 December 17]. Available from: https://www.franceagrimer.fr/Actualite/Filieres/Cereales/2016/L-observatoire-de-labiomasse-evaluation-des-ressources-disponibles-en-France-edition-decembre-2016.

7. Laborel-Préneron A, Magniont C, Aubert JE. Characterization of barley straw, hemp shiv and corn cob as resources for bioaggregate based building materials. Waste Biomass Valorization. 2018; 9: 1095-1112.

8. Sáez-Pérez MP, Brümmer M, Durán-Suárez JA. A review of the factors affecting the properties and performance of hemp aggregate concretes. J Build Eng. 2020; 31: 101323.

9. Jami T, Karade SR, Singh LP. A review of the properties of hemp concrete for green building applications. J Clean Prod. 2019; 239: 117852.

10. FRD. Évaluation de la disponibilité et de l'accessibilité de fibres végétales à usages matériaux en France (ADEME) [Internet]. Available from: https://librairie.ademe.fr/energiesrenouvelables-reseaux-et-stockage/3557-evaluation-de-la-disponibilite-et-de-l-accessibilitede-fibres-vegetales-a-usage-materiaux-en-france.html.

11. Asasutjarit C, Hirunlabh J, Khedari J, Charoenvai S, Zeghmati B, Shin UC. Development of coconut coir-based lightweight cement board. Constr Build Mater. 2007; 21: 277-288.

12. Jauberthie R, Rendell F, Tamba S, Cissé IK. Properties of cement-rice husk mixture. Constr Build Mater. 2003; 17: 239-243.

13. Monreal P, Mboumba-Mamboundou LB, Dheilly RM, Quéneudec M. Effects of aggregate coating on the hygral properties of lignocellulosic composites. Cem Concr Compos. 2011; 33: 301-308.

14. Laborel-Préneron A, Aubert JE, Magniont C, Tribout C, Bertron A. Plant aggregates and fibers in earth construction materials: A review. Constr Build Mater. 2016; 111: 719-34.

15. Niyigena $C$, Amziane $S$, Chateauneuf A. Multicriteria analysis demonstrating the impact of shiv on the properties of hemp concrete. Constr Build Mater. 2018; 160: 211-222.

16. Abbas MS, McGregor F, Fabbri A, Ferroukhi MY. The use of pith in the formulation of lightweight bio-based composites: Impact on mechanical and hygrothermal properties. Constr Build Mater. 2020; 259: 120573.

17. Ahmad MR, Chen B. Influence of type of binder and size of plant aggregate on the hygrothermal properties of bio-concrete. Constr Build Mater. 2020; 251: 118981. 
18. Akkaoui $A$, Caré $S$, Vandamme M. Experimental and micromechanical analysis of the elastic properties of wood-aggregate concrete. Constr Build Mater. 2017; 134: 346-357.

19. Alvarez VA, Vázquez A. Influence of fiber chemical modification procedure on the mechanical properties and water absorption of MaterBi-Y/sisal fiber composites. Compos Part A Appl Sci Manuf. 2006; 37: 1672-1680.

20. Arnaud L, Gourlay E. Experimental study of parameters influencing mechanical properties of hemp concretes. Constr Build Mater. 2012; 28: 50-56.

21. Aruan Efendy MG, Pickering KL. Comparison of harakeke with hemp fibre as a potential reinforcement in composites. Compos Part A Appl Sci Manuf. 2014; 67: 259-267.

22. Belhadj B, Bederina M, Makhloufi Z, Dheilly RM, Montrelay N, Quéneudéc M. Contribution to the development of a sand concrete lightened by the addition of barley straws. Constr Build Mater. 2016; 113: 513-522.

23. Benmahiddine F, Cherif R, Bennai F, Belarbi R, Tahakourt A, Abahri K. Effect of flax shives content and size on the hygrothermal and mechanical properties of flax concrete. Constr Build Mater. 2020; 262: 120077.

24. Bouasker M, Belayachi N, Hoxha D, Al-Mukhtar M. Physical characterization of natural straw fibers as aggregates for construction materials applications. Materials. 2014; 7: 3034-3048.

25. Brouard Y, Belayachi N, Hoxha D, Ranganathan N, Méo S. Mechanical and hygrothermal behavior of clay - Sunflower (Helianthus annuus) and rape straw (Brassica napus) plaster biocomposites for building insulation. Constr Build Mater. 2018; 161: 196-207.

26. Brouard Y, Belayachi N, Hoxha D, Méo S, Abdallah W. Hygrothermal behavior of clay - sunflower (helianthus annuus) and rape straw (brassica napus) plaster bio-composites for building insulation. Adv Eng Forum. 2017; 21: 242-248.

27. Brzyski P, Barnat-Hunek D, Suchorab Z, Łagód G. Composite materials based on hemp and flax for low-energy buildings. Materials. 2017; 10: 510.

28. Cérézo V. Propriétés mécaniques, thermiques et acoustiques d'un matériau à base de particules végétales: Approche expérimentale et modélisation théorique. Lyon: Institut National des Sciences Appliquées; 2005.

29. Chabannes M, Nozahic V, Amziane S. Design and multi-physical properties of a new insulating concrete using sunflower stem aggregates and eco-friendly binders. Mater Struct. 2015; 48: 1815-1829.

30. Chabannes M, Bénézet JC, Clerc L, Garcia-Diaz E. Use of raw rice husk as natural aggregate in a lightweight insulating concrete: An innovative application. Constr Build Mater. 2014; 70: 428438.

31. Chen YX, Yu QL, Brouwers HJ. Acoustic performance and microstructural analysis of bio-based lightweight concrete containing miscanthus. Constr Build Mater. 2017; 157: 839-851.

32. Colinart $T$, Vinceslas $T$, Lenormand $H$, Menibus AH, Hamard $E$, Lecompte T. Hygrothermal properties of light-earth building materials. J Build Eng. 2020; 29: 101134.

33. Dagilis TD. Bamboo composite materials for low-cost housing. Kingston, Ontario: Queen's University; 1999.

34. Delannoy G, Marceau S, Gle P, Gourlay E, Gueguen Minerbe M, Amziane S, et al. Evolution of hemp concrete properties exposed to different environments. Proceedings of the SynerCrete'18 International Conference on Interdisciplinary Approaches for Cement-based Materials and Structural Concrete; 2018 October 24-26; Funchal, Portugal. 
35. Dinh TM, Magniont C, Coutand M, Escadeillas G. Hemp concrete using innovative pozzolanic binder. Acad J Civ Eng. 2015; 33: 265-270.

36. Fourmentin M, Faure $P$, Pelupessy $P$, Sarou-Kanian V, Peter $U$, Lesueur D, et al. NMR and MRI observation of water absorption/uptake in hemp shives used for hemp concrete. Constr Build Mater. 2016; 124: 405-413.

37. Ghavami K, Toledo Filho RD, Barbosa NP. Behaviour of composite soil reinforced with natural fibres. Cem Concr Compos. 1999; 21: 39-48.

38. Giroudon M, Laborel-Préneron A, Aubert JE, Magniont C. Comparison of barley and lavender straws as bioaggregates in earth bricks. Constr Build Mater. 2019; 202: 254-265.

39. Güllü H, Khudir A. Effect of freeze-thaw cycles on unconfined compressive strength of finegrained soil treated with jute fiber, steel fiber and lime. Cold Reg Sci Technol. 2014; 106-107: 55-65.

40. Khazma M, El Hajj N, Goullieux A, Dheilly RM, Queneudec M. Influence of sucrose addition on the performance of a lignocellulosic composite with a cementious matrix. Compos Part A Appl Sci Manuf. 2008; 39: 1901-1908.

41. Laborel-Préneron A, Magniont C, Aubert JE. Hygrothermal properties of unfired earth bricks: Effect of barley straw, hemp shiv and corn cob addition. Energy Build. 2018; 178: 265-278.

42. Laborel-Préneron A, Aubert JE, Magniont C, Maillard P, Poirier C. Effect of plant aggregates on mechanical properties of earth bricks. J Mater Civ Eng. 2017; 29: 04017244.

43. Lagouin $M$, Magniont $C$, Sénéchal $P$, Moonen $P$, Aubert JE, Laborel-préneron A. Influence of types of binder and plant aggregates on hygrothermal and mechanical properties of vegetal concretes. Constr Build Mater. 2019; 222: 852-871.

44. Hoong JD, Escadeillas G. R-060 Amélioration du comportement mécanique des bétons biosourcés. Proceedings of the Internationale Francophone NoMaD; 2018 November 8-9; Liège, Belgium.

45. Magniont C, Escadeillas G, Coutand M, Oms-Multon C. Use of plant aggregates in building ecomaterials. Eur J Environ Civ Eng. 2012; 16: s17-s33.

46. Mazhoud B, Collet F, Pretot S, Chamoin J. Hygric and thermal properties of hemp-lime plasters. Build Environ. 2016; 96: 206-216.

47. Millogo Y, Aubert JE, Hamard E, Morel JC. How properties of kenaf fibers from burkina faso contribute to the reinforcement of earth blocks. Materials. 2015; 8: 2332-2345.

48. Millogo Y, Morel JC, Aubert JE, Ghavami K. Experimental analysis of pressed adobe blocks reinforced with hibiscus cannabinus fibers. Constr Build Mater. 2014; 52: 71-78.

49. Nguyen TT, Picandet V, Carre P, Lecompte T, Amziane S, Baley C. Effect of compaction on mechanical and thermal properties of hemp concrete. Eur J Environ Civ Eng. 2010; 14: 545-560.

50. Nguyen TT, Picandet V, Amziane S, Baley C. Influence of compactness and hemp hurd characteristics on the mechanical properties of lime and hemp concrete. Eur J Environ Civ Eng. 2009; 13: 1039-1050.

51. Niyigena C, Amziane S, Chateauneuf A. Assessing the impact of calculation methods on the variability of young's modulus for hemp concrete material. Constr Build Mater. 2019; 198: 332344.

52. Niyigena C, Amziane S, Chateauneuf A, Arnaud L, Bessette L, Collet F, et al. Variability of the mechanical properties of hemp concrete. Mater Today Commun. 2016; 7: 122-133. 
53. Nozahic V, Amziane S, Torrent G, Saïdi K, De Baynast H. Design of green concrete made of plantderived aggregates and a pumice-lime binder. Cem Concr Compos. 2012; 34: 231-241.

54. Rahim M, Douzane O, Tran Le AD, Promis G, Langlet T. Characterization and comparison of hygric properties of rape straw concrete and hemp concrete. Constr Build Mater. 2016; 102: 679-687.

55. Rahim M, Douzane O, Tran Le AD, Langlet T. Effect of moisture and temperature on thermal properties of three bio-based materials. Constr Build Mater. 2016; 111: 119-127.

56. Ratiarisoa RV, Magniont C, Ginestet S, Oms C, Escadeillas G. Assessment of distilled lavender stalks as bioaggregate for building materials: Hygrothermal properties, mechanical performance and chemical interactions with mineral pozzolanic binder. Constr Build Mater. 2016; 124: 801-815.

57. Segetin $M$, Jayaraman $K, X u X$. Harakeke reinforcement of soil-cement building materials: Manufacturability and properties. Build Environ. 2007; 42: 3066-3079.

58. Sellami A, Merzoud M, Amziane S. Improvement of mechanical properties of green concrete by treatment of the vegetals fibers. Constr Build Mater. 2013; 47: 1117-1124.

59. Sheridan J, Sonebi M, Taylor S, Amziane S. Effect of linseed oil and metakaolin on the mechanical, thermal and transport properties of hemp-lime concrete. Acad J Civ Eng. 2017; 35: 124-132.

60. Viel M, Collet F, Lanos C. Chemical and multi-physical characterization of agro-resources' byproduct as a possible raw building material. Ind Crops Prod. 2018; 120: 214-237.

61. Williams J, Lawrence M, Walker P. The influence of constituents on the properties of the bioaggregate composite hemp-lime. Constr Build Mater. 2018; 159: 9-17.

62. Williams J, Lawrence $M$, Walker P. A method for the assessment of the internal structure of bioaggregate concretes. Constr Build Mater. 2016; 116: 45-51.

63. Arizzi A, Cultrone G, Brümmer M, Viles H. A chemical, morphological and mineralogical study on the interaction between hemp hurds and aerial and natural hydraulic lime particles: Implications for mortar manufacturing. Constr Build Mater. 2015; 75: 375-384.

64. Bennai F, Hachem CE, Abahri K, Belarbi R. Microscopic hydric characterization of hemp concrete by X-ray microtomography and digital volume correlation. Constr Build Mater. 2018; 188: 983994.

65. Bourdot A, Magniont C, Lagouin M, Niyigena C, Evon P, Amziane S. Impact of bio-aggregates properties on the chemical interactions with mineral binder, application to vegetal concrete. J Adv Concr Technol. 2019; 17: 542-558.

66. Bütschi PY, Deschenaux C, Miao B, Srivastava NK. Utilisation du chanvre pour la préfabrication d'éléments de construction. Proceedings of the Annual Conference of the Canadian Society for Civil Engineering; 2003 June 4-7; Moncton, Nouveau-Brunswick, Canada.

67. de Bruijn $\mathrm{P}$, Johansson $\mathrm{P}$. Moisture fixation and thermal properties of lime-hemp concrete. Constr Build Mater. 2013; 47: 1235-1242.

68. del Valle-Zermeño R, Aubert JE, Laborel-Préneron A, Formosa J, Chimenos JM. Preliminary study of the mechanical and hygrothermal properties of hemp-magnesium phosphate cements. Constr Build Mater. 2016; 105: 62-68.

69. Delannoy G, Marceau S, Glé P, Gourlay E, Guéguen-Minerbe M, Diafi D, et al. Aging of hemp shiv used for concrete. Mater Des. 2018; 160: 752-762. 
70. Dinh TM. Contribution au développement de béton de chanvre préfabriqué utilisant un liant pouzzolanique innovant. Toulouse, France: Université Toulouse-III-Paul-Sabatier; 2014.

71. Diquélou Y, Gourlay E, Arnaud L, Kurek B. Influence of binder characteristics on the setting and hardening of hemp lightweight concrete. Constr Build Mater. 2016; 112: 506-517.

72. Diquélou Y, Gourlay E, Arnaud L, Kurek B. Impact of hemp shiv on cement setting and hardening: Influence of the extracted components from the aggregates and study of the interfaces with the inorganic matrix. Cem Concr Compos. 2015; 55: 112-121.

73. Dubois V, Wirquin E, Flament C, Sloma P. Fresh and hardened state properties of hemp concrete made up of a large proportion of quarry fines for the production of blocks. Constr Build Mater. 2016; 102: 84-93.

74. Evrard A. Transient hygrothermal behaviour of lime-hemp materials. Louvain-la-Neuve, Belgique: Catholic University of Louvain; 2008.

75. Evrard A. Sorption behaviour of Lime-Hemp Concrete and its relation to indoor comfort and energy demand. Proceedings of the 23rd Conference on Passive and Low Energy Architecture; 2006 September 6-8; Geneva, Switzerland.

76. Gourlay E, Glé P, Marceau S, Foy C, Moscardelli S. Effect of water content on the acoustical and thermal properties of hemp concretes. Constr Build Mater. 2017; 139: 513-523.

77. Hirst EA, Walker P, Paine KA, Yates T. Characterisation of low density hemp-lime composite building materials under compression loading. Proceedings of the Second International Conference on Sustainable Construction Materials and Technologies; 2010 June 28-30; Ancona, Italy.

78. Hussain A, Calabria-Holley J, Lawrence M, Jiang Y. Resilient hemp shiv aggregates with engineered hygroscopic properties for the building industry. Constr Build Mater. 2019; 212: 247-253.

79. Hussain A, Calabria-Holley J, Jiang Y, Lawrence M. Modification of hemp shiv properties using water-repellent sol-gel coatings. J Solgel Sci Technol. 2018; 86: 187-197.

80. Kidalova L, Stevulova N, Terpakova E, Sicakova A. Utilization of alternative materials in lightweight composites. J Clean Prod. 2012; 34: 116-119.

81. Rahim M, Douzane O, Tran Le AD, Promis G, Laidoudi B, Crigny A, et al. Characterization of flax lime and hemp lime concretes: Hygric properties and moisture buffer capacity. Energy Build. 2015; 88: 91-99.

82. Sheridan J, Sonebi M, Taylor S, Amziane S. Effect of viscosity modifying agent on the mechanical and transport properties of hemp and rapeseed straw concrete. Acad J Civ Eng. 2017; 35: 7380.

83. Stevulova N, Cigasova J, Estokova A, Terpakova E, Geffert A, Kacik F, et al. Properties characterization of chemically modified hemp hurds. Materials. 2014; 7: 8131-8150.

84. Stevulova N, Kidalova L, Cigasova J, Junak J, Sicakova A, Terpakova E. Lightweight composites containing hemp hurds. Procedia Eng. 2013; 65: 69-74.

85. Strandberg-de Bruijn P, Johansson P. Moisture transport properties of lime-hemp concrete determined over the complete moisture range. Biosyst Eng. 2014; 122: 31-41.

86. Tronet $\mathrm{P}$, Lecompte $\mathrm{T}$, Picandet V, Baley C. Study of lime hemp concrete (LHC) - Mix design, casting process and mechanical behaviour. Cem Concr Compos. 2016; 67: 60-72. 
87. Tronet $\mathrm{P}$, Lecompte $\mathrm{T}$, Picandet $\mathrm{V}$, Baley C. Study of lime hemp composite precasting by compaction of fresh mix - An instrumented die to measure friction and stress state. Powder Technol. 2014; 258: 285-296.

88. Viel M, Collet F, Prétot S, Lanos C. Hemp-straw composites: Gluing study and multi-physical characterizations. Materials. 2019; 12: 1199.

89. Youssef $A$, Lecompte $T$, Picandet $V$, Challamel $N$. Compressive and shearing behavior of lime and hemp concrete. Acad J Civ Eng. 2015; 33: 405-411.

90. Aamr-Daya E, Langlet T, Benazzouk A, Quéneudec M. Feasibility study of lightweight cement composite containing flax by-product particles: Physico-mechanical properties. Cem Concr Compos. 2008; 30: 957-963.

91. Garikapati KP, Sadeghian P. Mechanical behavior of flax-lime concrete blocks made of waste flax shives and lime binder reinforced with jute fabric. J Build Eng. 2020; 29: 101187.

92. Garikapati KP, Sadeghian P. Physical and mechanical properties of flax lime concrete. Proceedings of the Leadership in Sustainable Infrastructure; 2018 June 13-16; Fredericton, Canada.

93. Khazma M, Goullieux A, Dheilly RM, Rougier A, Quéneudec M. Optimization of flax shivecementitious composites: Impact of different aggregate treatments using linseed oil. Ind Crops Prod. 2014; 61: 442-452.

94. Khazma M, Goullieux A, Dheilly RM, Laidoudi B, Queneudec M. Impact of aggregate coating with a PEC elastomer on properties of lightweight flax shive concrete. Ind Crops Prod. 2011; 33: 49-56.

95. Lertwattanaruk $P$, Suntijitto A. Properties of natural fiber cement materials containing coconut coir and oil palm fibers for residential building applications. Constr Build Mater. 2015; 94: 664669.

96. Brasileiro GA, Vieira JA, Barreto LS. Use of coir pith particles in composites with Portland cement. J Environ Manage. 2013; 131: 228-238.

97. Al Rim K, Ledhem A, Douzane O, Dheilly RM, Queneudec M. Influence of the proportion of wood on the thermal and mechanical performances of clay-cement-wood composites. Cem Concr Compos. 1999; 21: 269-276.

98. Al Rim K, Ledhem A, de Roodenbeke MQ. Study of parameters in making clayey concretes lightened with wood aggregates. Mat Struct. 1996; 29: 514-518.

99. Ashour T, Wieland H, Georg H, Bockisch FJ, Wu W. The influence of natural reinforcement fibres on insulation values of earth plaster for straw bale buildings. Mater Des. 2010; 31: 4676-4685.

100.Bederina M, Gotteicha M, Belhadj B, Dheily RM, Khenfer MM, Queneudec M. Drying shrinkage studies of wood sand concrete - effect of different wood treatments. Constr Build Mater. 2012; 36: 1066-1075.

101. Bederina M, Marmoret L, Mezreb K, Khenfer MM, Bali A, Quéneudec M. Effect of the addition of wood shavings on thermal conductivity of sand concretes: Experimental study and modelling. Constr Build Mater. 2007; 21: 662-668.

102. Bouguerra A, Ledhem A, de Barquin F, Dheilly RM, Quéneudec M. Effect of microstructure on the mechanical and thermal properties of lightweight concrete prepared from clay, cement, and wood aggregates. Cem Concr Res. 1998; 28: 1179-1190.

103. Coatanlem P, Jauberthie R, Rendell F. Lightweight wood chipping concrete durability. Constr Build Mater. 2006; 20: 776-781. 
104.Govin A, Peschard A, Guyonnet R. Modification of cement hydration at early ages by natural and heated wood. Cem Concr Compos. 2006; 28: 12-20.

105. Karade SR, Irle M, Maher K. Influence of granule properties and concentration on cork-cement compatibility. Eur J Wood Wood Prod. 2006; 64:281-286.

106.Ledhem A, Dheilly RM, Benmalek ML, Quéneudec M. Properties of wood-based composites formulated with aggregate industry waste. Constr Build Mater. 2000; 14: 341-350.

107. Lee AW, Hong ZL, Phillips DR, Hse CY. Effect of cement/wood ratios and wood wood storage conditions on hydration temperature, hydration time and compressive strength of woodcement mixtures. Wood Fiber Sci. 1987; 19: 262-268.

108. Mougel E, Beraldo AL, Zoulalian A. Controlled dimensional variations of a wood-cement composite. Holzforschung. 1995; 49: 471-477.

109. Oyagade AO. Compatibility of some tropical hardwood species with Portland cement. J Trop For Sci. 1994; 6: 387-396.

110.Semple KE, Cunningham RB, Evans PD. The suitability of five Western Australian mallee eucalypt species for wood-cement composites. Ind Crops Prod. 2002; 16: 89-100.

111. Shiroma L, Camarini G, Beraldo AL, Shiroma L, Camarini G, Beraldo AL. Effect of wood particle treatment on the properties of gypsum plaster pastes and composites. Matéria (Rio J). 2016; 21: 1032-1044.

112. Turgut P. Cement composites with limestone dust and different grades of wood sawdust. Build Environ. 2007; 42: 3801-3807.

113. Bederina M, Belhadj B, Ammari MS, Gouilleux A, Makhloufi Z, Montrelay N, et al. Improvement of the properties of a sand concrete containing barley straws - Treatment of the barley straws. Constr Build Mater. 2016; 115: 464-477.

114. Bui R, Labat M, Aubert JE. Comparison of the saturated salt solution and the dynamic vapor sorption techniques based on the measured sorption isotherm of barley straw. Constr Build Mater. 2017; 141: 140-151.

115. Allam M, Garas G. Recycled chopped rice straw-cement bricks: An analytical and economical study. In: Waste Management and the Environment V. Ashurst, New Forest: WIT Press; 2010.

116.Jin SY, Chen HZ. Near-infrared analysis of the chemical composition of rice straw. Ind Crops Prod. 2007; 26: 207-211.

117. Morsy MI. Properties of rice straw cementitious composite. Darmstadt, Hessen: Technische Universität Darmstadt; 2011.

118. Nozahic V, Amziane S. Influence of sunflower aggregates surface treatments on physical properties and adhesion with a mineral binder. Compos Part A Appl Sci Manuf. 2012; 43: $1837-$ 1849.

119. Sabathier V, Louvel S, Correa G, Magniont C, Evon P, Labonne L. Incidence of the water-soluble compounds contained into lavender and sunflower bioaggregates on the hardening process of mineral binders. Acad J Civ Eng. 2017; 35: 62-68.

120.Asdrubali F, D'Alessandro F, Schiavoni S. A review of unconventional sustainable building insulation materials. Sustain Mater Technol. 2015; 4: 1-17.

121. Panyakaew S, Fotios S. 321: Agricultural waste materials as thermal Insulation for dwellings in Thailand: Preliminary results. Proceedings of the 25th Conference on Passive and Low Energy Architectu; 2008 October 22-24; Dublin, Ireland. 
122.Salas J, Alvarez M, Veras J. Lightweight insulating concretes with rice husk. Int J Cem Compos Lightweight Concret. 1986; 8: 171-180.

123.Son NK, Toan NP, Dung TT, Huynh NN. Investigation of agro-concrete using by-products of rice husk in mekong delta of Vietnam. Procedia Eng. 2017; 171: 725-733.

124. Fertikh S, Merzoud M, Benazzouk A, Habita MF. Comportement mécanique et hydrique des composites à matrice cimentaire et argileuse à base de diss «Ampelodesma mauritanica ». 2011. Available from: http://dspace.univ-tlemcen.dz/handle/112/629.

125. Merzoud M, Habita MF. Elaboration de composite cimentaire à base de diss "Ampelodesma Mauritanica ». Afr Sci. 2008; 4:231-245.

126. Merzoud M, Habita MF. Elaboration and characterization of cementitious composites with Diss fibers as masonry units. Asian J Civ Eng. 2008; 9: 367-377.

127. Corrêa AA, Mendes LM, Barbosa NP, de Paula Protásio T, de A Campos N, Tonoli GH. Incorporation of bamboo particles and "synthetic termite saliva" in adobes. Constr Build Mater. 2015; 98: 250-256.

128. Omoniyi T, Akinyemi B. Development of bamboo - rice husk ash and cement mixture for livestock house roofing sheets. Am J Sci Ind Res. 2013; 4: 201-209.

129.Sudin R, Swamy N. Bamboo and wood fibre cement composites for sustainable infrastructure regeneration. J Mater Sci. 2006; 41: 6917-6924.

130. Bilba K, Arsene MA, Ouensanga A. Sugar cane bagasse fibre reinforced cement composites. Part I. Influence of the botanical components of bagasse on the setting of bagasse/cement composite. Cem Concr Compos. 2003; 25: 91-96.

131. Bilba K, Ouensanga A. Fourier transform infrared spectroscopic study of thermal degradation of sugar cane bagasse. J Anal Appl Pyrolysis. 1996; 38: 61-73.

132. Loh YR, Sujan D, Rahman ME, Das CA. Sugarcane bagasse-The future composite material: $A$ literature review. Resour Conserv Recycl. 2013; 75: 14-22.

133. Onésippe C, Passe-Coutrin N, Toro F, Delvasto S, Bilba K, Arsène MA. Sugar cane bagasse fibres reinforced cement composites: Thermal considerations. Compos Part A Appl Sci Manuf. 2010; 41: 549-556.

134. Costantine G, Harb E, Bliard C, Maalouf C, Kinab E, Abbès B, et al. Experimental characterization of starch/beet-pulp bricks for building applications: Drying kinetics and mechanical behavior. Constr Build Mater. 2020; 264: 120270.

135.Le Ngoc Huyen T, Queneudec T'Kint M, Remond C, Chabbert B, Dheilly RM. Saccharification of Miscanthus $x$ giganteus, incorporation of lignocellulosic by-product in cementitious matrix. Comptes Rendus Biologies. 2011; 334: 837.

136. Le Ngoc Huyen T, Rémond C, Dheilly RM, Chabbert B. Effect of harvesting date on the composition and saccharification of Miscanthus x giganteus. Bioresour Technol. 2010; 101: 8224-8231.

137. Food and Agriculture Organization of the United Nations statistical pocketbook 2015: world food and agriculture [Internet]. Rome: FAO; 2015. Available from: http://www.fao.org/3/i4691e/i4691e.pdf.

138. Ouagne P, Barthod-Malat B, Evon Ph, Labonne L, Placet V. Fibre extraction from oleaginous flax for technical textile applications: Influence of pre-processing parameters on fibre extraction yield, size distribution and mechanical properties. Procedia Eng. 2017; 200: 213-220. 
139.ASTM D1109-84 - Standard test method for $1 \%$ sodium hydroxide solubility of wood [Internet]. ASTM International; 2007. Available from: http://www.astm.org/cgi-bin/resolver.cgi?D110984R07.

140. Pinto J, Vieira B, Pereira H, Jacinto C, Vilela P, Paiva A, et al. Corn cob lightweight concrete for non-structural applications. Constr Build Mater. 2012; 34: 346-351.

141. Pinto J, Cruz D, Paiva A, Pereira S, Tavares P, Fernandes L, et al. Characterization of corn cob as a possible raw building material. Constr Build Mater. 2012; 34: 28-33.

142. Palumbo M, Avellaneda J, Lacasta AM. Availability of crop by-products in Spain: New raw materials for natural thermal insulation. Resour Conserv Recycl. 2015; 99: 1-6.

143. Toulon A, Bouhaddi F. Statistique agricole annuelle 2018-2019 - Données provisoires [Internet]. France: Agreste; 2020 [cited 2020 April 05]. Available from: https://agreste.agriculture.gouv.fr/agreste-web/disaron/Chd2002/detail/.

144.Amziane S, Collet F, Lawrence M, Magniont C, Picandet V, Sonebi M. Recommendation of the RILEM TC 236-BBM: Characterisation testing of hemp shiv to determine the initial water content, water absorption, dry density, particle size distribution and thermal conductivity. Mater Struct. 2017; 50: 167.

145.ISO 3310-1: Tamis de contrôle - Exigences techniques et vérifications - Partie 1: Tamis de contrôle en tissus métalliques [Internet]. ISO; 2000. Available from: https://www.iso.org/fr/standard/25147.html.

146.ASTM E11-95 - Standard specification for wire cloth and sieves for testing purposes [Internet]. ASTM International; 1995. Available from: http://www.astm.org/cgi-bin/resolver.cgi?E11-95.

147. Karaky H, Maalouf C, Bliard C, Polidori G. Elaboration and physical characterization of an agromaterial based on sugar beet pulp and potato starch. Acad J Civ Eng. 2017; 35: 606-612.

148.NF EN 1270: Équipements de jeux - Équipements de basket-ball - Exigences fonctionnelles et de sécurité, méthodes d'essai. Boutique AFNOR; 2006. Available from: https://www.boutique.afnor.org/norme/nf-en-1270/equipements-de-jeux-equipements-debasket-ball-exigences-fonctionnelles-et-de-securite-methodes-dessai/article/738537/fa125208.

149. Collet F, Bart M, Serres L, Miriel J. Porous structure and water vapour sorption of hemp-based materials. Constr Build Mater. 2008; 22: 1271-1280.

150. Magniont C, Escadeillas G. Chapter 1 chemical composition of bio-aggregates and their interactions with mineral binders. In: Bio-aggregates based building materials: State-of-the-art report of the RILEM technical committee 236-BBM. Berlin: Springer; 2017.

151.Vassilev SV, Baxter D, Andersen LK, Vassileva CG. An overview of the chemical composition of biomass. Fuel. 2010; 89: 913-933.

152. Mohanty AK, Misra M, Drzal LT. Natural fibers, biopolymers, and biocomposites. 1st ed. Boca Raton, Florida: CRC Press; 2005.

153. Klason P. Contribution to a more exact knowledge of the chemical composition of spruce wood. Part I Pap Trade J. 1992; 74: 45-51.

154.Saeman JF, Moore WE, Mitchell RL, Millet MA. Techniques for the determination of pulp constituents by quantitative paper chromatography. J AOAC. 1954; 37: 336-343.

155.Van Soest PJ, Wine RH. Determination of lignin and cellulose in acid-detergent fiber with permanganate. J AOAC. 1968; 51: 780-785. 
156. Sluiter JB, Ruiz RO, Scarlata CJ, Sluiter AD, Templeton DW. Compositional analysis of lignocellulosic feedstocks. 1. Review and description of methods. J Agric Food Chem. 2010; 58: 9043-9053.

157. Ashour T, Georg H, Wu W. An experimental investigation on equilibrium moisture content of earth plaster with natural reinforcement fibres for straw bale buildings. Appl Therm Eng. 2011; 31: 293-303.

158. Ollivier JP, Association française de recherches et d'essais sur les matériaux et les constructions. Durabilité des bétons, méthodes recommandées pour la mesure des grandeurs associées à la durabilité: compte rendu des journées techniques AFPC-AFREM Laboratoire matériaux et durabilité des constructions, Institut National des Sciences Appliquées, Université Paul Sabatier,11 et 12 décembre 1997, Toulouse. France: Toulouse: Laboratoire matériaux et durabilité des constructions; 1997.

159.ASTM C67-03 - Standard test methods for sampling and testing brick and structural clay tile [Internet]. ASTM International; 2003. Available from: http://www.astm.org/cgibin/resolver.cgi?C67-03.

160.NF EN ISO 15148: Performance hygrothermique des matériaux et produits pour le bâtiment Détermination du coefficient d'absorption d'eau par immersion partielle. Boutique AFNOR; 2003. Available from: https://m.boutique.afnor.org/norme/nf-en-iso-15148/performancehygrothermique-des-materiaux-et-produits-pour-le-batiment-determination-du-coefficient-dabsorption-d-eau-par-immers/article/745949/fa024084.

161. Algin HM, Turgut P. Cotton and limestone powder wastes as brick material. Constr Build Mater. 2008; 22: 1074-1080.

162. Chen YX, Wu F, Yu QL, Brouwers HJ. Bio-based ultra-lightweight concrete applying miscanthus fibers: Acoustic absorption and thermal insulation. Cem Concr Compos. 2020; 114: 103829.

163. Glé P, Gourdon E, Arnaud L. Acoustical properties of materials made of vegetable particles with several scales of porosity. Appl Acoust. 2011; 72: 249-259.

164. Kinnane O, Reilly A, Grimes J, Pavia S, Walker R. Acoustic absorption of hemp-lime construction. Constr Build Mater. 2016; 122: 674-682.

165. Abbas MS, Gourdon E, Glé P, McGregor F, Ferroukhi MY, Fabbri A. Relationship between hygrothermal and acoustical behavior of hemp and sunflower composites. Build Environ. 2021; 188: 107462.

166.Degrave-Lemeurs M, Glé P, de Menibus AH. Acoustical properties of hemp concretes for buildings thermal insulation: Application to clay and lime binders. Constr Build Mater. 2018; 160: 462-474.

167.Ntimugura F, Vinai R, Harper A, Walker P. Mechanical, thermal, hygroscopic and acoustic properties of bio-aggregates - lime and alkali - activated insulating composite materials: A review of current status and prospects for miscanthus as an innovative resource in the South West of England. Sustain Mater Technol. 2020; 26: e00211. 




Enjoy Recent Progress in Materials by:

1. Submitting a manuscript

2. Joining in volunteer reviewer bank

3. Joining Editorial Board

4. Guest editing a special issue

For more details, please visit:

http://www.lidsen.com/journals/rpm 